Supporting Information for

\title{
Synthesis and Site-Specific Incorporation of Red-Shifted Azobenzene Amino Acids into Proteins
}

\author{
Alford A. John, Carlo P. Ramil, Yulin Tian, Gang Cheng, and Qing Lin* \\ Department of Chemistry, State University of New York at Buffalo, Buffalo, New \\ York 14260-3000, United States, qinglin@buffalo.edu
}

\section{Supplemental Data}

Supplemental data for Table 2: Determination of trans:cis ratios by ${ }^{19} \mathrm{~F}$ or ${ }^{1} \mathrm{H} \mathrm{NMR}$ and UV-vis spectra for the various azobenzene-alanine analogs S2-S10

Supplemental data for Table 3: Deconvoluted intact mass of sfGFP proteins incorporating the various azobenzene-alanine analogs S11-S20

Table S1: Measuring trans:cis ratios for $\mathbf{3 h}$ with varying photoirradiation time S21

Figure S1: Measurement of cis-pss of compound $\mathbf{3 h}$ after dark adaptation S22

Figure S2: UV-vis spectra of sfGFP-4h with alternating green/blue photoirradiation S23

General Information S24

Experimental Procedures and Characterization Data S24-S34

References S34

${ }^{1} \mathrm{H}$ and ${ }^{13} \mathrm{C}$ NMR Spectra S35-S69 
Table 2, compound 3g:<smiles>O=C(O)C(Cc1ccc(N=Nc2ccc(N=Nc3c(F)cccc3F)cc2)cc1)NC(Cc1ccccc1F)C(=O)O</smiles>

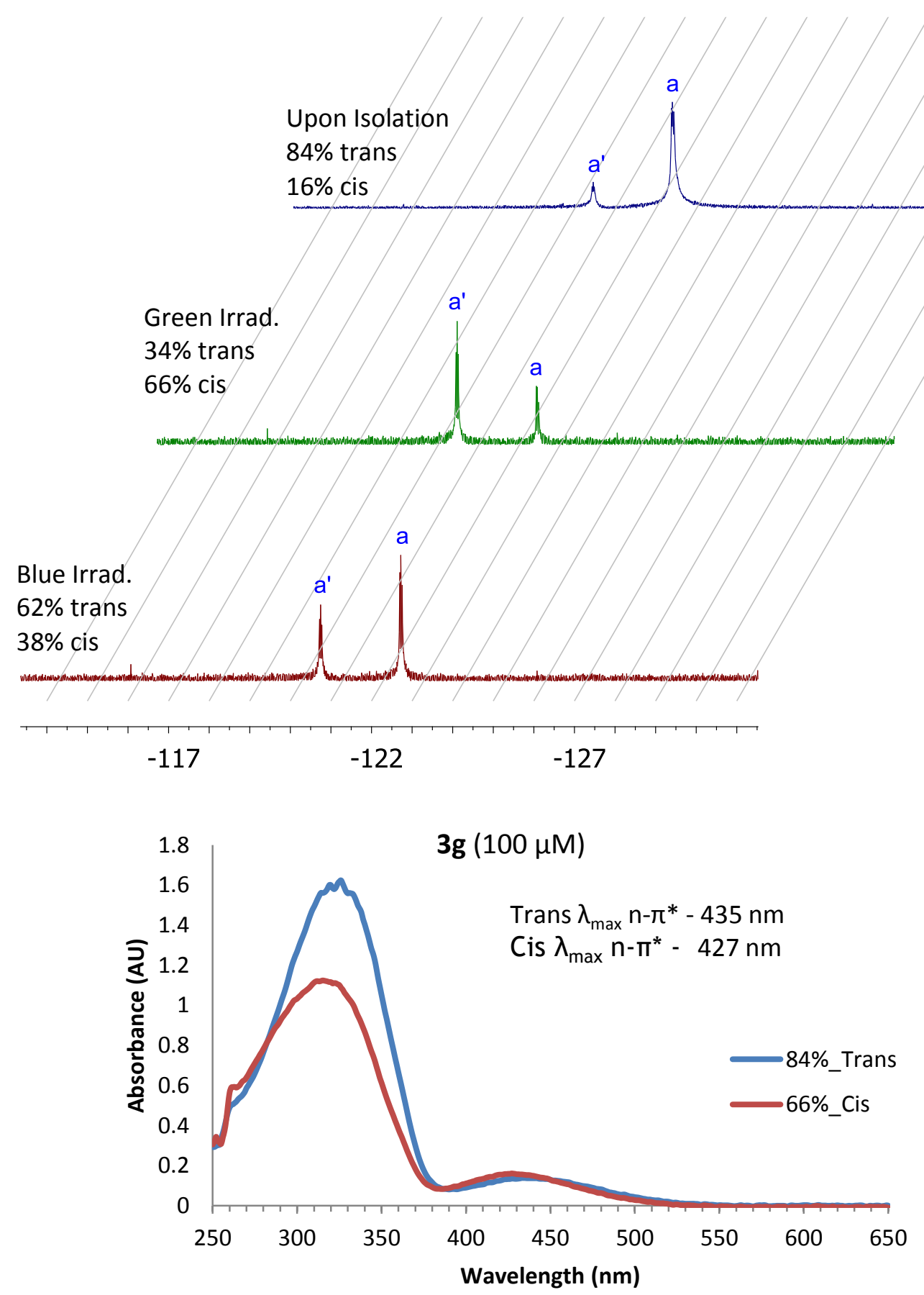


Table 2, compound 3h:
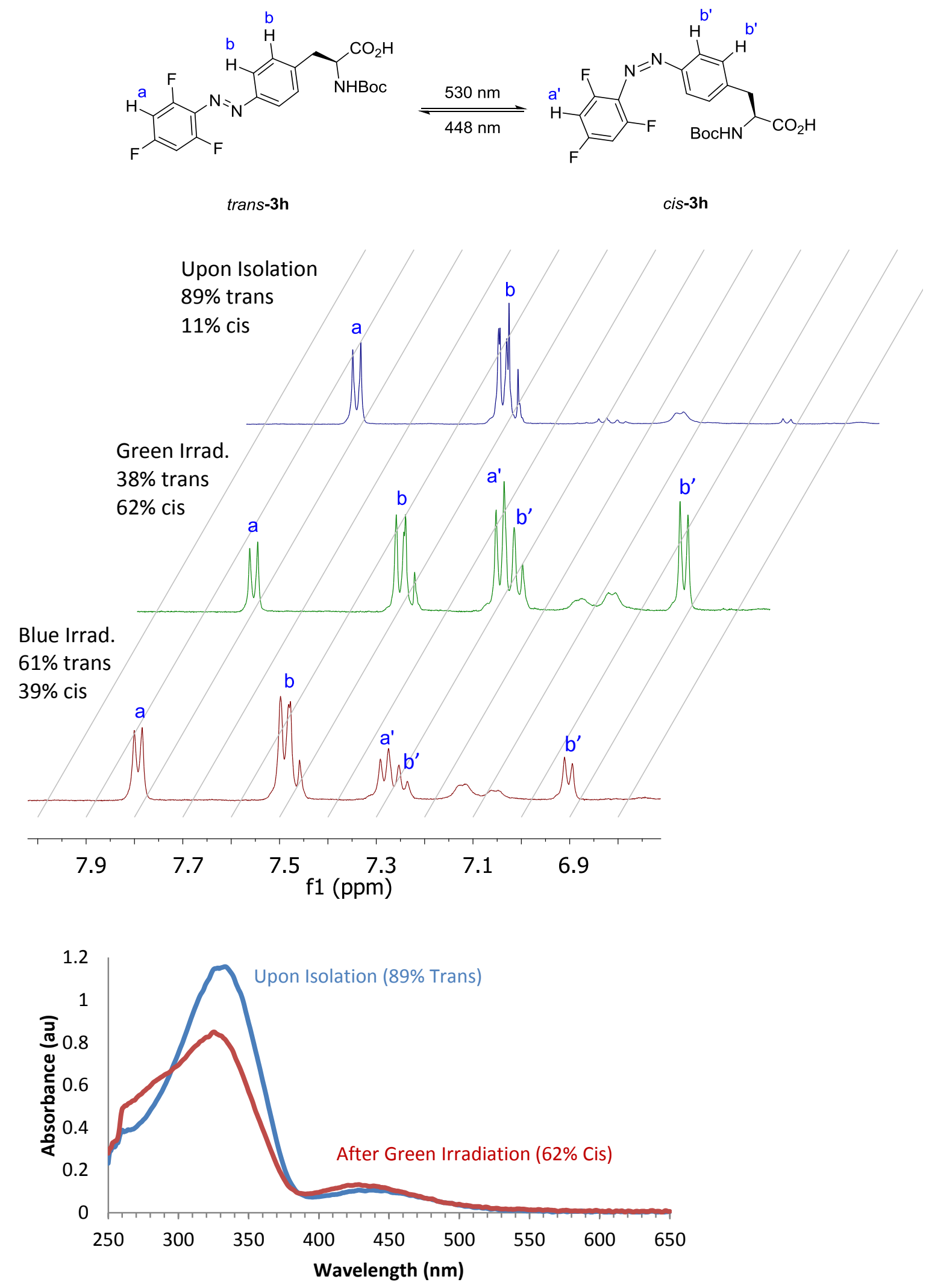
Table 2, compound 3k:

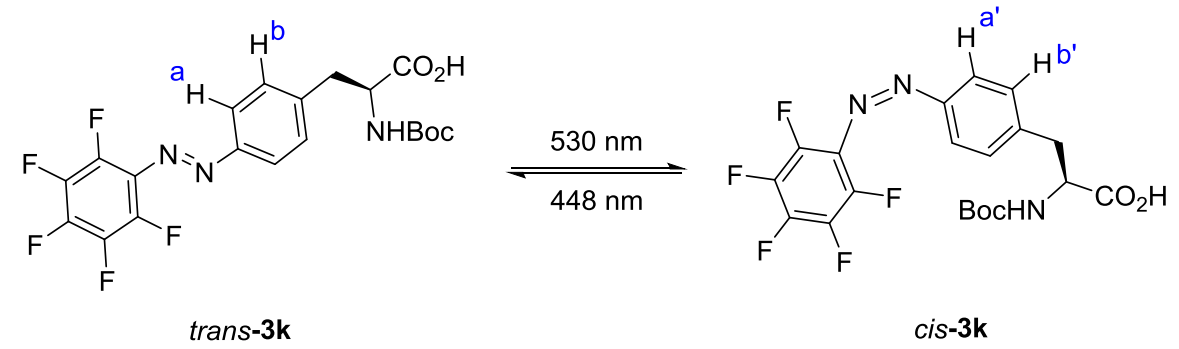

Upon isolation:

$82 \%$ Trans, $18 \%$ Cis
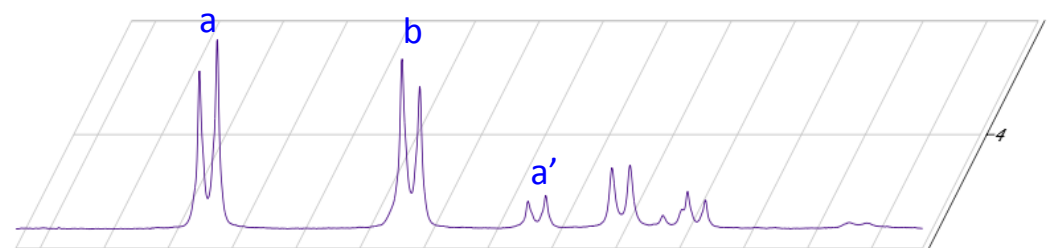

Blue irradiation (448 $\mathrm{nm}, 30 \mathrm{~min}$ ): $64 \%$ Trans, $36 \%$ Cis

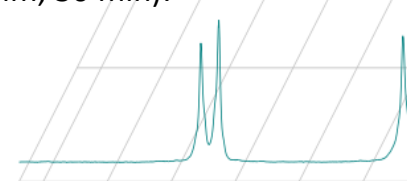

Green irradiation (530 nm, $30 \mathrm{~min}$ ):

$43 \%$ Trans, $57 \%$ Cis

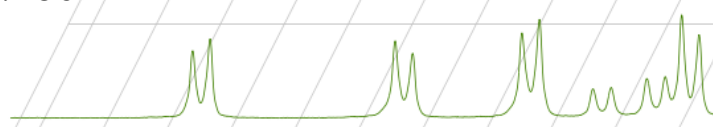

Dark adapted (11 days):

$46 \%$ Trans, $54 \%$ Cis
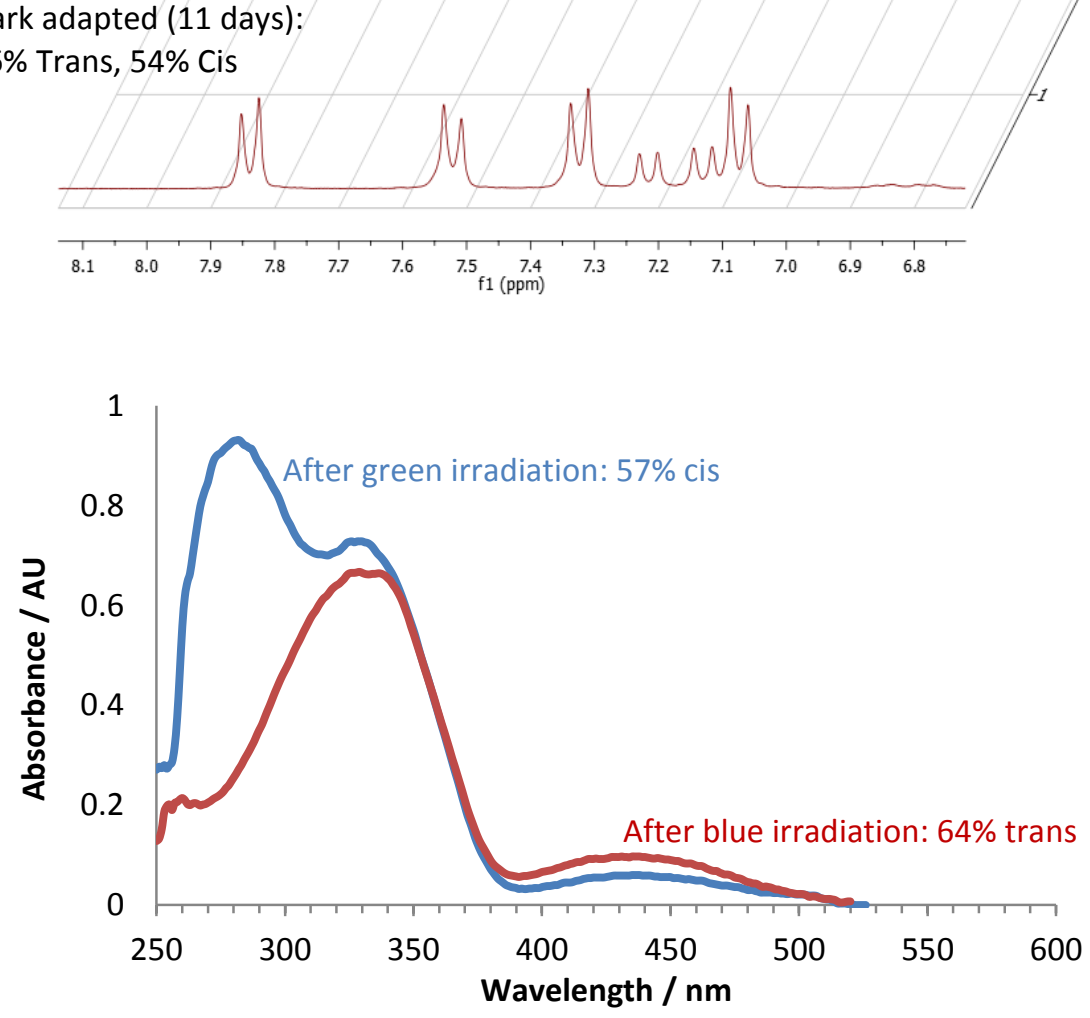
Table 2, compound 31:
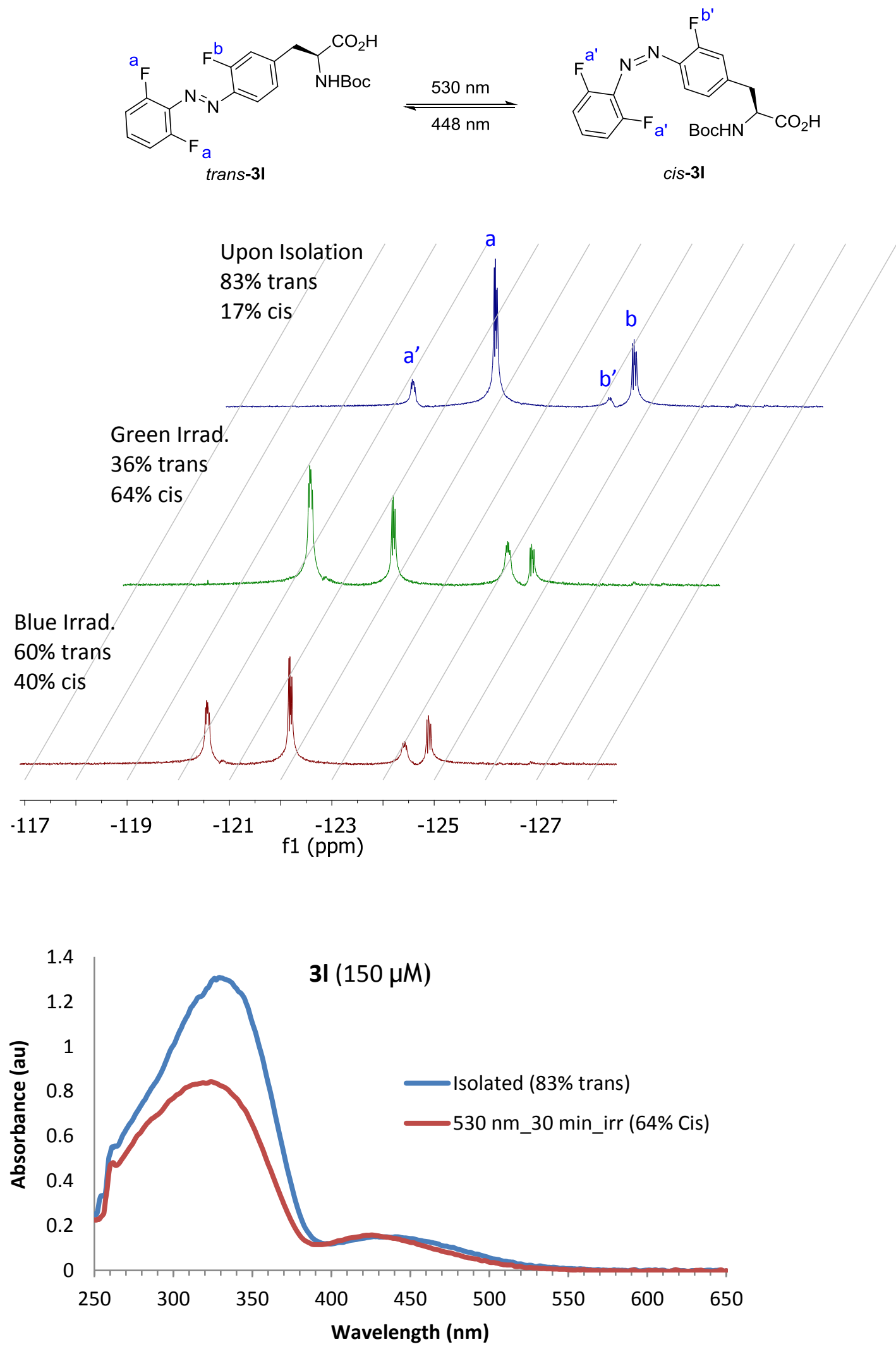
Table 2, compound 3m:
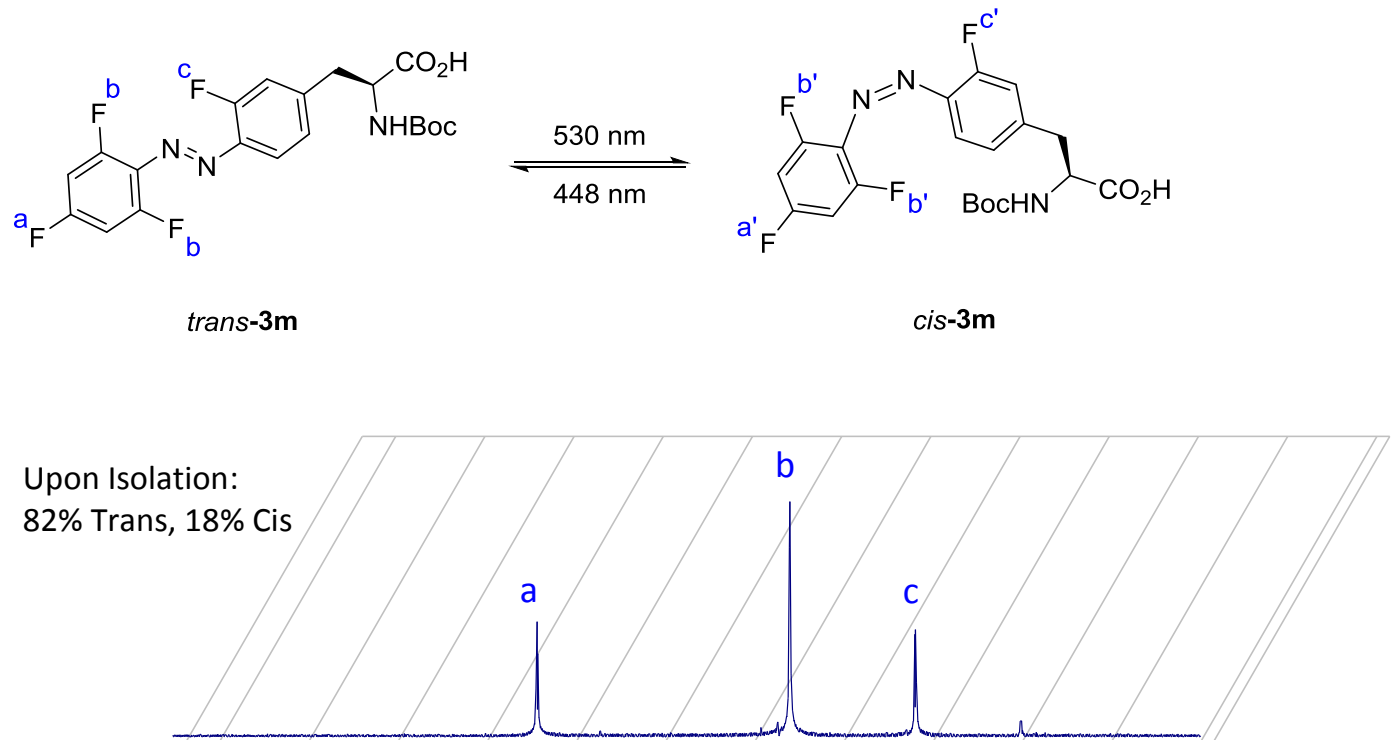

Green irradiation (30 min): $24 \%$ Trans, $76 \%$ Cis

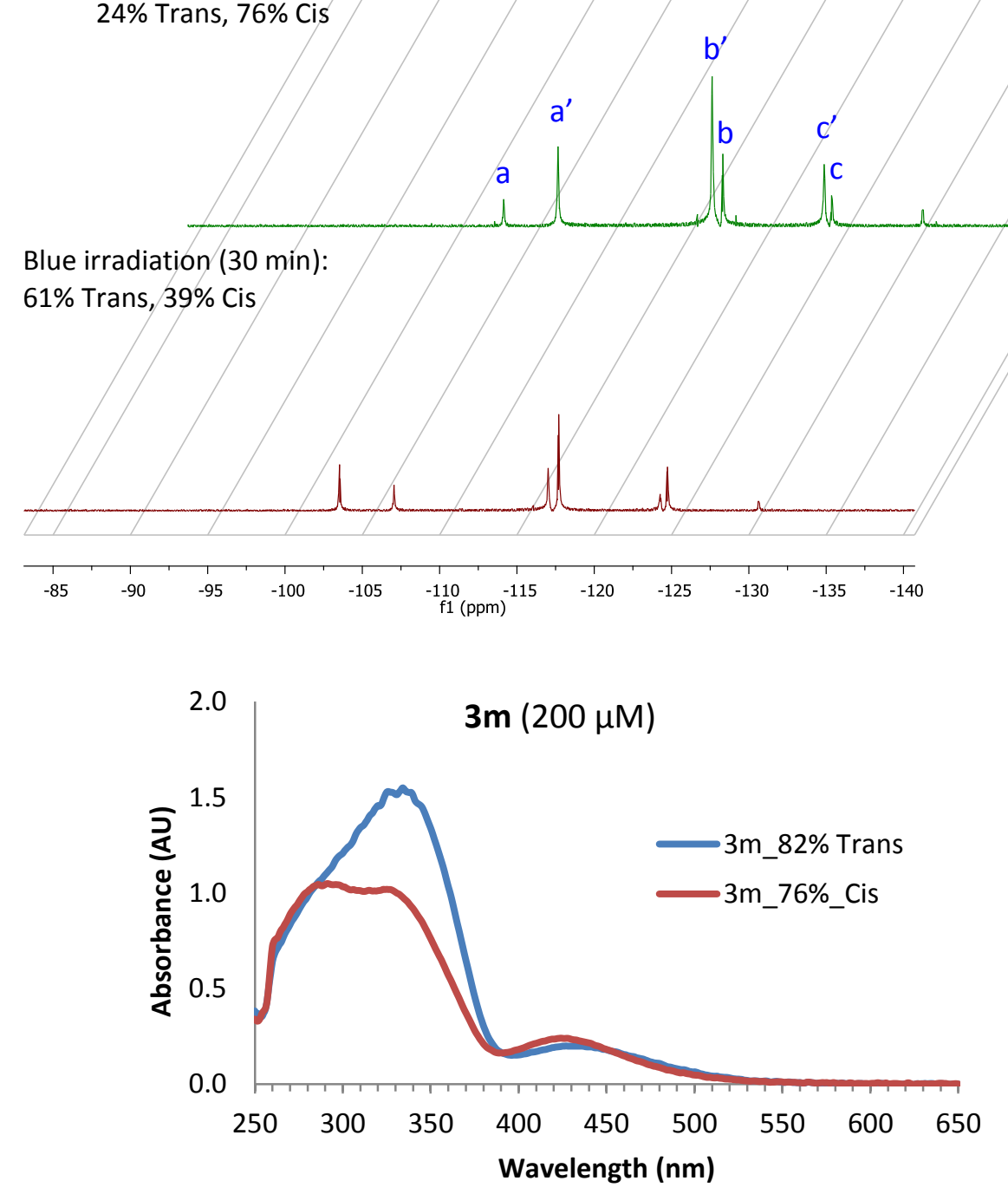


Table 2, compound 3n:<smiles>O=C(NC(Cc1ccc(N=Nc2c(F)c(F)c(F)c(F)c2N=Nc2ccc(N=Nc3c(F)c(F)c(F)c(F)c3F)c(F)c2F)c(F)c1)C(=O)O)OCc1ccccc1</smiles>
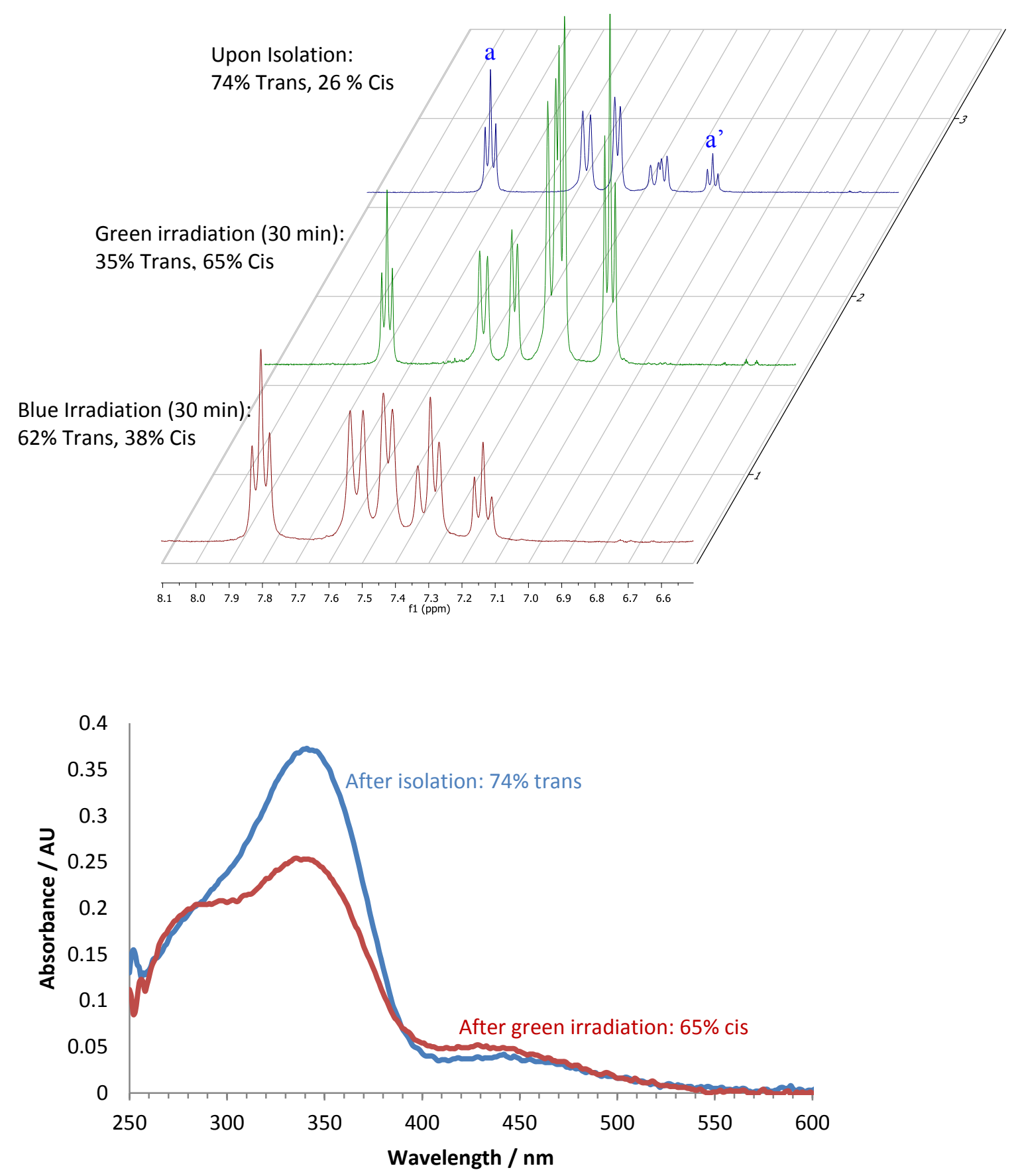
Table 2, compound 3o:

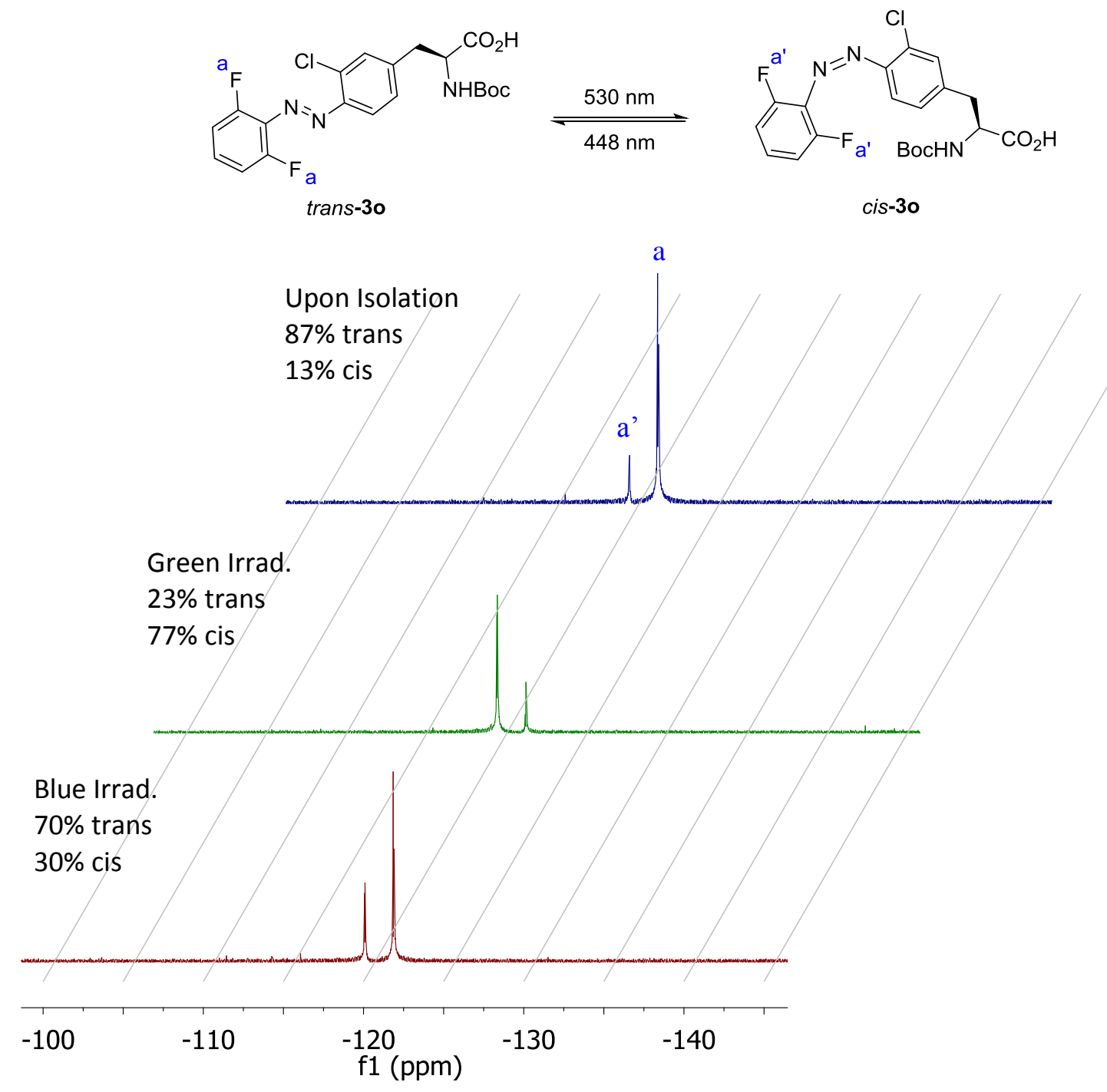

3o (100 $\mu \mathrm{M})$

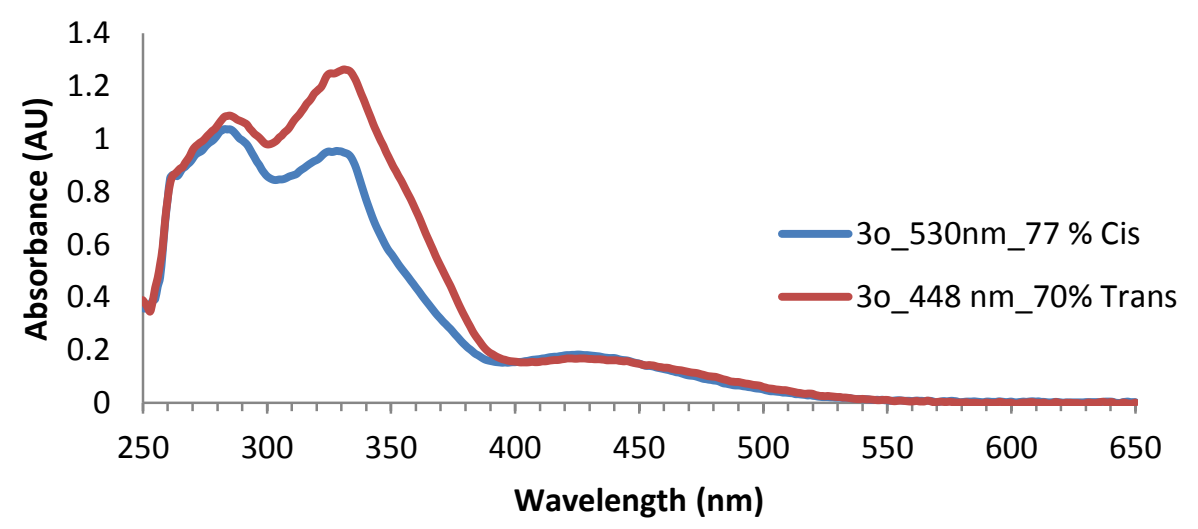


Table 2, compound 3p:
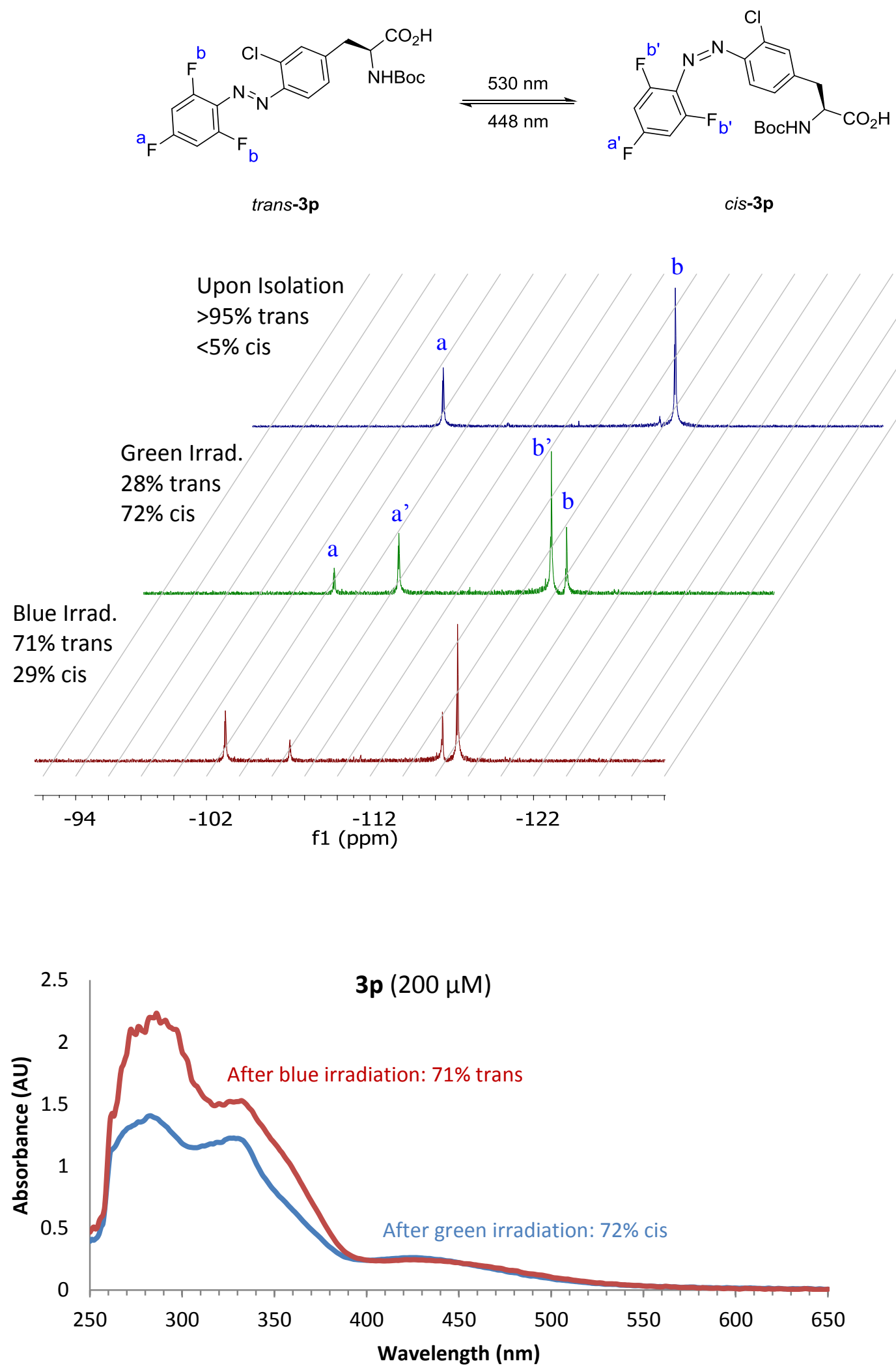
Table 2, compound 3q:
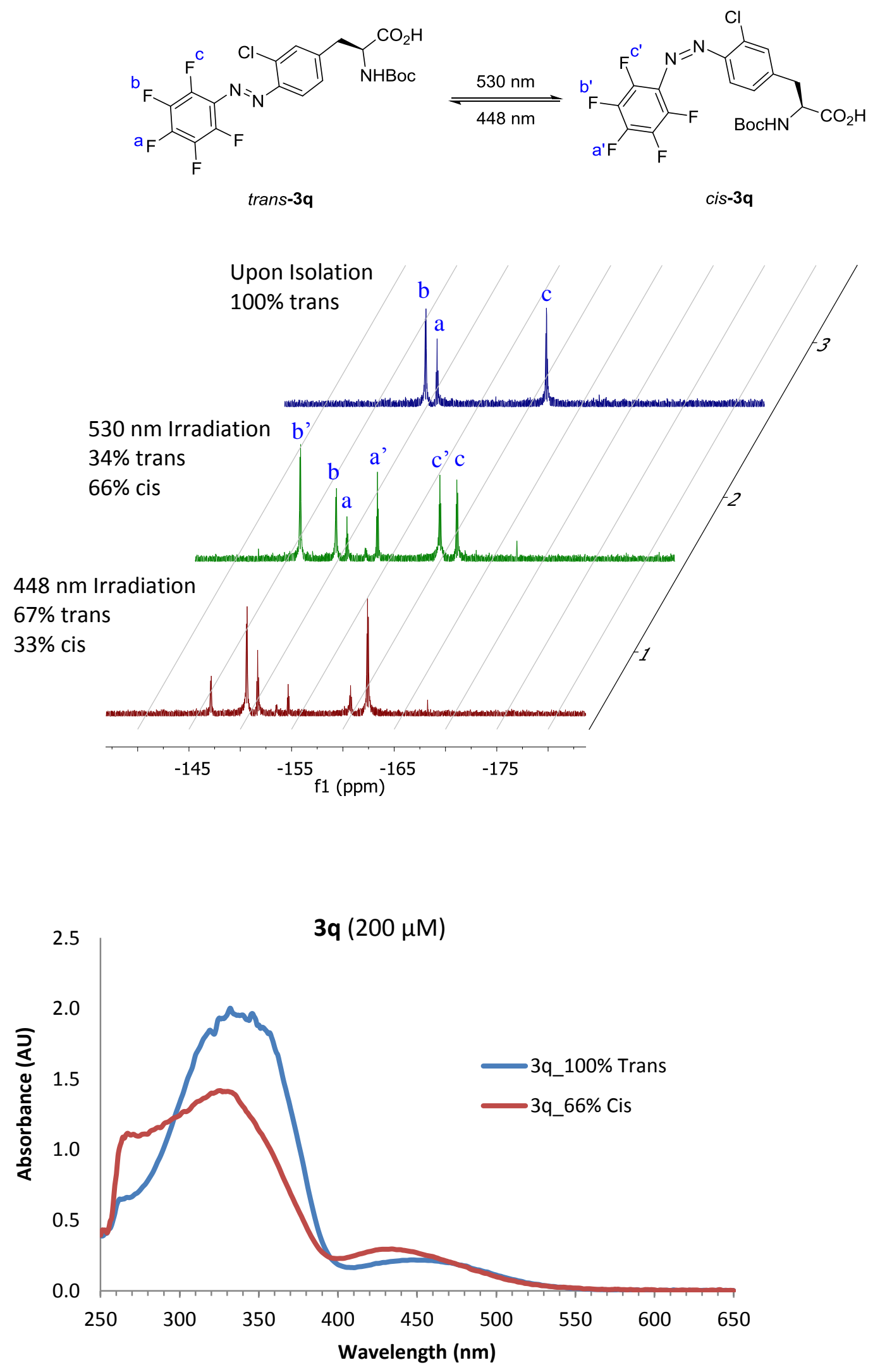
Table 3, (-) Control: sfGFP-S2Gln with first Met removed: MS-ESI calcd for sfGFP-S2Gln, 27708.6, found 27707.4.
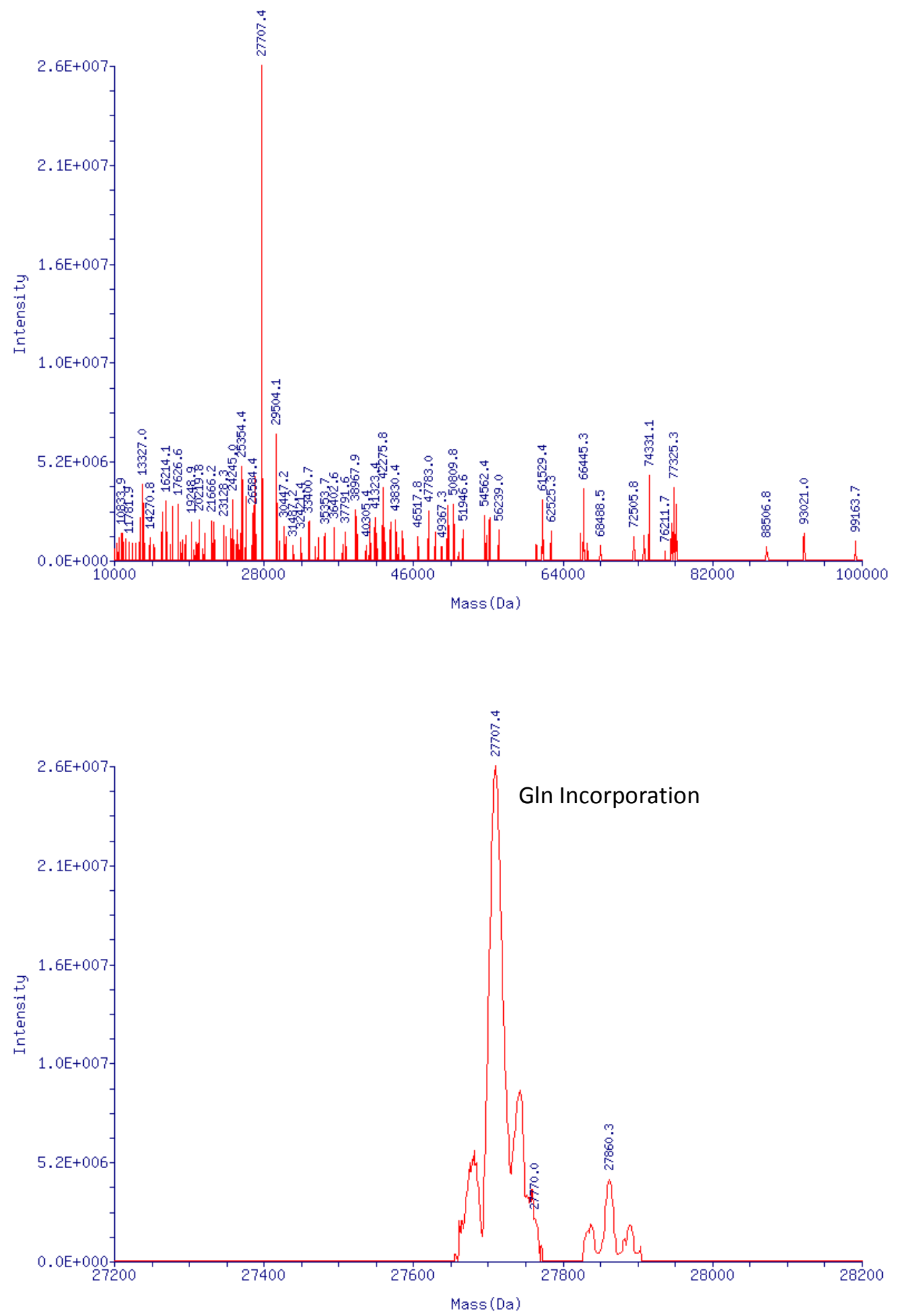
Table 3, compound 4d: sfGFP-S2 $\rightarrow \mathbf{4 d}$ with first Met removed: MS-ESI calcd 27856.3, found 27857.6.
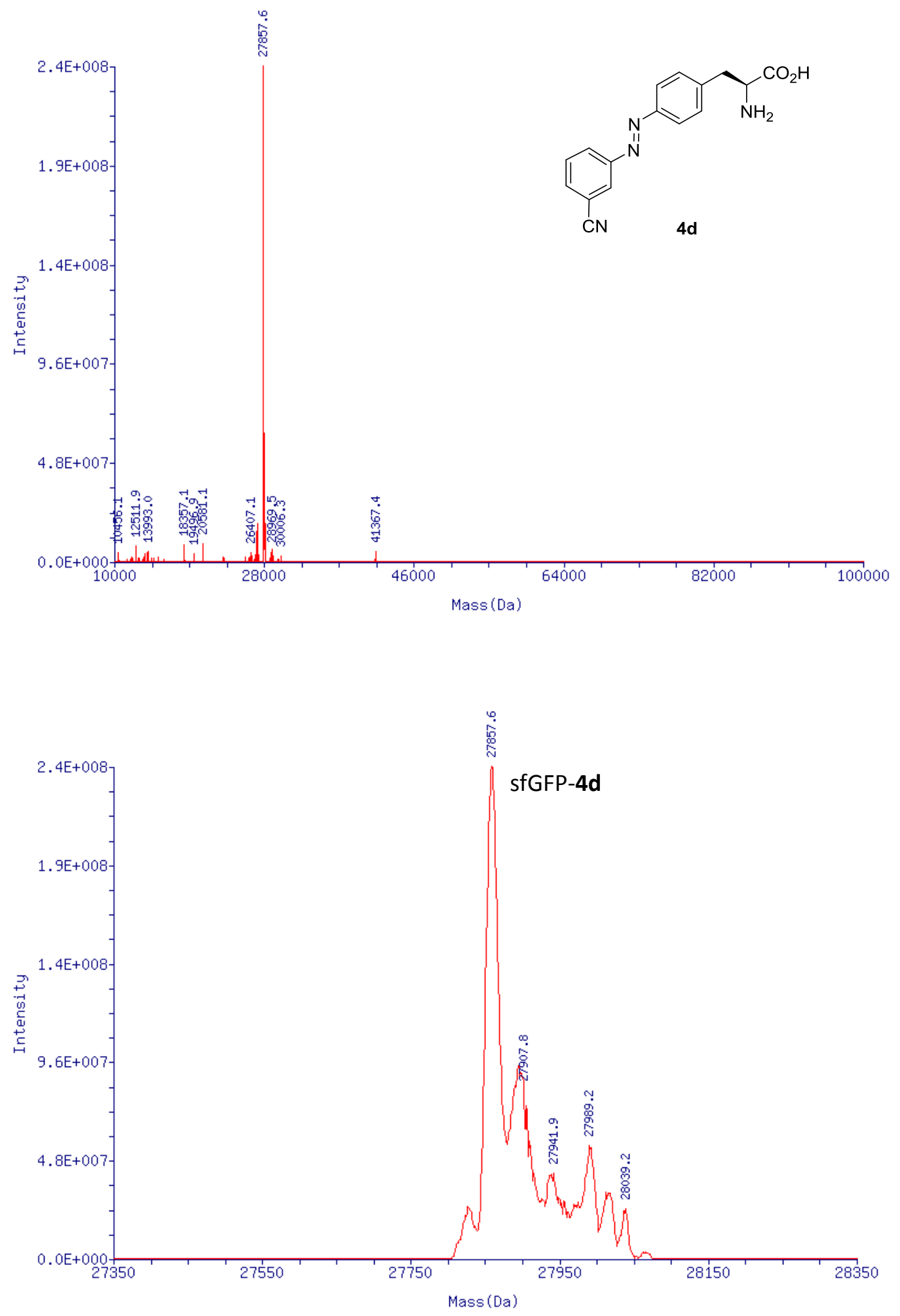
Table 3, compound 4g: sfGFP-S2 $\rightarrow$ 4g with first Met removed: MS-ESI calcd 27868.1, found 27867.6.
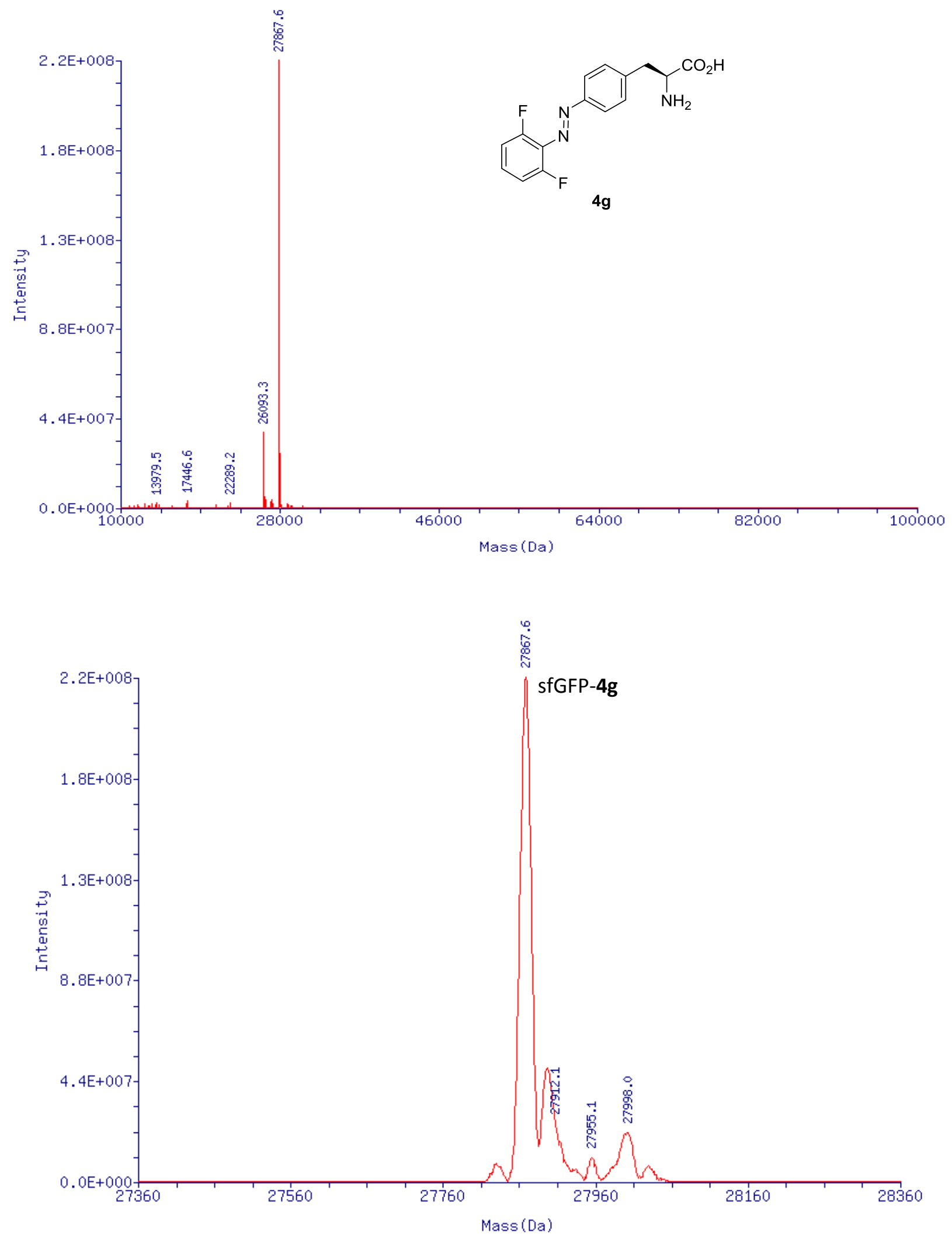
Table 3, compound $\mathbf{4 h}$ : sfGFP-S2 $\rightarrow \mathbf{4 h}$ with first Met removed: MS-ESI calcd 27886.1, found 27885.2.
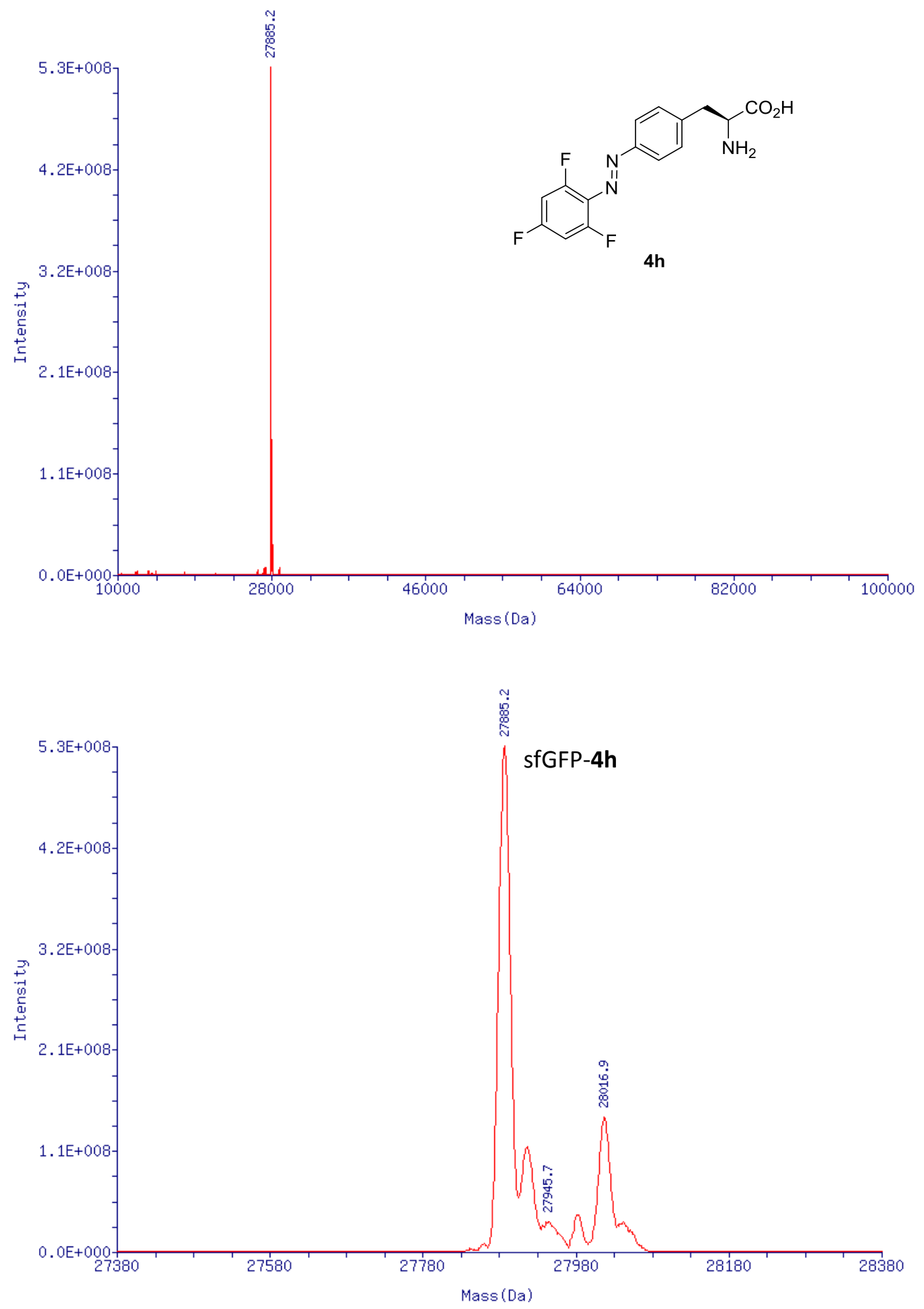
Table 3, compound 4k: sfGFP-S2 $\rightarrow \mathbf{4 k}$ with first Met removed: MS-ESI calcd 27921.3, found 27920.3 .
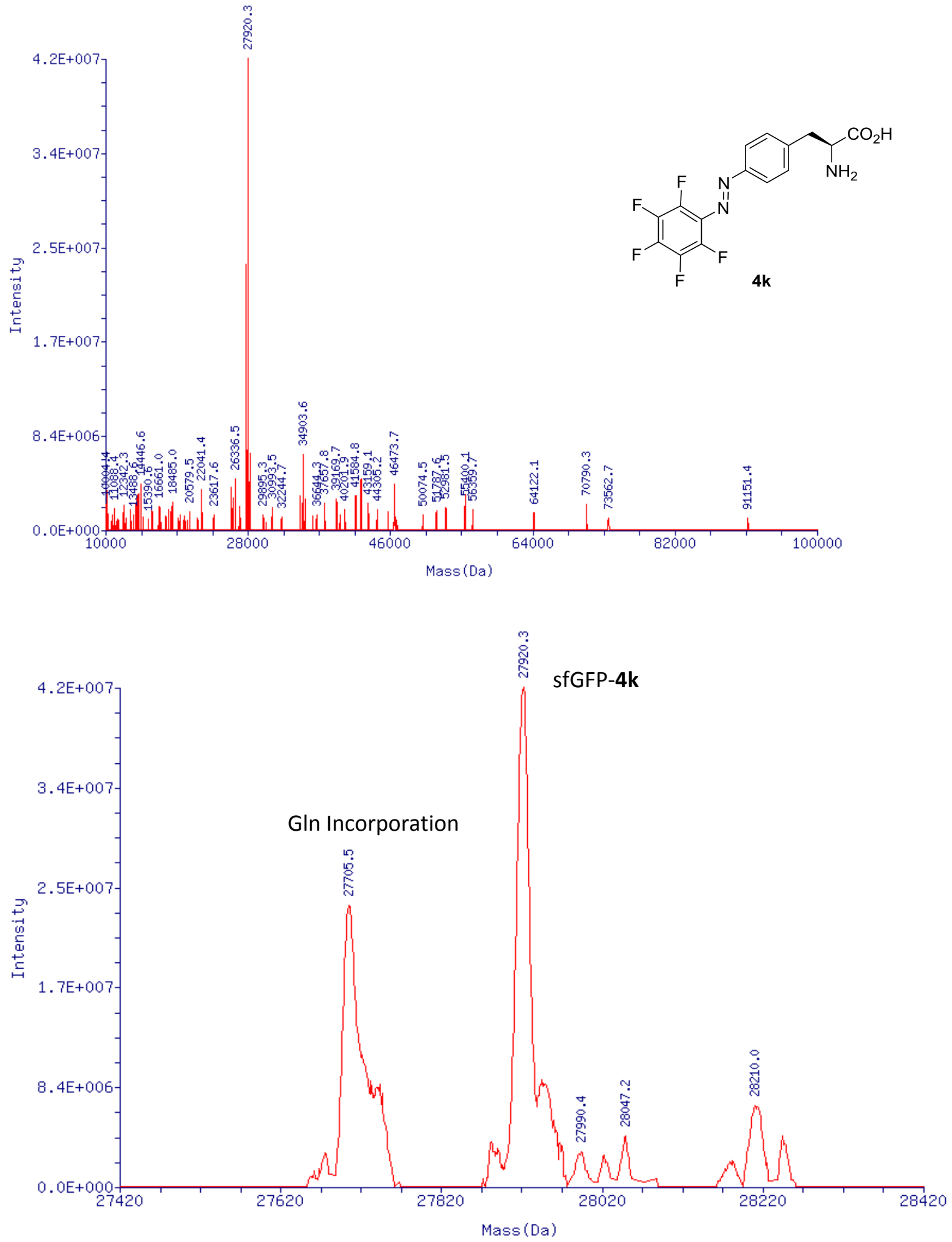
Table 3, compound 4l: sfGFP-S2 $\rightarrow 41$ with first Met removed: MS-ESI calcd 27886.1, found 27886.0.
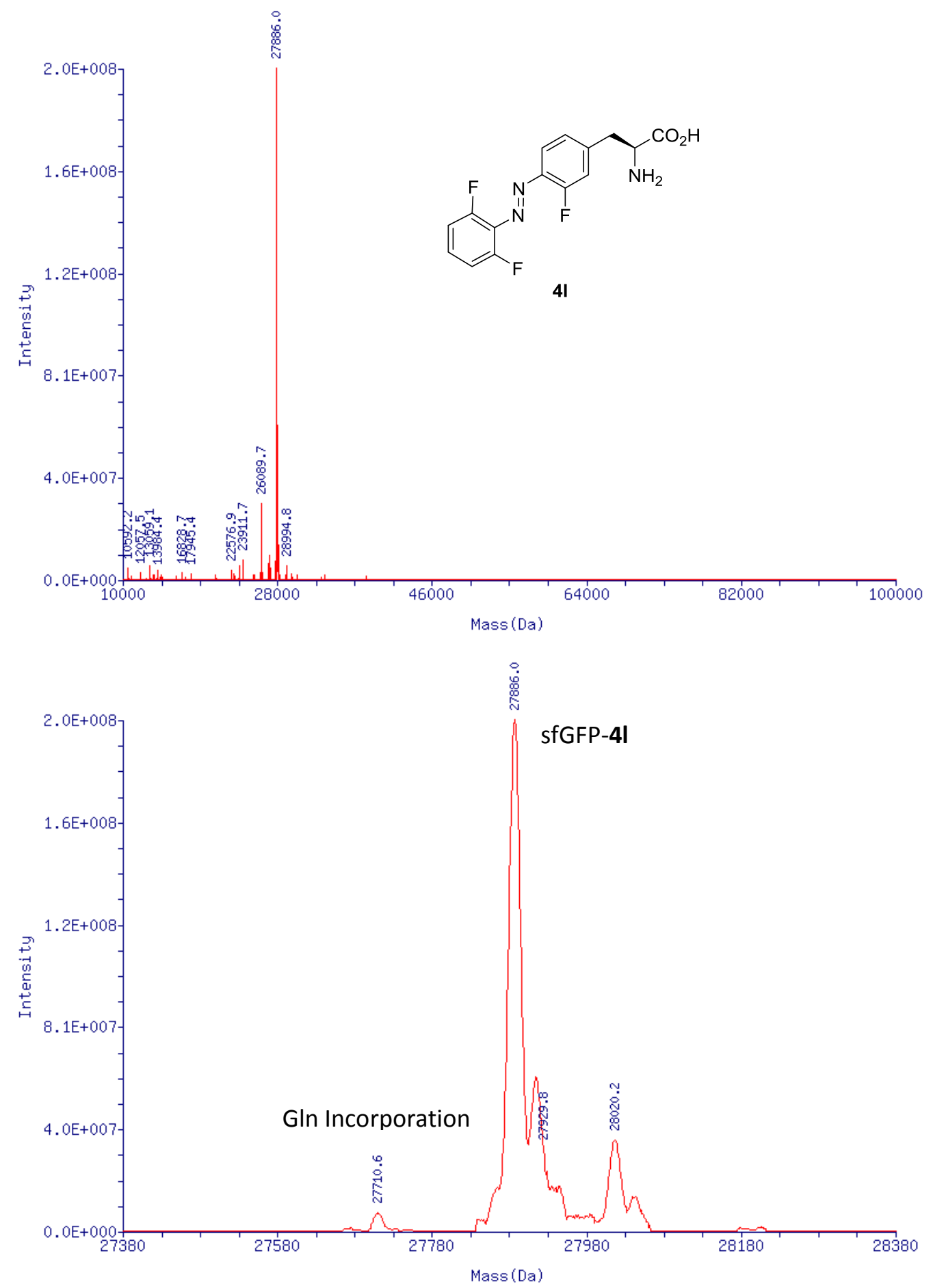
Table 3, compound 4m: sfGFP-S2 $\rightarrow \mathbf{4 m}$ with first Met removed: MS-ESI calcd 27903.3, found 27901.9 .
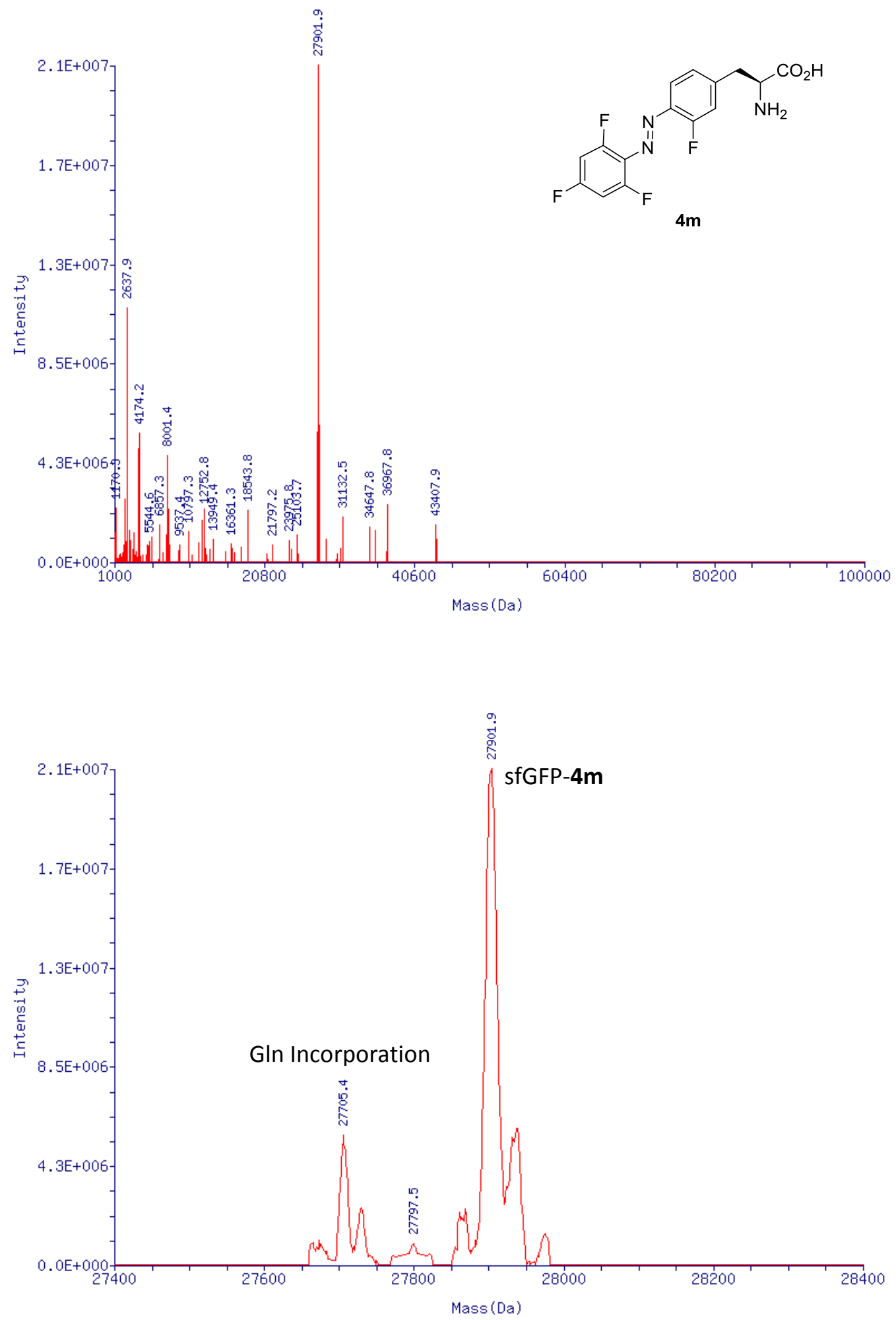
Table 3, compound 4n: sfGFP-S2 $\rightarrow \mathbf{4 n}$ with first Met removed: MS-ESI calcd 27941.1, found 27940.3.
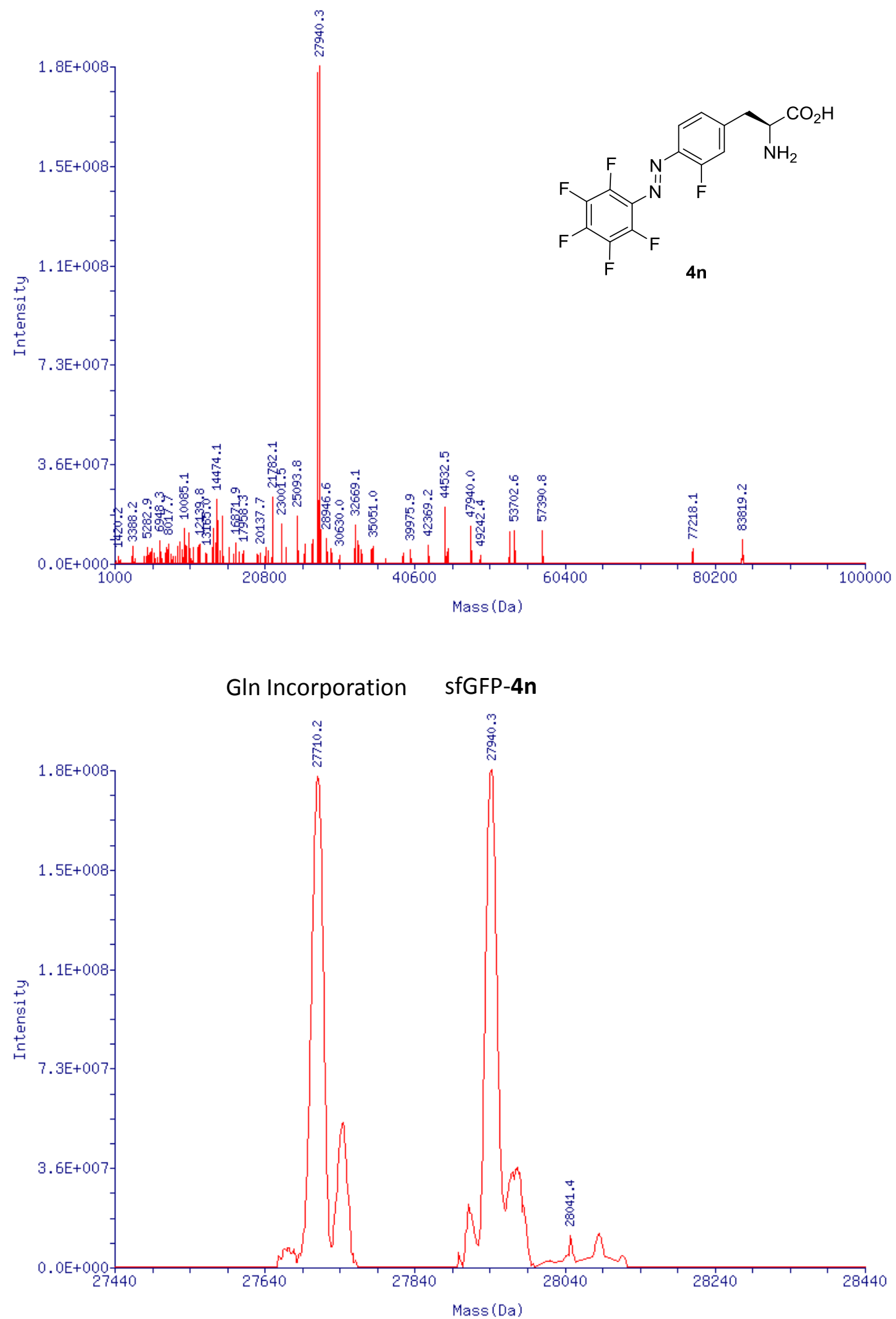
Table 3, compound 4o: sfGFP-S2 $\rightarrow \mathbf{4 o}$ with first Met removed: MS-ESI calcd 27902.1, found 27904.6.
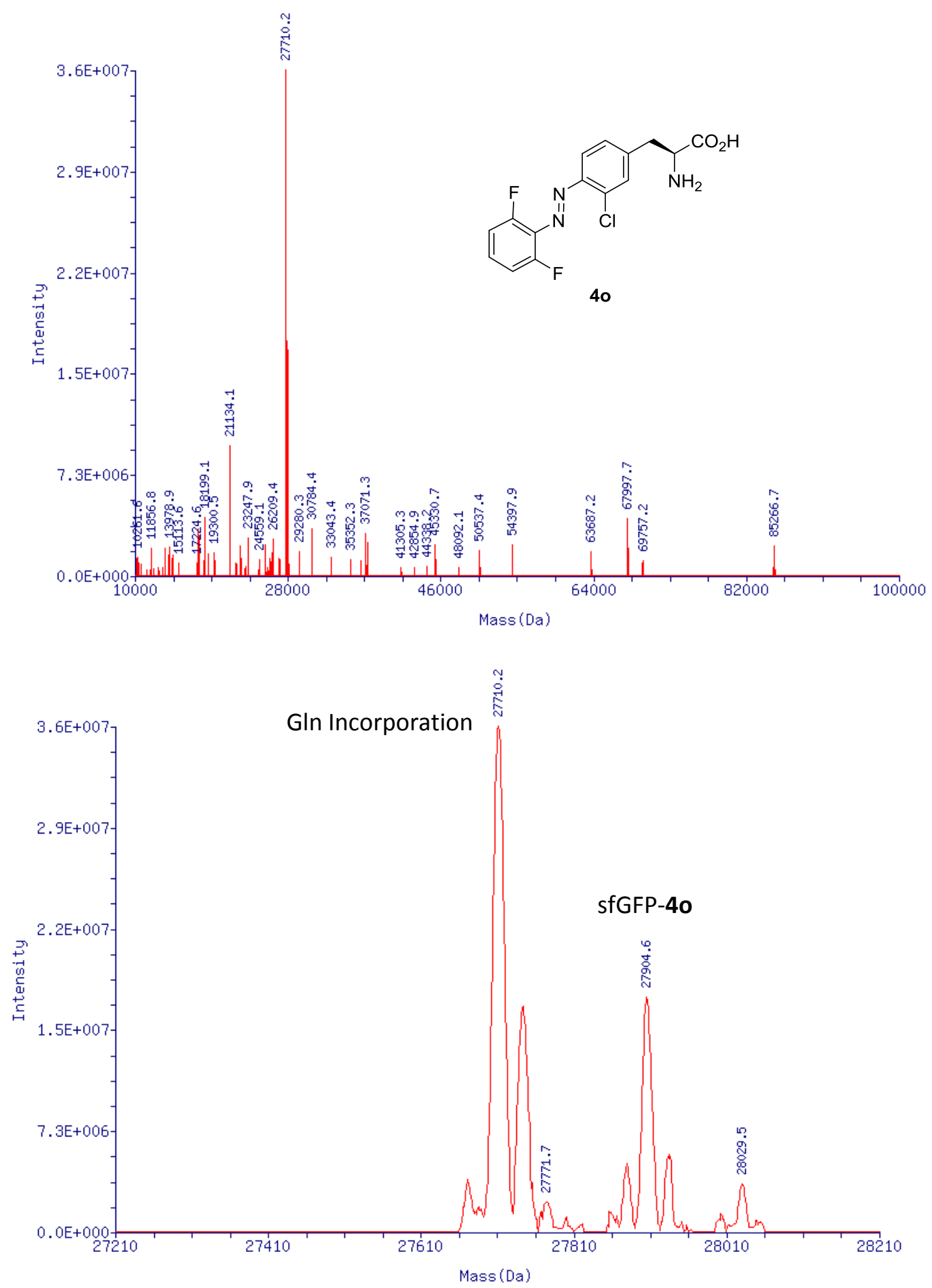
Table 3, compound 4p: sfGFP-S2 $\rightarrow \mathbf{4 p}$ with first Met removed: MS-ESI calcd 27920.5, found 27920.3 .
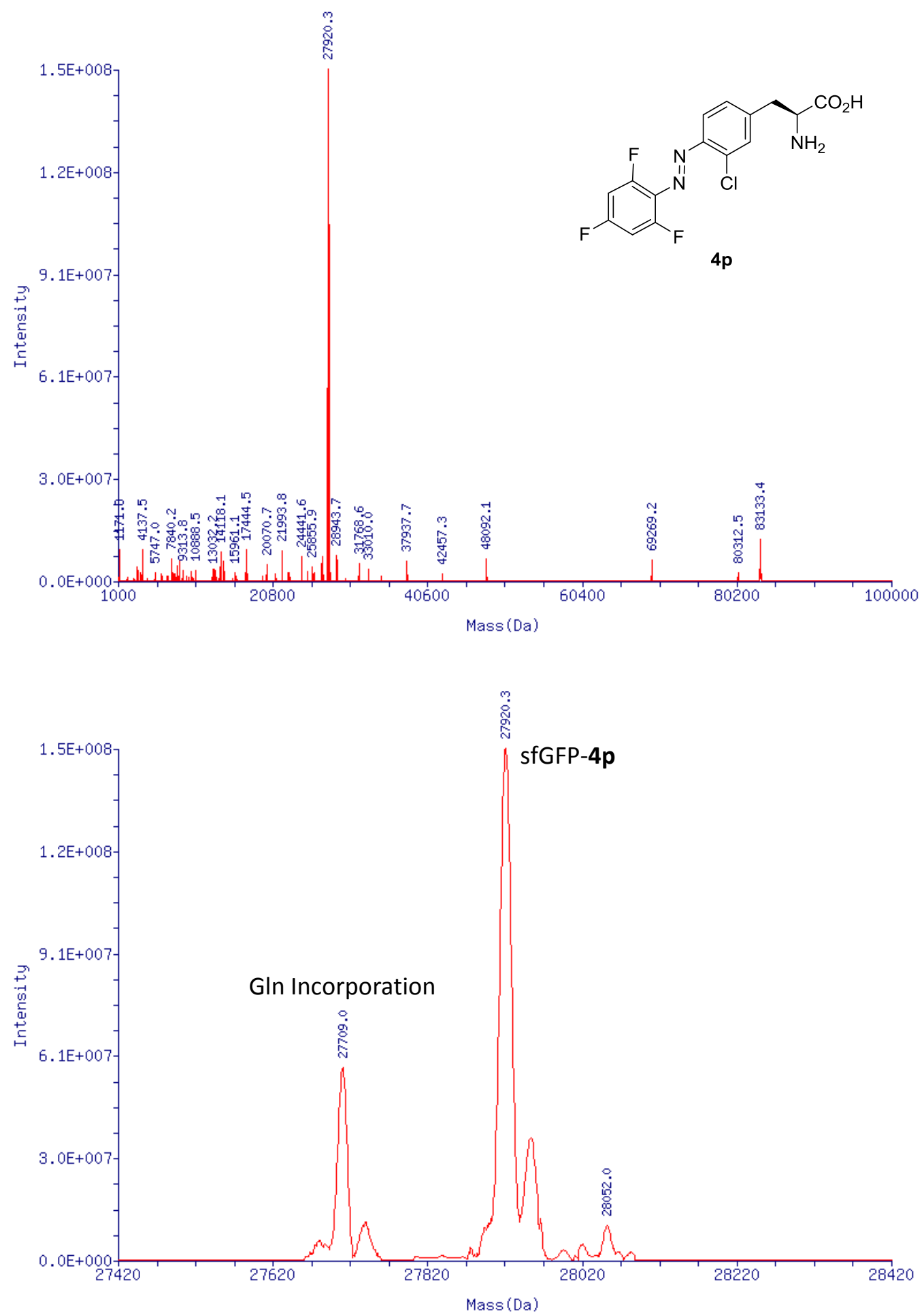
Table S1. Measuring trans:cis ratios for $\mathbf{3 h}$ with varying photoirradiation time.
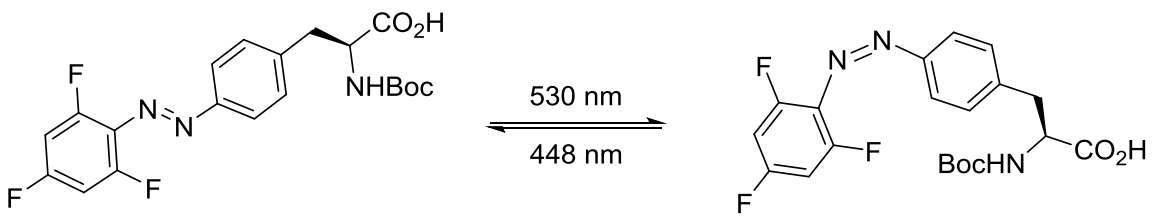

trans-3h

cis-3h

\begin{tabular}{|c|c|c|}
\hline LED light source $(\mathrm{nm})$ & Irradiation Time $(\mathrm{min})$ & ${\text { Trans }: \text { Cis }^{a}}^{\mathrm{a}}$ \\
\hline 530 & 5 & $37: 63$ \\
\hline 448 & 5 & $64: 36$ \\
\hline 530 & 10 & $37: 63$ \\
\hline 448 & 10 & $63: 37$ \\
\hline 530 & 15 & $36: 64$ \\
\hline 448 & 15 & $63: 37$ \\
\hline 530 & 30 & $38: 62$ \\
\hline 448 & 30 & $61: 39$ \\
\hline
\end{tabular}

${ }^{a}$ The trans:cis ratio was determined by ${ }^{19} \mathrm{~F}$ NMR. 


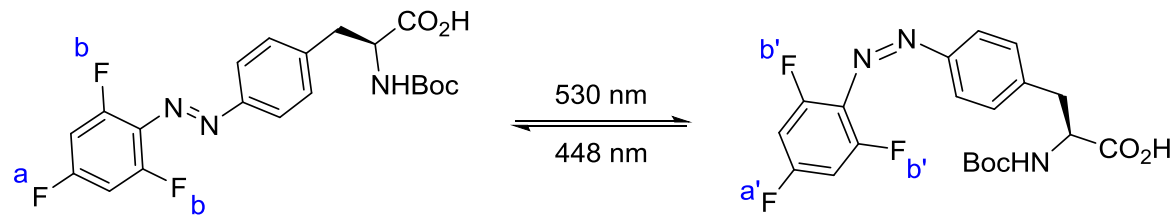

trans-3h

cis-3h

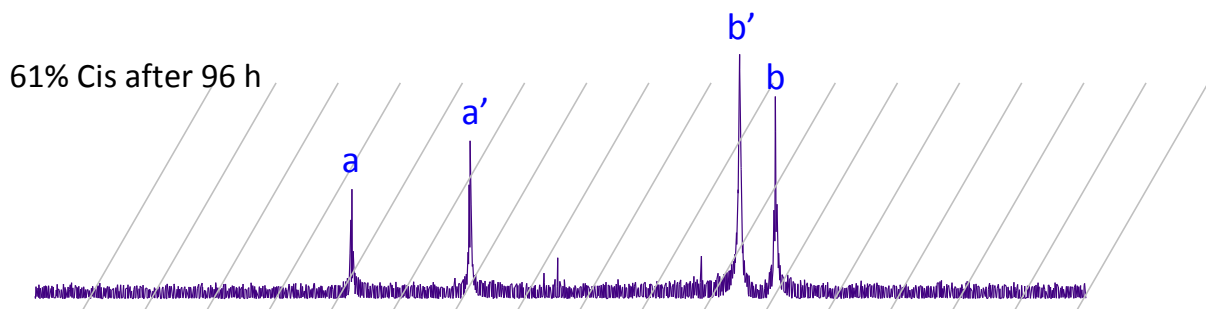

$62 \%$ Cis after $20 \mathrm{~h}$

$62 \%$ Cis after $3 \mathrm{~h}$
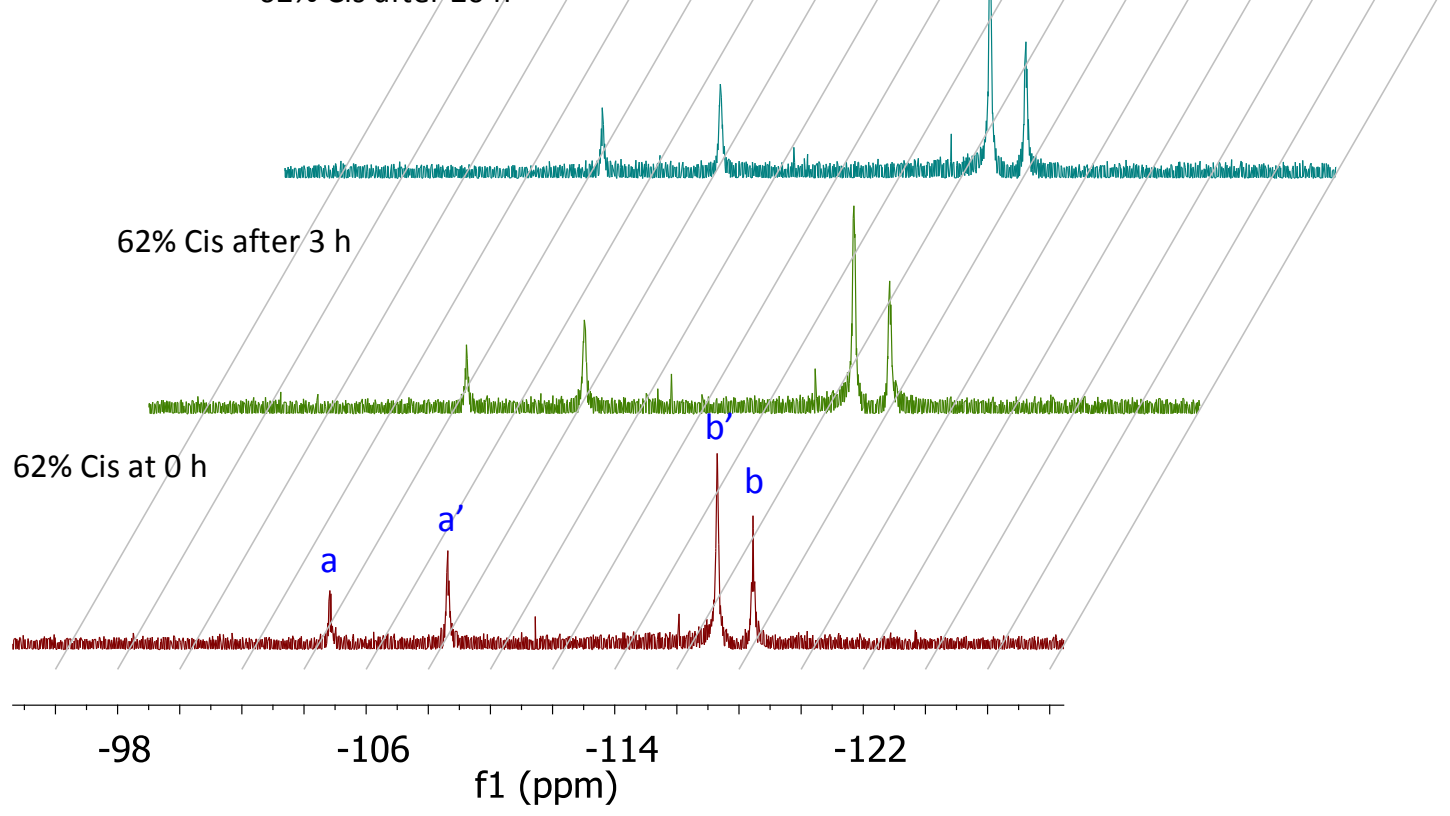

Figure S1. Measurement of cis-pss at various time points by ${ }^{19} \mathrm{~F}$ NMR after photo-irradiating compound $\mathbf{3 h}$ with a $530 \mathrm{~nm}$ LED light for $30 \mathrm{~min}$ followed by dark adaptation at room temperature. 
a)

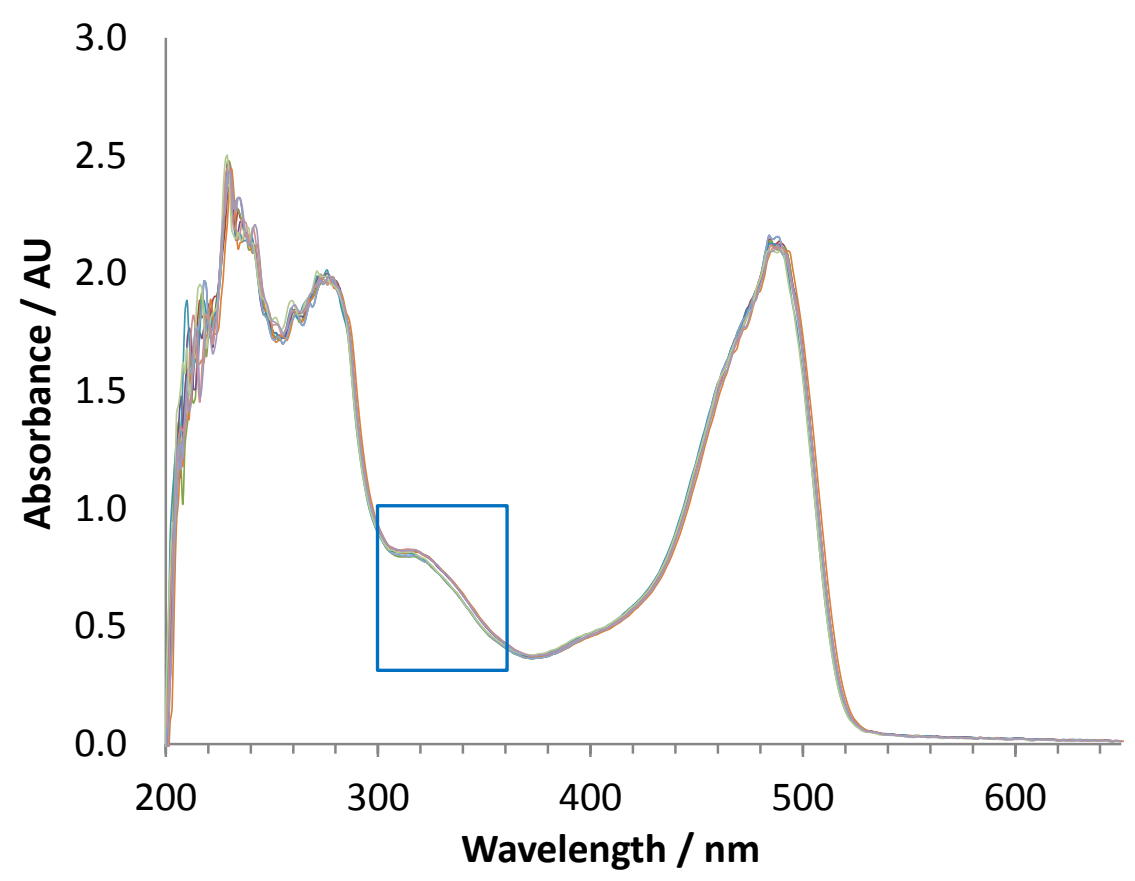

b)

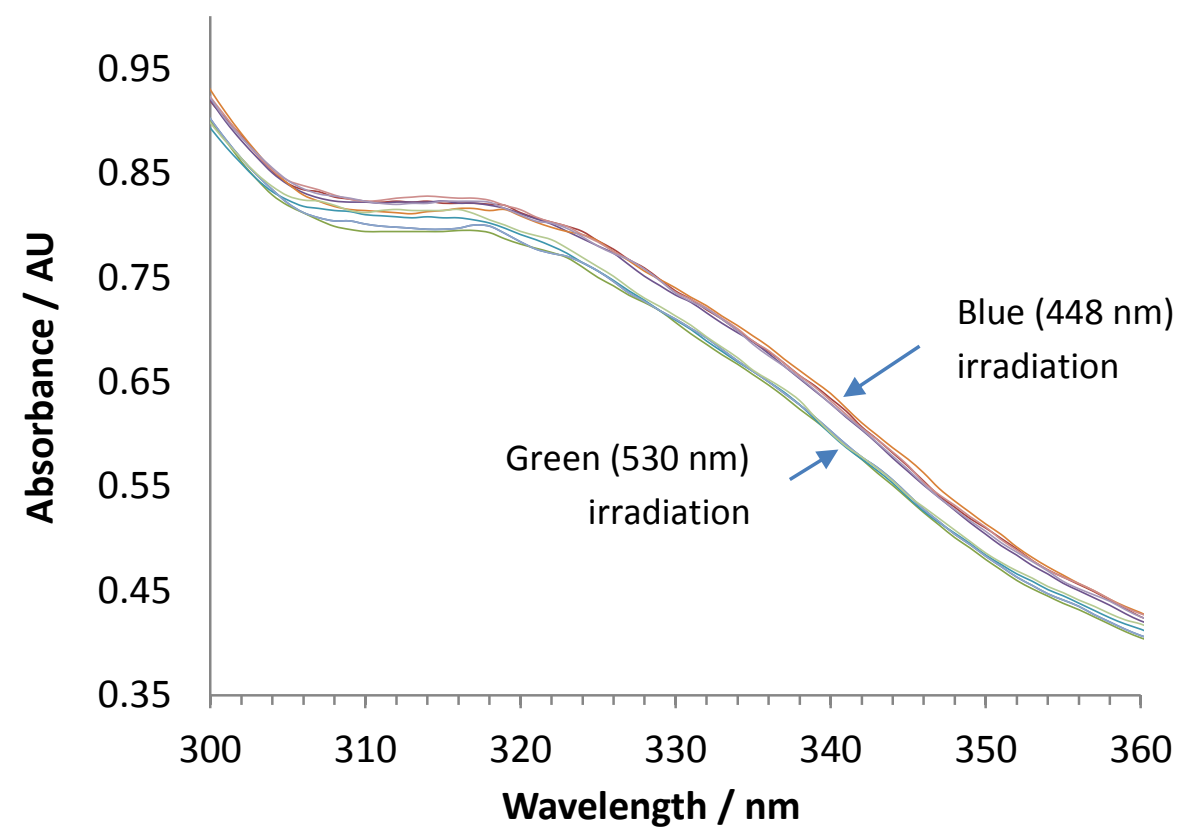

Figure S2. (a) Overlaid UV-vis spectra of sfGFP-4h with 5-min alternating rounds of blue/green LED light irradiation. The protein was dissolved in PBS buffer to obtain a concentration of 57 $\mu \mathrm{M}$. (b) A zoom-in view of the 300-360 nm region (boxed in a) associated with the $\pi \rightarrow \pi^{*}$ transition of the trifluoroazobenzene $\mathbf{4 h}$. 


\section{General Information}

Solvents and chemicals were purchased from commercial sources and used directly without further purification. Flash chromatography was performed with SiliCycle P60 silica gel (40-63 $\mu \mathrm{m}, 60 \AA)$. ${ }^{1} \mathrm{H}$ NMR spectra were recorded with Inova-300, -400 or $-500 \mathrm{MHz}$ spectrometers and chemical shifts were reported in ppm using either TMS or deuterated solvents as internal standards (TMS, $\left.0.00 ; \mathrm{CDCl}_{3}, 7.26 ; \mathrm{CD}_{3} \mathrm{OD}, 3.31 ; \mathrm{DMSO}-d_{6}, 2.50\right)$. Multiplicity was reported as follows: $\mathrm{s}=$ singlet, $\mathrm{d}=$ doublet, $\mathrm{t}=$ triplet, $\mathrm{q}=$ quartet, $\mathrm{m}=$ multiplet, brs = broad. ${ }^{13} \mathrm{C}$ NMR spectra were recorded at $75.4 \mathrm{MHz}$, and chemical shifts were reported in ppm using the deuterated solvents as internal standards $\left(\mathrm{CDCl}_{3}, 77.0 ; \mathrm{DMSO}-d_{6}, 39.5 ; \mathrm{CD}_{3} \mathrm{OD}, 49.05\right)$. Absorption spectra were recorded using 1-cm quartz cuvette on a Thermo Scientific NanoDrop 2000c spectrometer. LED lights were purchased from Luxeonstar: Royal-Blue LED light (447.5 nm), LUXEON Rebel ES LED on a SinkPAD-II 20 mm Star Base, 1030 mW @ 700 mA; and Green LED light (530 nm), LUXEON Rebel LED on a SinkPAD-II 20 mm Star Base, 125 lm @ 700 mA.

\section{Experimental Procedures and Characterization Data}

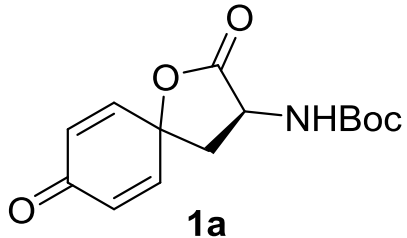

diluting with $20 \mathrm{~mL}$ ethyl acetate and $20 \mathrm{~mL}$ brine. The reaction mixture was extracted with ethyl acetate $(20 \mathrm{~mL} \times 2)$, and the organic layers were combined, dried over anhydrous sodium sulfate, and concentrated under reduced pressure. The crude mixture was purified using the Yamazen Smart Flash chromatography purification system (gradient elution - 25-55\% ethyl acetate in hexanes over $30 \mathrm{~min})$. The titled compound was obtained as a white solid (37 mg, 37\% yield): ${ }^{1} \mathrm{H}$ NMR (300 MHz, DMSO- $\left.d_{6}\right) \delta 7.57$ (d, $\left.J=8.1 \mathrm{~Hz}, 1 \mathrm{H}\right), 7.41-7.37(\mathrm{~m}, 1 \mathrm{H}), 7.01-6.97(\mathrm{~m}, 1 \mathrm{H})$, 6.29-6.20 (m, 2H), 4.80-4.71 (m, 1H), 2.56-2.53 (m, 1H), 2.41-2.33 (m, 1H), $1.40(\mathrm{~s}, 9 \mathrm{H}) ;{ }^{13} \mathrm{C}$ NMR (75 MHz, DMSO-d6) $\delta 184.6,174.6,155.4,148.1,147.4,129.2,128.0,79.4,75.6,49.7$, 40.8, 36.6, 28.5; HRMS (ESI) calcd for $\mathrm{C}_{14} \mathrm{H}_{17} \mathrm{NO}_{5} 278.1028\left[\mathrm{M}-\mathrm{H}^{+}\right]$, found 278.1044.

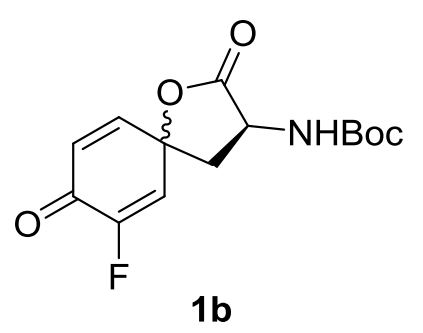

tert-Butyl (7-fluoro-2,8-dioxo-1-oxaspiro[4.5]deca-6,9-dien-3-yl) carba mate (1b): The compound was synthesized from 3-fluoro- $N$ Boc-L-tyrosine (190 mg, $0.603 \mathrm{mmol}$ ) using the same procedure as 1a. After flash chromatography, the desired product was obtained as a white diastereomeric mixture (32 mg, 17\% yield). Diastereomer 1: ${ }^{1} \mathrm{H}$ NMR $\left(300 \mathrm{MHz}, \mathrm{CDCl}_{3}\right) \delta 6.97((\mathrm{~s}, 1 \mathrm{H}), 6.35-6.30(\mathrm{~m}, 1 \mathrm{H}), 5.29(\mathrm{~d}, J$ $=6.3 \mathrm{~Hz}, 1 \mathrm{H}), 4.55-4.46(\mathrm{~m}, 1 \mathrm{H}) 2.85-2.78(\mathrm{~m}, 1 \mathrm{H}), 2.59-2.50(\mathrm{~m}, 1 \mathrm{H})$,

1.46 (s, 9H); Diastereomer 2: ${ }^{1} \mathrm{H}$ NMR $\left(300 \mathrm{MHz}^{\mathrm{C}} \mathrm{CDCl}_{3}\right) \delta 6.88-6.84(\mathrm{~m}, 1 \mathrm{H}), 6.50(\mathrm{~s}, 1 \mathrm{H})$, 6.32-6.27 (m, 1H), 6.35-6.30 (m, 1H), $5.21(\mathrm{~s}, 1 \mathrm{H}), 4.49(\mathrm{~s}, 1 \mathrm{H}), 2.83-2.74(\mathrm{~m}, 1 \mathrm{H}), 2.62-2.53(\mathrm{~m}$, 
1H), 1.45 (s, 9H); $\left.{ }^{13} \mathrm{C} \mathrm{NMR} \mathrm{(75} \mathrm{MHz,} \mathrm{CDCl}_{3}\right) \delta 174.1,156.0,154.7,151.1,147.9,127.4,122.0$, 121.8, 79.9, 49.5, 36.7, 27.3; HRMS (ESI) calcd for $\mathrm{C}_{14} \mathrm{H}_{16} \mathrm{FNO}_{5} 314.3\left[\mathrm{M}+\mathrm{H}_{2} \mathrm{O}-\mathrm{H}^{+}\right]^{-}$, found 314.1.

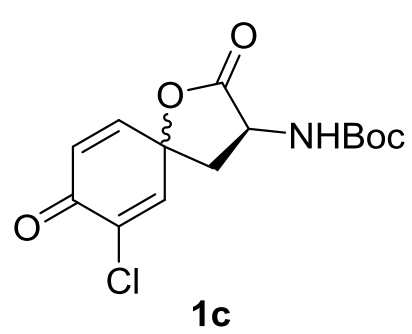

tert-Butyl (7-chloro-2,8-dioxo-1-oxaspiro[4.5]deca-6,9-dien-3-yl) carbamate: The compound was synthesized from 3-chloro- $N$-Boc-Ltyrosine (127 $\mathrm{mg}, 0.402 \mathrm{mmol}$ ) using the same procedure as 1a. After flash chromatography, the desired product was obtained as a white diastereomeric mixture (25 mg, 20\% yield). Diastereomer 1: ${ }^{1} \mathrm{H} \mathrm{NMR}$ $\left(300 \mathrm{MHz}, \mathrm{CDCl}_{3}\right) \delta 7.05(\mathrm{~d}, J=2.7 \mathrm{~Hz}, 1 \mathrm{H}), 6.95(\mathrm{~s}, 1 \mathrm{H}), 6.40(\mathrm{~d}, J$ $=10.2,1 \mathrm{H}), 5.30(\mathrm{~s}, 1 \mathrm{H}), 4.56-4.48(\mathrm{~m}, 1 \mathrm{H}), 2.81-2.74(\mathrm{~m}, 1 \mathrm{H}), 2.58-$

$2.50(\mathrm{~m}, 1 \mathrm{H}), 1.45(\mathrm{~s}, 9 \mathrm{H})$; Diastereomer 2: ${ }^{1} \mathrm{H}$ NMR $\left(300 \mathrm{MHz}, \mathrm{CDCl}_{3}\right) \delta 7.05(\mathrm{~d}, J=2.7 \mathrm{~Hz}$, 1H), 7.10 (s, 1H), 6.90-6.86 (m, 1H), 5.27 (s, 1H), 4.54-4.46 (m, 1H), 2.80-2.73 (m, 1H), 2.59$2.51(\mathrm{~m}, 1 \mathrm{H}), 1.46(\mathrm{~s}, 9 \mathrm{H}) ;{ }^{13} \mathrm{C} \mathrm{NMR}\left(75 \mathrm{MHz}, \mathrm{CDCl}_{3}\right) \delta 175.5,155.4,150.6,129.9,129.2,119.9$, 116.4, 80.4, 54.5, 36.8, 31.0, 28.3; HRMS (ESI) calcd for $\mathrm{C}_{14} \mathrm{H}_{16} \mathrm{ClNO}_{5} 368.0871[\mathrm{M}+\mathrm{MeOH}+$ $\mathrm{Na}^{+}$, found 368.1083 .

\section{General procedure for synthesis of phenylhydrazine derivatives}<smiles>Cc1ccc(N)cc1</smiles><smiles>O=[N+]([O-])O[SnH3]</smiles><smiles>Cc1ccc(NN)cc1</smiles>

p-Tolylhydrazine (2a): 4-Methylaniline (428 mg, $4 \mathrm{mmol}$ ) was added to a round bottom flask containing $10 \mathrm{~mL} 6 \mathrm{~N} \mathrm{HCl}$. The solution was vigorously stirred at $0{ }^{\circ} \mathrm{C}$ for $10 \mathrm{~min}$. Sodium nitrite (280 mg, $4 \mathrm{mmol}$ ) dissolved in $2 \mathrm{~mL}$ water was added dropwise to the aniline solution, and the resulting mixture was stirred at $0^{\circ} \mathrm{C}$ for an additional $1 \mathrm{~h}$. To a beaker containing $\mathrm{SnCl}_{2}(1.9 \mathrm{~g}, 10$ mmol) was added $10 \mathrm{~mL}$ of concentrated $\mathrm{HCl}$, and the solution was sonicated and cooled to $0{ }^{\circ} \mathrm{C}$. The $\mathrm{SnCl}_{2}$ solution was then added dropwise to the diazonium salt solution, and the mixture was stirred for additional $90 \mathrm{~min}$ at room temperature. Then, sodium hydroxide $(7.2 \mathrm{~g}, 0.18 \mathrm{~mol})$ dissolved in $20 \mathrm{~mL}$ water was added to quench the reaction. The solution was extracted with 20 $\mathrm{mL}$ of diethyl ether three times, and the organic layers were combined and concentrated under reduced pressure to give pale-orange crude product (347 $\mathrm{mg}, 71 \%$ yield). The crude product was further purified by recrystallization in hot ethanol. ${ }^{1} \mathrm{H}$ NMR $\left(300 \mathrm{MHz}, \mathrm{CDCl}_{3}\right) \delta 7.11-7.00(\mathrm{~m}$, 2H), 6.77-6.71 (m, 2H), 3.85 (s, 3H), 2.27 (s, 3H).

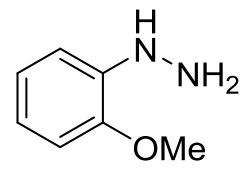

$\mathbf{2 b}$

2-Methoxyphenyl)hydrazine (2b): The hydrazine derivative was synthesized from $o$-anisidine $(123 \mathrm{mg}, 1 \mathrm{mmol})$ using the same procedure as procedures as 2a.The desired product ( $69 \mathrm{mg}, 50 \%$ yield) was used without further purification. ${ }^{1} \mathrm{H}$ NMR (300 MHz, $\left.\mathrm{CDCl}_{3}\right) \delta 7.01-6.89(\mathrm{~m}, 2 \mathrm{H}), 6.79(\mathrm{dd}, J=5.2,2.6 \mathrm{~Hz}, 2 \mathrm{H})$, $3.85(\mathrm{~d}, J=2.6 \mathrm{~Hz}, 3 \mathrm{H}), 3.67(\mathrm{~s}, 3 \mathrm{H})$. 
<smiles>N#Cc1ccc(NN)cc1</smiles><smiles>N#Cc1cccc(NN)c1</smiles>

2d

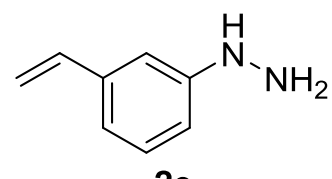

$2 e$

4-Hydrazinylbenzonitrile (2c): The hydrazine derivative was prepared from 4-cyanoaniline ( $236 \mathrm{mg}, 2.0 \mathrm{mmol}$ ) using the same procedure as $\mathbf{2 a}$; $51 \%$ yield: ${ }^{1} \mathrm{H} \mathrm{NMR}\left(300 \mathrm{MHz}, \mathrm{CDCl}_{3}\right) \delta 7.56-7.39(\mathrm{~m}, 2 \mathrm{H}), 6.90-6.76(\mathrm{~m}$, 2H), $5.61(\mathrm{~s}, 1 \mathrm{H}), 3.65(\mathrm{~s}, 2 \mathrm{H})$.

3-Hydrazinylbenzonitrile (2d): The hydrazine derivative was prepared from 3-aminobenzonitrile $(118 \mathrm{mg}, 1.0 \mathrm{mmol})$ using the same procedure as 2a; 80\% yield. ${ }^{1} \mathrm{H}$ NMR (500 MHz, DMSO- $\left.d_{6}\right) \delta 7.23(\mathrm{dd}, J=17.4,9.4 \mathrm{~Hz}$, 2H), $7.08(\mathrm{~s}, 1 \mathrm{H}), 7.01$ (dd, $J=8.4,2.3 \mathrm{~Hz}, 1 \mathrm{H}), 6.96-6.89(\mathrm{~m}, 1 \mathrm{H}), 4.11$ (s, $2 \mathrm{H})$.

3-Vinylphenyl)hydrazine (2e): The hydrazine derivative was synthesized from 3-aminostyrene (300 $\mathrm{mg}, 2.5 \mathrm{mmol}$ ) using the same procedure as $\mathbf{2 a}$. The titled compound was obtained as a yellow oil (246 mg, 73\%), which was used without further purification. ${ }^{1} \mathrm{H}$ NMR (400 MHz, DMSO-d 6$) \delta 7.06(\mathrm{t}$, $J=7.8 \mathrm{~Hz}, 1 \mathrm{H}), 6.88(\mathrm{~s}, 1 \mathrm{H}), 6.69-6.58(\mathrm{~m}, 4 \mathrm{H}), 5.70(\mathrm{dd}, J=17.6,1.1 \mathrm{~Hz}$, $1 \mathrm{H}), 5.17(\mathrm{dd}, J=10.8,1.0 \mathrm{~Hz}, 1 \mathrm{H}), 3.93(\mathrm{~s}, 2 \mathrm{H})$.<smiles>C#Cc1cccc(NN)c1</smiles><smiles>NNc1c(F)cccc1F</smiles>

$2 \mathbf{g}$<smiles>NNc1c(F)cc(C(N)=O)cc1F</smiles>

$2 \mathbf{i}$

(3-Ethynylphenyl)hydrazine (2f): The hydrazine derivative was prepared from 3-ethynylaniline $(200 \mathrm{mg}, 1.7 \mathrm{mmol})$ using the same procedure as $\mathbf{2 a}$. The titled compound was obtained as a red oil (250 mg, 91\% yield). ${ }^{1} \mathrm{H}$ NMR $\left(300 \mathrm{MHz}, \mathrm{CDCl}_{3}\right) \delta$ 7.21-7.14 (m, 1H), 6.97-6.94 (m, 2H), 6.83-6.77 (m, $1 \mathrm{H}), 5.20(\mathrm{~s}, 1 \mathrm{H}), 3.57(\mathrm{~s}, 2 \mathrm{H}), 3.03(\mathrm{~s}, 1 \mathrm{H})$.

(2,6-Difluorophenyl)hydrazine hydrochloride (2g): The hydrazine derivative was prepared from 2,6-difluoroaniline $(2.1 \mathrm{~g}, 16 \mathrm{mmol})$ using the same procedure as $\mathbf{2 a}$. The $\mathrm{HCl}$ salt form of the product was obtained after acidification (2.3 g, 79\% yield). ${ }^{1} \mathrm{H}$ NMR (300 MHz, DMSO- $\left.d_{6}\right) \delta 10.22$ (s, $3 \mathrm{H}), 7.88$ (s, 1H), $7.36-6.98(\mathrm{~m}, 3 \mathrm{H})$.

3,5-Difluoro-4-hydrazinylbenzamide (2i): The hydrazine derivative was prepared from 4-amino-3,5-difluorobenzamide (200 mg, $1.2 \mathrm{mmol}$ ) using the procedure as $\mathbf{2 a}$. Purification was carried out using silica gel flash chromatography with methylene chloride/methanol (8:1) as eluent to give the titled compound as a brown solid (164 mg, $76 \%$ yield). ${ }^{1} \mathrm{H}$ NMR (300 MHz, DMSO-d6) $\delta 7.83(\mathrm{~s}, 1 \mathrm{H}), 7.57-7.12(\mathrm{~m}, 3 \mathrm{H}), 6.68$ (s,

$1 \mathrm{H}), 4.48$ (s, 2H).<smiles>NNc1c(F)cc(I)cc1F</smiles>

2j

(2,6-Difluoro-4-iodophenyl)hydrazine (2j): The hydrazine derivative was synthesized from 2,6-difluoro-4-iodoaniline (322 $\mathrm{mg}, 1.3 \mathrm{mmol}$ ) using the same procedure as $\mathbf{2 a}$. The titled compound was obtained as a dark brown solid (305 mg, $87 \%$ yield). ${ }^{1} \mathrm{H}$ NMR (400 MHz, $\left.\mathrm{CDCl}_{3}\right) \delta 7.19$ (s, 2H), 5.14 (s, 1H), 3.87 $(\mathrm{s}, 2 \mathrm{H})$. 


\section{General procedure for synthesis of azobenzene amino acids}

The azobenzene amino acid was synthesized by incubating $90 \mathrm{mM}$ spirolactone with $100 \mathrm{mM}$ phenylhydrazine in $2 \mathrm{~mL}$ acetonitrile in the presence of $3 \mathrm{~mol} \%$ of cerium(IV) ammonium nitrate at room temperature. The reaction was monitored by TLC and the solution was concentrated under reduced pressure after the disappearance of the spirolactones starting materials. The crude product were purified by flash chromatography using ethyl acetate/hexanes (2:3) first and then acetic acid/ethyl acetate/hexanes (1:9:10) as eluents to yield the desired azobenzene amino acids.

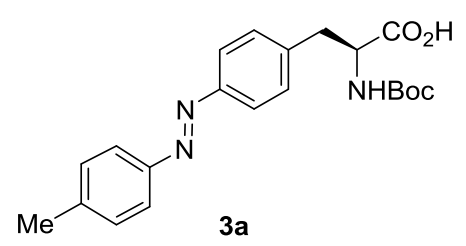

$(S, E)-2-((t e r t-B u t o x y c a r b o n y l) a m i n o)-3-(4-(p-t o l y l d i a z e n y l)$ phenyl)propanoic acid (3a): The corresponding hydrazine (2a, 24 $\mathrm{mg}, 0.2 \mathrm{mmol})$ and spirolactone $1 \mathrm{a}(50 \mathrm{mg}, 0.18 \mathrm{mmol})$ were combined, incubated, and purified according to the general procedure. An orange product was obtained $(51 \mathrm{mg}, 73 \%$ yield $) .{ }^{1} \mathrm{H}$ NMR (300 MHz, DMSO-d6) $\delta$ 7.80-7.77 (m, 4H), 7.46-7.38 (m, 4H), 7.11-7.09 (m, 1H), 4.18$4.10(\mathrm{~m}, 1 \mathrm{H}), 3.15-3.09(\mathrm{~m}, 1 \mathrm{H}), 2.96-2.92(\mathrm{~m}, 1 \mathrm{H}), 2.40(\mathrm{~s}, 3 \mathrm{H}), 1.31(\mathrm{~s}, 9 \mathrm{H}) ;{ }^{13} \mathrm{C} \mathrm{NMR}(75 \mathrm{MHz}$, DMSO-d $d_{6} \delta 174.0,150.4,141.9,130.6,130.3,127.7,122.8,122.6,115.3,104.5,78.4,55.7,49.0$, 28.5, 21.5; HRMS (ESI) calcd for $\mathrm{C}_{21} \mathrm{H}_{25} \mathrm{~N}_{3} \mathrm{O}_{4} 384.1924\left[\mathrm{M}+\mathrm{H}^{+}\right]$, found 384.1928.

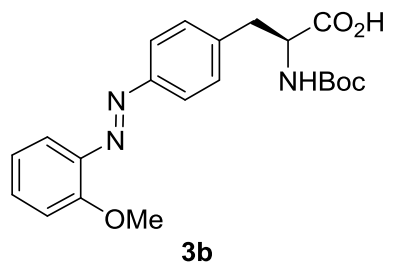

(S,E)-2-((tert-Butoxycarbonyl)amino)-3-(4-((2-methoxyphenyl) diazenyl)phenyl)propanoic acid (3b): The corresponding hydrazine (2b, $27 \mathrm{mg}, 0.2 \mathrm{mmol})$ and spirolactone $1 \mathbf{a}(50 \mathrm{mg}, 0.18 \mathrm{mmol})$ were combined, incubated, and purified according to the general procedure. An orange product was obtained (53 mg, $72 \%$ yield). ${ }^{1} \mathrm{H}$ NMR $(300 \mathrm{MHz}$, DMSO- $\left.d_{6}\right) \delta 7.71(\mathrm{~d}, J=7.9 \mathrm{~Hz}, 2 \mathrm{H}), 7.52-7.47(\mathrm{~m}, 2 \mathrm{H}), 7.39(\mathrm{~d}, J=7.9$ Hz, 2H), 7.27-7.25 (m, 2.8 Hz, 1H), $7.07-6.99$ (m, 1H), 6.39 (d, J = 6.2 Hz, 1H), 4.08 - 3.90 (m, 4H), $3.25-3.12(\mathrm{~m}, 1 \mathrm{H}), 3.04-2.89(\mathrm{~m}, 1 \mathrm{H}), 1.37-1.22(\mathrm{~m}, 9 \mathrm{H}) .,{ }^{13} \mathrm{CNMR}(75 \mathrm{MHz}, \mathrm{DMSO}-$ $\left.d_{6}\right) \delta 157.0,155.3,151.4,143.2,142.0,139.0,133.1,130.8,122.6,121.0,116.7,113.9,78.0,56.5$, 28.6; HRMS (ESI) calcd for $\mathrm{C}_{21} \mathrm{H}_{25} \mathrm{~N}_{3} \mathrm{O}_{5} 400.1873\left[\mathrm{M}+\mathrm{H}^{+}\right]$, found 400.1876 .

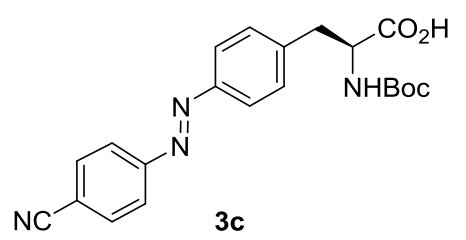

(S,E)-2-((tert-Butoxycarbonyl)amino)-3-(4-((4-cyanophenyl) diazenyl)phenyl)propanoic acid (3c): The corresponding hydrazine (2c, $27 \mathrm{mg}, 0.2 \mathrm{mmol})$ and spirolactone $1 \mathbf{a}(50 \mathrm{mg}, 0.18$ mmol) were combined, incubated, and purified according to the general procedure. An orange product was obtained $(51 \mathrm{mg}, 72 \%$

yield). ${ }^{1} \mathrm{H}$ NMR (300 MHz, DMSO- $\left.d_{6}\right) \delta 8.09(\mathrm{~d}, J=5.1 \mathrm{~Hz}, 2 \mathrm{H}), 8.00(\mathrm{~d}, J=4.8 \mathrm{~Hz}, 2 \mathrm{H}), 7.87$ $(\mathrm{d}, J=4.8 \mathrm{~Hz}, 2 \mathrm{H}), 7.51(\mathrm{~d}, J=5.1 \mathrm{~Hz}, 2 \mathrm{H}), 7.13(\mathrm{~d}, J=5.1 \mathrm{~Hz}, 1 \mathrm{H}), 4.18(\mathrm{~s}, 1 \mathrm{H}), 3.18-3.14(\mathrm{~m}$, $1 \mathrm{H}), 2.99-2.94(\mathrm{~m}, 1 \mathrm{H}), 1.32(\mathrm{~s}, 9 \mathrm{H}) ;{ }^{13} \mathrm{C}$ NMR $\left(75 \mathrm{MHz}, \mathrm{DMSO}-d_{6}\right) \delta 173.8,155.8,154.4,150.9$, 144.0, 134.2, 130.8, 123.5, 123.3, 118.9, 113.5, 78.5, 55.4, 37.0, 28.6; HRMS (ESI) calcd for $\mathrm{C}_{21} \mathrm{H}_{22} \mathrm{~N}_{4} \mathrm{O}_{4} 395.1720\left[\mathrm{M}+\mathrm{H}^{+}\right]$, found 395.1702. 


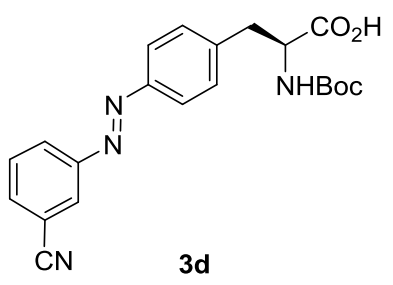

(S,E)-2-((tert-Butoxycarbonyl)amino)-3-(4-((3-cyanophenyl) diazenyl)phenyl)propanoic acid (3d): The corresponding hydrazine (2d, $27 \mathrm{mg}, 0.2 \mathrm{mmol})$ and spirolactone $1 \mathbf{a}(50 \mathrm{mg}, 0.18 \mathrm{mmol})$ were combined, incubated, and purified according to the general procedure. An orange product was obtained (60 mg, $85 \%$ yield). ${ }^{1} \mathrm{H}$ NMR (300 MHz, DMSO- $\left.d_{6}\right) \delta 8.26(\mathrm{~s}, 1 \mathrm{H}), 8.16(\mathrm{~d}, J=5.1 \mathrm{~Hz}, 1 \mathrm{H}), 8.01(\mathrm{~d}, J=4.2$ $\mathrm{Hz}, 1 \mathrm{H}), 7.85-7.78(\mathrm{~m}, 3 \mathrm{H}), 7.48(\mathrm{~d}, J=4.8 \mathrm{~Hz}, 2 \mathrm{H}), 7.08(\mathrm{~d}, J=4.8 \mathrm{~Hz}, 1 \mathrm{H}), 4.16-4.14(\mathrm{~m}, 1 \mathrm{H})$, 3.16-3.12 (m, 1H), 2.97-2.92 (m, 1H), $1.31(\mathrm{~s}, 9 \mathrm{H}) ;{ }^{13} \mathrm{C}$ NMR (75 MHz, DMSO-d 6 ) $\delta$ 173.9, 155.8, 152.3, 143.7, 134.8, 131.3, 130.8, 127.3, 126.4, 123.2, 118.5, 113.0, 78.5, 55.4, 37.0, 28.6; HRMS (ESI) calcd for $\mathrm{C}_{21} \mathrm{H}_{22} \mathrm{~N}_{4} \mathrm{O}_{4} 393.1562\left[\mathrm{M}-\mathrm{H}^{+}\right]$, found 393.1581 .

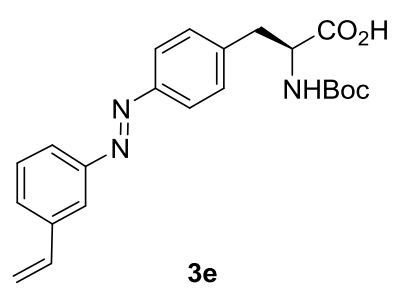

(S,E)-2-((tert-Butoxycarbonyl)amino)-3-(4-((3-vinylphenyl) diazenyl)phenyl)propanoic acid (3e): ): The corresponding hydrazine (2e, $38 \mathrm{mg}, 0.29 \mathrm{mmol})$ and spirolactone $1 \mathrm{a}(73 \mathrm{mg}, 0.26 \mathrm{mmol})$ were combined, incubated, and purified according to the general procedure. An orange product was obtained (70 $\mathrm{mg}, 68 \%$ yield). ${ }^{1} \mathrm{H}$ NMR $(300$ MHz, DMSO- $\left.\left.d_{6}\right) \delta 7.92(\mathrm{~s}, 1 \mathrm{H}), 7.82-7.44\right)(\mathrm{m}, 7 \mathrm{H}), 7.12(\mathrm{~d}, J=8.1 \mathrm{~Hz}$, 1), 6.87-6.81 (m, 1H), $5.96(\mathrm{~d}, J=17.4 \mathrm{~Hz}, 1 \mathrm{H}), 5.36(\mathrm{~d}, J=11.1 \mathrm{~Hz}, 1 \mathrm{H}), 4.19(\mathrm{~s}, 1 \mathrm{H}), 3.15-3.09$ $(\mathrm{m}, 1 \mathrm{H}), 2.97-2.92(\mathrm{~m}, 1 \mathrm{H}), 1.29(\mathrm{~s}, 9 \mathrm{H}) ;{ }^{13} \mathrm{C}$ NMR $\left(75 \mathrm{MHz}\right.$, DMSO- $\left.d_{6}\right) \delta 173.8,155.9,152.8$, 151.1, 142.7, 138.9, 136.4, 130.7, 130.1, 129.2, 122.9, 122.1, 120.7, 116.2, 78.5, 55.4, 36.8, 28.6; HRMS (ESI) calcd for $\mathrm{C}_{22} \mathrm{H}_{25} \mathrm{~N}_{3} \mathrm{O}_{4} 396.1924\left[\mathrm{M}+\mathrm{H}^{+}\right]$, found 396.1931 .

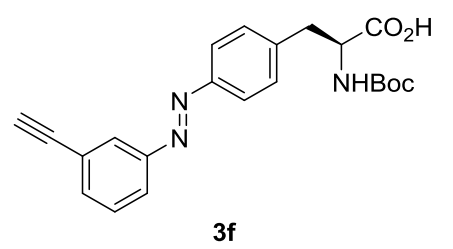

(S,E)-2-((tert-Butoxycarbonyl)amino)-3-(4-((3-ethynylphenyl) diazenyl)phenyl)propanoic acid (3f): The corresponding hydrazine (2f, $26 \mathrm{mg}, 0.2 \mathrm{mmol})$ and spirolactone $1 \mathrm{a}(50 \mathrm{mg}, 0.18 \mathrm{mmol})$ were combined, incubated, and purified according to the general procedure. A red product was obtained $\left(59 \mathrm{mg}, 83 \%\right.$ yield). ${ }^{1} \mathrm{H}$ NMR $(300 \mathrm{MHz}$, DMSO- $\left.d_{6}\right) \delta 7.90-7.88(\mathrm{~m}, 2 \mathrm{H}), 7.78(\mathrm{~d}, J=8.0 \mathrm{~Hz}, 2 \mathrm{H}), 7.66-7.55(\mathrm{~m}, 2 \mathrm{H}), 7.40(\mathrm{~d}, J=8.0 \mathrm{~Hz}$, 2H), $6.29(\mathrm{~d}, J=6.5 \mathrm{~Hz}, 1 \mathrm{H}), 4.32(\mathrm{~s}, 1 \mathrm{H}), 4.04-3.95(\mathrm{~m}, 1 \mathrm{H}), 3.24-3.17(\mathrm{~m}, 1 \mathrm{H}), 3.03-2.96(\mathrm{~m}$, $1 \mathrm{H}), 1.30(\mathrm{~s}, 9 \mathrm{H}){ }_{4}{ }^{13} \mathrm{C}$ NMR $\left(75 \mathrm{MHz}\right.$, DMSO- $\left.d_{6}\right) \delta 155.3,152.3,150.7,144.3,134.4,130.9,130.4$, 125.4, 123.7, 123.3, 122.7, 83.0, 82.2, 77.9, 56.3, 37.8, 28.6; HRMS (ESI) calcd for $\mathrm{C}_{22} \mathrm{H}_{23} \mathrm{~N}_{3} \mathrm{O}_{4}$ $394.1768\left[\mathrm{M}+\mathrm{H}^{+}\right]$, found 394.1768 .

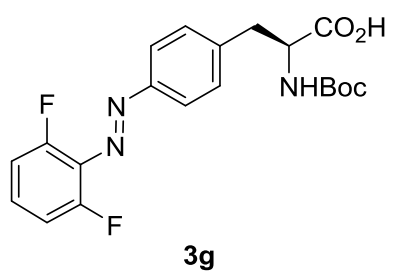

(S,E)-2-((tert-Butoxycarbonyl)amino)-3-(4-((2,6-difluorophenyl) diazenyl)phenyl)propanoic acid (3g): The corresponding hydrazine $(\mathbf{g g}, 29 \mathrm{mg}, 0.2 \mathrm{mmol})$ and spirolactone $1 \mathrm{a}(50 \mathrm{mg}, 0.18 \mathrm{mmol})$ were combined, incubated, and purified according to the general procedure. A red product was obtained $\left(69 \mathrm{mg}, 95 \%\right.$ yield). ${ }^{1} \mathrm{H}$ NMR $(300 \mathrm{MHz}$, DMSO- $\left.d_{6}\right) \delta 7.79(\mathrm{~d}, J=8.0 \mathrm{~Hz}, 2 \mathrm{H}), 7.48(\mathrm{~d}, J=8.0 \mathrm{~Hz}, 2 \mathrm{H}), 7.01(\mathrm{~d}$, $J=8.0 \mathrm{~Hz}, 1 \mathrm{H}), 4.18-4.12(\mathrm{~m}, 1 \mathrm{H}), 3.18-3.13(\mathrm{~m}, 1 \mathrm{H}), 3.01-2.92(\mathrm{~m}, 1 \mathrm{H}), 1.32(\mathrm{~s}, 9 \mathrm{H}) ;{ }^{13} \mathrm{C}$ NMR $\left(75 \mathrm{MHz}, \mathrm{DMSO}-d_{6}\right) \delta 173.8,155.8,151.6,144.1,130.8,122.8,113.6 .113 .4,110.0,104.5,79.4$, 55.5, 37.0, 28.6; HRMS (ESI) calcd for $\mathrm{C}_{20} \mathrm{H}_{21} \mathrm{~F}_{2} \mathrm{~N}_{3} \mathrm{O}_{4} 406.1579$ [M+H ${ }^{+}$, found 406.1571 . 


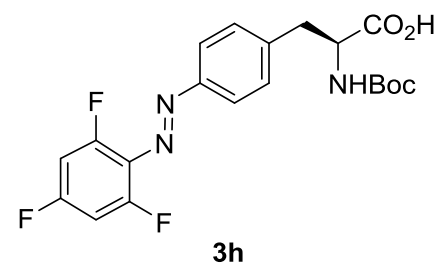

(S,E)-2-((tert-Butoxycarbonyl)amino)-3-(4-((2,4,6-trifluoro phenyl)diazenyl)phenyl)propanoic acid (3h): The corresponding hydrazine (2h, $32 \mathrm{mg}, 0.2 \mathrm{mmol})$ and spirolactone $1 \mathbf{a}(50 \mathrm{mg}, 0.18$ mmol) were combined, incubated, and purified according to the general procedure. A red product was obtained $(69 \mathrm{mg}, 91 \%$ yield $) .{ }^{1} \mathrm{H}$ NMR (300 MHz, DMSO- $\left.d_{6}\right) \delta 12.4(\mathrm{~s}, 1 \mathrm{H}), 7.79-7.77(\mathrm{~m}, 2 \mathrm{H}), 7.50-$ $7.45(\mathrm{~m}, 4 \mathrm{H}), 4.20-4.13(\mathrm{~m}, 1 \mathrm{H}), 3.24-3.11(\mathrm{~m}, 1 \mathrm{H}), 2.98-2.90(\mathrm{~m}, 1 \mathrm{H}), 1.31(\mathrm{~s}, 9 \mathrm{H}) ;{ }^{13} \mathrm{C} \mathrm{NMR}(75$ MHz, DMSO-d $d_{6} \delta 173.7,172.4,155.8,151.6,143.9,130.8,122.8,113.4,102.5,78.5,55.4,40.8$, 40.5, 40.2, 39.9, 39.7, 39.4, 39.1, 28.5, 21.5; MS (ESI) calcd for $\mathrm{C}_{20} \mathrm{H}_{20} \mathrm{~F}_{3} \mathrm{~N}_{3} \mathrm{O}_{4} 422.1327$ [M- $\mathrm{H}^{+}$], found 422.1349 .

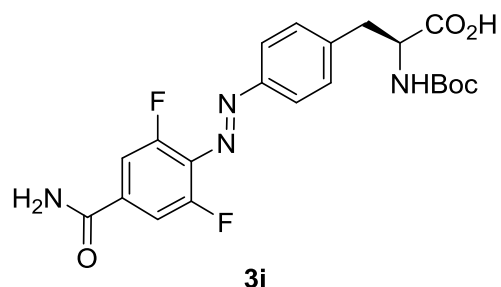

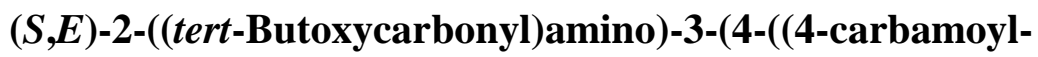
2,6-difluorophenyl)diazenyl) phenyl)propanoic acid (3i): The corresponding hydrazine (2i, $37 \mathrm{mg}, 0.2 \mathrm{mmol})$ and spirolactone $1 \mathrm{a}(50 \mathrm{mg}, 0.18 \mathrm{mmol}$ ) were combined, incubated, and purified according to the general procedure. An orange product was obtained (78 mg, 94\% yield). ${ }^{1} \mathrm{H}$ NMR (300 MHz, DMSO- $\left.d_{6}\right) \delta$ $8.30(\mathrm{~s}, 1 \mathrm{H}), 7.79(\mathrm{dd}, J=8.7,3.7 \mathrm{~Hz}, 4 \mathrm{H}), 7.45(\mathrm{~d}, J=8.0 \mathrm{~Hz}, 2 \mathrm{H}), 6.66(\mathrm{~d}, J=6.7 \mathrm{~Hz}, 1 \mathrm{H}), 4.09$ $(\mathrm{s}, 1 \mathrm{H}), 3.26-3.08(\mathrm{~m}, 1 \mathrm{H}), 3.07-2.88(\mathrm{~m}, 1 \mathrm{H}), 1.52-0.92(\mathrm{~m}, 9 \mathrm{H}) ;{ }^{13} \mathrm{C}$ NMR $\left(75 \mathrm{MHz}, \mathrm{DMSO}-d_{6}\right)$ $\delta 165.1,156.4,156.4,155.5,153.0,153.0,151.6,145.1,136.9,131.0,122.9,118.4,112.7,112.4$, 112.4, 78.3, 78.2, 56.1, 28.6; HRMS (ESI) calcd for $\mathrm{C}_{21} \mathrm{H}_{22} \mathrm{~F}_{2} \mathrm{IN}_{4} \mathrm{O}_{5} 449.1637\left[\mathrm{M}+\mathrm{H}^{+}\right]$, found 449.1634 .

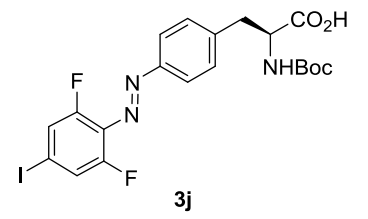

(S,E)-2-((tert-Butoxycarbonyl)amino)-3-(4-((2,6-difluoro-4-iodo phenyl)diazenyl)phenyl)propanoic acid (3j): The corresponding hydrazine (2j, $54 \mathrm{mg}, 0.2 \mathrm{mmol}$ ) and spirolactone $\mathbf{1 a}(50 \mathrm{mg}, 0.18 \mathrm{mmol})$ were combined, incubated, and purified according to the general procedure. An orange product was obtained (78 mg, 82\% yield). ${ }^{1} \mathrm{H}$ NMR (300 $\mathrm{MHz}$, DMSO- $\left.d_{6}\right) \delta 7.87-7.73(\mathrm{~m}, 4 \mathrm{H}), 7.48(\mathrm{~d}, J=8.3 \mathrm{~Hz}, 2 \mathrm{H}), 7.10(\mathrm{~d}, J=8.4 \mathrm{~Hz}, 1 \mathrm{H}), 4.20-4.12$ $(\mathrm{m}, 1 \mathrm{H}), 3.17-3.11(\mathrm{~m}, 1 \mathrm{H}), 2.98-2.90(\mathrm{~m}, 1 \mathrm{H}), 1.31(\mathrm{~s}, 9 \mathrm{H}) ;{ }^{13} \mathrm{C}$ NMR $\left(75 \mathrm{MHz}, \mathrm{DMSO}-d_{6}\right) \delta$ 173.7, 172.4, 156.6, 155.8, 153.1, 153.0, 151.7, 144.2, 130.8, 122.9, 122.5, 78.5, 55.3, 28.6, 21.5; HRMS (ESI) calcd for $\mathrm{C}_{20} \mathrm{H}_{20} \mathrm{~F}_{2} \mathrm{IN}_{3} \mathrm{O}_{4} 532.0546\left[\mathrm{M}+\mathrm{H}^{+}\right]$, found 532.0554.

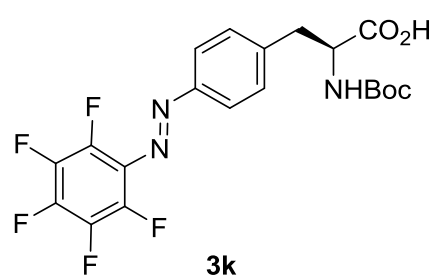

(S,E)-2-((tert-Butoxycarbonyl)amino)-3-(4-((perfluorophenyl) diazenyl)phenyl)propanoic acid (3k): The corresponding hydrazine $(\mathbf{2 k}, 20 \mathrm{mg}, 0.1 \mathrm{mmol})$ and spirolactone $1 \mathbf{a}(30 \mathrm{mg}, 0.11 \mathrm{mmol})$ were combined, incubated, and purified according to the general procedure. An orange product was obtained (41 mg, 89\% yield). ${ }^{1} \mathrm{H}$ NMR (300 MHz, DMSO-d $\left.d_{6}\right) 12.68(\mathrm{~s}, 1 \mathrm{H}), 7.84(\mathrm{~d}, J=8.1 \mathrm{~Hz}, 2 \mathrm{H}), 7.52(\mathrm{~d}, J$ $=8.7 \mathrm{~Hz}, 2 \mathrm{H}), 7.20(\mathrm{~d}, \mathrm{~J}=8.4 \mathrm{~Hz}, 1 \mathrm{H}), 4.21-4.14(\mathrm{~m}, 1 \mathrm{H}), 3.18-3.12(\mathrm{~m}, 1 \mathrm{H}), 3.02-2.91(\mathrm{~m}, 1 \mathrm{H})$, $1.31-1.29(\mathrm{~m}, 9 \mathrm{H}) ;{ }^{13} \mathrm{C}$ NMR (75 MHz, DMSO-d6) $\delta 173.7,155.9,151.5,145.0,141.5,130.9$, 
130.5, 123.1, 119.9, 78.5, 55.2, 36.9, 28.5; HRMS (ESI) calcd for $\mathrm{C}_{20} \mathrm{H}_{18} \mathrm{~F}_{5} \mathrm{~N}_{3} \mathrm{O}_{4} 458.1138$ [M$\mathrm{H}^{+}$, found 458.1159 .

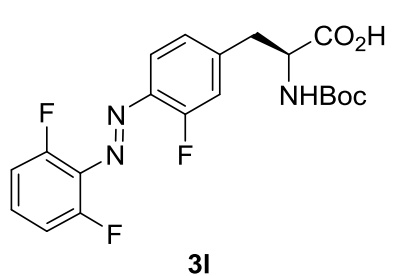

$4.12(\mathrm{~s}, 1 \mathrm{H}), 3.20-3.14(\mathrm{~m}, 1 \mathrm{H}), 2.97-2.81(\mathrm{~m}, 1 \mathrm{H}), 1.30(\mathrm{~s}, 9 \mathrm{H}) ;{ }^{13} \mathrm{C}$ NMR $\left(75 \mathrm{MHz}, \mathrm{DMSO}-d_{6}\right) \delta$ 172.5, 157.9, 155.6, 153.6, 147.3, 139.3, 132.6, 126.5, 116.8, 113.7, 113.4, 113.3, 78.5, 28.6, 21.5; HRMS (ESI) calcd for $\mathrm{C}_{20} \mathrm{H}_{20} \mathrm{~F}_{3} \mathrm{~N}_{3} \mathrm{O}_{4} 424.1485\left[\mathrm{M}+\mathrm{H}^{+}\right]$, found 424.1489 .

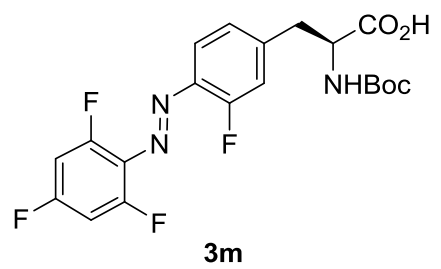

$(\mathrm{m}, 2 \mathrm{H}), 4.20-4.12(\mathrm{~m}, 1 \mathrm{H}), 3.19-3.13(\mathrm{~m}, 1 \mathrm{H}), 2.97-2.89(\mathrm{~m}, 1 \mathrm{H}), 1.31(\mathrm{~s}, 9 \mathrm{H}) ;{ }^{13} \mathrm{C}$ NMR $(100$ MHz, DMSO- $\left.d_{6}\right) \delta 173.4,155.8,147.4,146.6,135.6,132.1,129.6,116.9,78.6,54.9,36.6,28.5$; HRMS (ESI) calcd for $\mathrm{C}_{20} \mathrm{H}_{20} \mathrm{~F}_{4} \mathrm{~N}_{3} \mathrm{O}_{4} 442.1391\left[\mathrm{M}+\mathrm{H}^{+}\right]$, found 442.1386 .

(S,E)-2-((tert-Butoxycarbonyl)amino)-3-(3-fluoro-4-((perfluoro

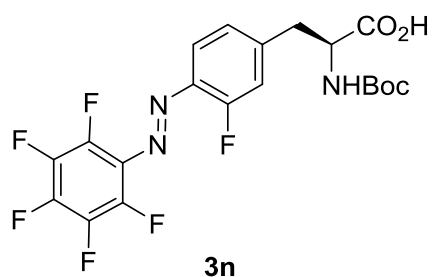
phenyl)diazenyl)phenyl)propanoic acid (3n): The corresponding hydrazine (2k, $13 \mathrm{mg}, 0.07 \mathrm{mmol})$ and spirolactone $\mathbf{1 b}$ (16 mg, 0.05 mmol) were combined, incubated, and purified according to the general procedure. A red-orange product was obtained (14 $\mathrm{mg}, 60 \%$ yield). ${ }^{1} \mathrm{H}$ NMR (300 MHz, DMSO-d6) $\delta 12.83(\mathrm{~s}, 1 \mathrm{H}), 7.63(\mathrm{t}, J=$ $7.8 \mathrm{~Hz}, 1 \mathrm{H}), 7.44(\mathrm{~d}, J=11.9 \mathrm{~Hz}, 1 \mathrm{H}), 7.28(\mathrm{~d}, J=8.2 \mathrm{~Hz}, 1 \mathrm{H}), 7.17$ (d, $J=8.5 \mathrm{~Hz}, 1 \mathrm{H}), 4.19$ (s, $1 \mathrm{H}), 3.18(\mathrm{~d}, J=13.1 \mathrm{~Hz}, 1 \mathrm{H}), 3.04-2.88(\mathrm{~m}, 1 \mathrm{H}), 1.43-1.14(\mathrm{~m}, 9 \mathrm{H}) ;{ }^{13} \mathrm{C}$ NMR $(75 \mathrm{MHz}$, $\left.\mathrm{CD}_{3} \mathrm{COCD}_{3}\right) \delta 172.4,161.9,158.5,147.2,147.1,139.4,126.2,126.1,118.4,118.1,116.5,92.6$, 78.5, 54.4, 37.4, 27.6 ; HRMS (ESI) calcd for $\mathrm{C}_{20} \mathrm{H}_{17} \mathrm{~F}_{6} \mathrm{~N}_{3} \mathrm{O}_{4} 476.1044$ [M-H ${ }^{+}$] found 476.1064.

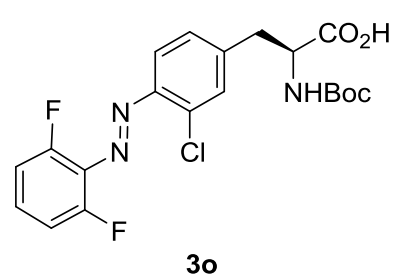

(S,E)-2-((tert-Butoxycarbonyl)amino)-3-(3-chloro-4-((2,6-difluoro phenyl)diazenyl)phenyl)propanoic acid (3o): The corresponding hydrazine $(\mathbf{2 g}, 36 \mathrm{mg}, 0.25 \mathrm{mmol})$ and spirolactone $1 \mathrm{c}(31 \mathrm{mg}, 0.10$ mmol) were combined, incubated, and purified according to the general procedure. An orange product was obtained (30 mg, 68\% yield). ${ }^{1} \mathrm{H}$ NMR (300 MHz, DMSO- $\left.d_{6}\right) \delta 7.75-7.24(\mathrm{~m}, 4 \mathrm{H}), 7.22-7.00(\mathrm{~m}, 2 \mathrm{H})$, $6.85(\mathrm{~s}, 1 \mathrm{H}), 3.96(\mathrm{~s}, 1 \mathrm{H}), 3.17-3.11(\mathrm{~m}, 1 \mathrm{H}), 3.05-2.83(\mathrm{~m}, 1 \mathrm{H}), 1.29\left(\mathrm{~s}, 9 \mathrm{H} ;{ }^{13} \mathrm{C} \mathrm{NMR}(75\right.$ MHz, DMSO- $\left.d_{6}\right) \delta 170.6,158.6,157.0,153.6,148.2,142.4,135.0,133.0,132.3,129.9,117.4$, 
113.5, 53.5, 46.0, 35.8, 34.6; HRMS (ESI) calcd for $\mathrm{C}_{20} \mathrm{H}_{20} \mathrm{~F}_{2} \mathrm{ClN}_{3} \mathrm{O}_{4} 440.1189$ [M+H $\mathrm{H}^{+}$, found 440.1176 .

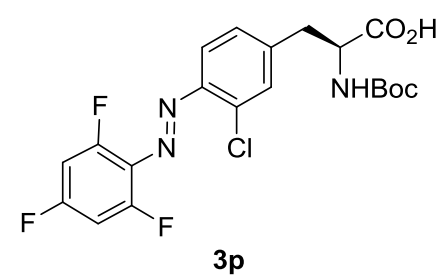

$=8.4 \mathrm{~Hz}, 1 \mathrm{H}), 7.05(\mathrm{~d}, J=7.9 \mathrm{~Hz}, 1 \mathrm{H}), 4.14(\mathrm{~s}, 1 \mathrm{H}), 3.18-3.12(\mathrm{~m}, 1 \mathrm{H}), 2.96-2.88(\mathrm{~m}, 1 \mathrm{H})$ $1.32(\mathrm{~s}, 9 \mathrm{H}) ;{ }^{13} \mathrm{C}$ NMR $\left(75 \mathrm{MHz}, \mathrm{DMSO}-d_{6}\right) \delta 172.5,155.6,154.6,147.5,146.0,134.7,131.9$, 129.6, 116.7, 102.6, 102.3, 78.3, 55.5, 28.5, 21.6; MS (ESI) calcd for $\mathrm{C}_{20} \mathrm{H}_{19} \mathrm{ClF}_{3} \mathrm{~N}_{3} \mathrm{O}_{4} 458.1095$ $\left[\mathrm{M}+\mathrm{H}^{+}\right]$, found 458.1108 .

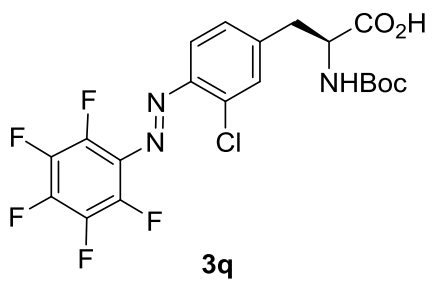

(S,E)-2-((tert-Butoxycarbonyl)amino)-3-(3-chloro-4-((perfluoro phenyl)diazenyl)phenyl)propanoic acid (3q): The corresponding hydrazine (2k, $13 \mathrm{mg}, 0.06 \mathrm{mmol}$ ) and spirolactone $\mathbf{1 c}(18 \mathrm{mg}, 0.06$ $\mathrm{mmol})$ were combined, incubated, and purified according to the general procedure. An orange product was obtained $(19 \mathrm{mg}, 63 \%$ yield). ${ }^{1} \mathrm{H}$ NMR $\left(500 \mathrm{MHz}, \mathrm{DMSO}-d_{6}\right) \delta 7.64(\mathrm{~s}, 1 \mathrm{H}), 7.61(\mathrm{~d}, J=$ $8.2 \mathrm{~Hz}, 1 \mathrm{H}), 7.40$ (d, $J=8.2 \mathrm{~Hz}, 1 \mathrm{H}), 7.00$ (s, 1H), 4.14 (s, 1H), 3.20 - 3.16 (m, 2H), 2.97 - 2.93 $(\mathrm{m}, 1 \mathrm{H}), 1.32(\mathrm{~d}, J=9.7 \mathrm{~Hz}, 9 \mathrm{H}) ;{ }^{13} \mathrm{C}$ NMR (100 MHz, DMSO-d 6$) \delta 173.4,155.8,147.4,146.6$, 146.6, 135.6, 132.1, 129.6, 116.9, 78.6, 54.8, 36.5, 28.5; HRMS (ESI) calcd for $\mathrm{C}_{20} \mathrm{H}_{17} \mathrm{~F}_{5} \mathrm{ClN}_{3} \mathrm{O}_{4}$ $494.0907\left[\mathrm{M}+\mathrm{H}^{+}\right]$, found 494.0902 .

\section{General procedure for Boc-deprotection}

The Boc-protected azobenzene amino acid (50 mg) was dissolved in $1 \mathrm{~mL}$ of methylene chloride/trifluoroacetic acid (1:1). The resulting solution was stirred for $20 \mathrm{~min}$, and then concentrated under reduced pressure. The solid was dried by lyophilization for $24 \mathrm{~h}$. The dried product was characterized and used without further purification.

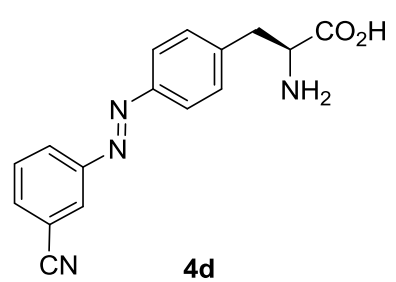

(S,E)-2-Amino-3-(4-((3-cyanophenyl)diazenyl)phenyl)propanoic acid (4d): ${ }^{1} \mathrm{H}$ NMR (400 MHz, DMSO-d $) \delta 8.45(\mathrm{~s}, 3 \mathrm{H}), 8.45(\mathrm{~s}, 3 \mathrm{H})$, $8.25(\mathrm{~s}, 1 \mathrm{H}), 8.16(\mathrm{~d}, J=8.0 \mathrm{~Hz}, 1 \mathrm{H}), 8.01(\mathrm{~d}, J=8.0,1 \mathrm{H}), 7.89(\mathrm{~d}, J=$ 8.0, 2H), 7.81-7.77 (m, 1H), $7.52(\mathrm{~d}, J=8.0,2 \mathrm{H}), 4.11(\mathrm{~s}, 1 \mathrm{H}), 3.24-$ $2.99(\mathrm{~m}, 2 \mathrm{H}) ;{ }^{13} \mathrm{C}$ NMR $\left(100 \mathrm{MHz}, \mathrm{DMSO}-d_{6}\right) \delta 170.7,152.3,151.3$, $140.2,135.0,131.4,131.2,127.4,126.4,123.5,118.5,113.0,104.5$,

53.4, 36.1; HRMS (ESI) calcd for $\mathrm{C}_{16} \mathrm{H}_{14} \mathrm{~N}_{4} \mathrm{O}_{2} 295.1196\left[\mathrm{M}+\mathrm{H}^{+}\right]$, found 295.1200. 


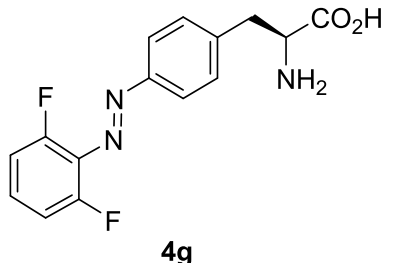

$\left[\mathrm{M}+\mathrm{H}^{+}\right]$, found 306.1065 .

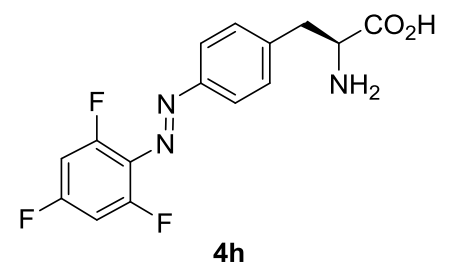

$324.0961\left[\mathrm{M}+\mathrm{H}^{+}\right]$, found 324.0959 .
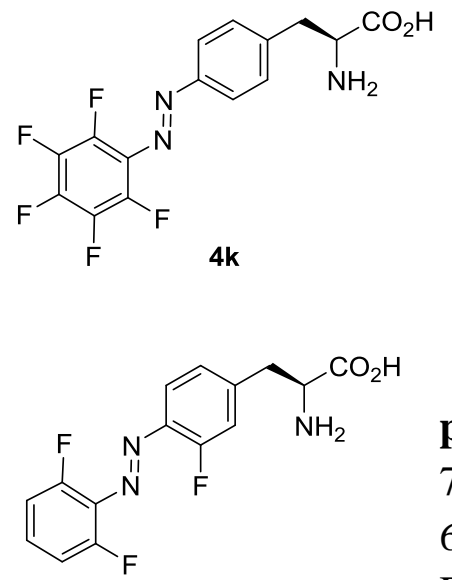

4!

(S,E)-2-amino-3-(4-((2,6-difluorophenyl)diazenyl)phenyl)propanoic acid (4g): ${ }^{1} \mathrm{H}$ NMR (400 MHz, DMSO- $\left.d_{6}\right) \delta 8.43(\mathrm{~s}, 3 \mathrm{H}), 7.84(\mathrm{~d}, J=$ $8.4 \mathrm{~Hz}, 2 \mathrm{H}), 7.60-7.48(\mathrm{~m}, 3 \mathrm{H}), 7.37-7.27$ (m, 2H), 4.28 (s, 1H), 3.37 $-3.13(\mathrm{~m}, 2 \mathrm{H}) ;{ }^{13} \mathrm{C}$ NMR $\left(125 \mathrm{MHz}, \mathrm{DMSO}-d_{6}\right) \delta 170.7,156.2,154.2$, 152.2, 140.5, 131.2, 123.2, 113.5, 113.4, 53.5, 40.4, 40.3, 40.1, 39.9, 39.8, 39.6, 39.4, 36.1; HRMS (ESI) calcd for $\mathrm{C}_{15} \mathrm{H}_{13} \mathrm{~F}_{2} \mathrm{~N}_{3} \mathrm{O}_{2} 306.1079$

(S,E)-2-Amino-3-(4-((2,4,6-trifluorophenyl)diazenyl)phenyl) propanoic acid (4h): ${ }^{1} \mathrm{H} \mathrm{NMR}\left(300 \mathrm{MHz}, \mathrm{CD}_{3} \mathrm{OD}\right) \delta$ 7.94-7.86 (m, 2H), 7.54-7.49 (m, 2H), 7.15-7.03 (m, 2H), 4.32 (dd, $J=7.8,5.6 \mathrm{~Hz}$, $1 \mathrm{H}), 3.42(\mathrm{dd}, J=14.5,5.6 \mathrm{~Hz}, 1 \mathrm{H}), 3.29-3.21(\mathrm{~m}, 1 \mathrm{H}) ;{ }^{13} \mathrm{C} \mathrm{NMR}(75$ MHz, DMSO- $\left.d_{6}\right) \delta 170.5,148.2,142.1,135.0,132.3,129.9,117.5$, 113.73 113.4, 53.3, 34.6; HRMS (ESI) calcd for $\mathrm{C}_{15} \mathrm{H}_{12} \mathrm{~F}_{3} \mathrm{~N}_{3} \mathrm{O}_{2}$

(S,E)-2-Amino-3-(4-((perfluorophenyl)diazenyl)phenyl) propanoic acid (4k): ${ }^{1} \mathrm{H}$ NMR $\left(300 \mathrm{MHz}, \mathrm{DMSO}-d_{6}\right) \delta 8.52(\mathrm{~s}, 2 \mathrm{H})$, $7.86(\mathrm{~d}, J=8.4 \mathrm{~Hz}, 2 \mathrm{H}), 7.55(\mathrm{~d}, J=8.4 \mathrm{~Hz}, 2 \mathrm{H}), 4.23(\mathrm{t}, J=6.4 \mathrm{~Hz}$, $1 \mathrm{H}), 3.25(\mathrm{~d}, J=6.4 \mathrm{~Hz}, 2 \mathrm{H}) ;{ }^{13} \mathrm{C}$ NMR $\left(101 \mathrm{MHz}, \mathrm{DMSO}-d_{6}\right) \delta 170.7$, 152.0, 141.6, 131.4, 123.5, 116.0, 104.2, 53.4, 36.1; HRMS (ESI) calcd for $\mathrm{C}_{15} \mathrm{H}_{10} \mathrm{~F}_{5} \mathrm{~N}_{3} \mathrm{O}_{2} 360.0772\left[\mathrm{M}+\mathrm{H}^{+}\right]$, found 360.0775 .

(S,E)-2-Amino-3-(4-((2,6-difluorophenyl)diazenyl)-3-fluorophenyl) propanoic acid (4l): ${ }^{1} \mathrm{HNMR}\left(400 \mathrm{MHz}, \mathrm{DMSO}-d_{6}\right) \delta 8.37$ (s, 2H), 7.73-7.49 (m, 2H), 7.38-7.15 (m, 3H), 7.03-6.78 (m, 1H), $4.27(\mathrm{~d}, J=$ $6.0 \mathrm{~Hz}, 1 \mathrm{H}), 3.26-3.14(\mathrm{~m}, 1 \mathrm{H}), 3.10-2.82(\mathrm{~m}, 1 \mathrm{H}) ;{ }^{13} \mathrm{C} \mathrm{NMR}(100 \mathrm{MHz}$, DMSO- $\left.d_{6}\right) \delta 170.6,143.4,126.9,126.1,121.4,119.1,118.9,117.5$, 116.0, 113.7, 113.5, 53.8, 53.2; HRMS (ESI) calcd for $\mathrm{C}_{15} \mathrm{H}_{12} \mathrm{~F}_{3} \mathrm{~N}_{3} \mathrm{O}_{2} 324.0961\left[\mathrm{M}+\mathrm{H}^{+}\right]$, found 324.0953 .

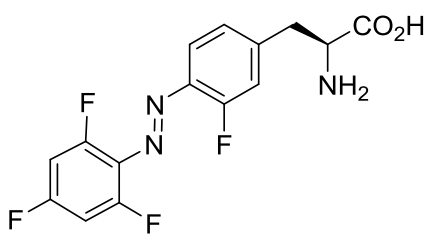

$4 m$
(S,E)-2-Amino-3-(3-fluoro-4-((2,4,6-trifluorophenyl)diazenyl) phenyl)propanoic acid (4m): ${ }^{1} \mathrm{H}$ NMR $\left(300 \mathrm{MHz}, \mathrm{DMSO}-d_{6}\right) \delta 8.38$ $(\mathrm{s}, 3 \mathrm{H}), 7.64-7.60(\mathrm{~m}, 1 \mathrm{H}), 7.51-7.44(\mathrm{~m}, 3 \mathrm{H}), 7.29-7.26(\mathrm{~m}, 1 \mathrm{H})$, $4.32(\mathrm{~m}, 1 \mathrm{H}), 3.36-3.23(\mathrm{~m}, 2 \mathrm{H}){ }^{13} \mathrm{C}$ NMR (75 MHz, DMSO- $\left.d_{6}\right) \delta$ 170.5, 158.4, 143.1, 140.0, 126.8, 119.0, 118.8, 117.6, 102.9, 102.7, 102.4, 49.0, 35.9; HRMS (ESI) calcd for $\mathrm{C}_{15} \mathrm{H}_{11} \mathrm{~F}_{4} \mathrm{~N}_{3} \mathrm{O}_{2} 342.0866$ $\left[\mathrm{M}+\mathrm{H}^{+}\right]$, found 342.0862 . 


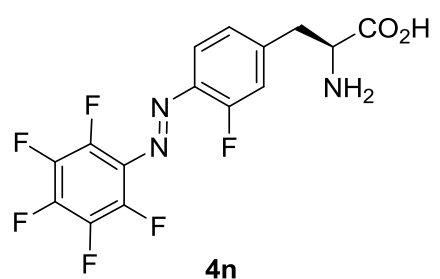

(S,E)-2-Amino-3-(3-fluoro-4-(perfluorophenyl)diazenyl)phenyl)

propanoic acid (4n): ${ }^{1} \mathrm{H}$ NMR $\left(300 \mathrm{MHz}, \mathrm{CD}_{3} \mathrm{OD}\right) \delta 7.71$ (t, $J=8.0$ $\mathrm{Hz}, 1 \mathrm{H}), 7.38-7.34(\mathrm{~m}, 1 \mathrm{H}), 7.25$ (dd, $J=8.4,1.3 \mathrm{~Hz}, 3 \mathrm{H}), 4.37-4.33$ $(\mathrm{m}, 1 \mathrm{H}), 3.43-3.36(\mathrm{~m}, 1 \mathrm{H}), 3.31-3.27(\mathrm{~m}, 1 \mathrm{H}) ;{ }^{13} \mathrm{C}$ NMR $(75 \mathrm{MHz}$, DMSO- $\left.d_{6}\right) \delta 169.6,162.1,1585.6,142.8,142.7,140.2,140.1,125.7$, 125.6, 118.3, 118.0, 117.1, 53.2, 35.6; HRMS (ESI) calcd for $\mathrm{C}_{15} \mathrm{H}_{9} \mathrm{~F}_{6} \mathrm{~N}_{3} \mathrm{O}_{2} 378.0678\left[\mathrm{M}+\mathrm{H}^{+}\right]$, found 378.0678.

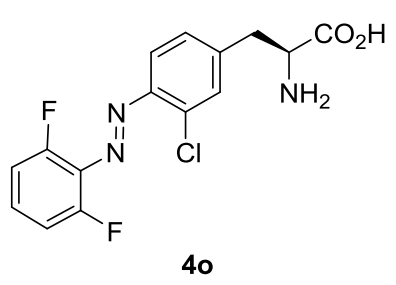

(S,E)-2-Amino-3-(3-chloro-4-((2,6-difluorophenyl)diazenyl)phenyl) propanoic acid (4o): ${ }^{1} \mathrm{H}$ NMR (300 MHz, DMSO- $\left.d_{6}\right) \delta 8.47$ (s, 3H), $7.81(\mathrm{~d}, J=8.3 \mathrm{~Hz}, 2 \mathrm{H}), 7.51(\mathrm{~d}, J=8.3 \mathrm{~Hz}, 2 \mathrm{H}), 7.41(\mathrm{t}, J=9.3 \mathrm{~Hz}$, $2 \mathrm{H}), 4.27(\mathrm{t}, J=6.1 \mathrm{~Hz}, 1 \mathrm{H}), 3.23(\mathrm{~d}, J=6.4 \mathrm{~Hz}, 3 \mathrm{H}) ;{ }^{13} \mathrm{C}$ NMR $(75$ $\left.\mathrm{MHz}, \mathrm{DMSO}-d_{6}\right) \delta 170.5,148.2,142.1,135.0,133.1,132.3,131.3$, 129.9, 117.5, 113.7, 113.7, 113.4, 53.3, 34.7; HRMS (ESI) calcd for $\mathrm{C}_{15} \mathrm{H}_{12} \mathrm{~F}_{2} \mathrm{ClN}_{3} \mathrm{O}_{2} 340.0665\left[\mathrm{M}+\mathrm{H}^{+}\right]$, found 340.0681 .

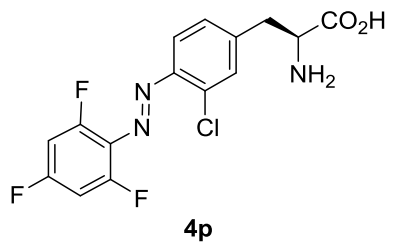

(S,E)-2-Amino-3-(3-chloro-4-((2,4,6-trifluorophenyl)diazenyl) phenyl)propanoic acid (4p): ${ }^{1} \mathrm{H} \mathrm{NMR}\left(300 \mathrm{MHz}, \mathrm{CD}_{3} \mathrm{OD}\right) \delta 7.65(\mathrm{t}$, $J=9.0 \mathrm{~Hz}, 2 \mathrm{H}), 7.36(\mathrm{~d}, J=9.0 \mathrm{~Hz} 1 \mathrm{H}), 7.11(\mathrm{t}, J=9.0 \mathrm{~Hz}, 2 \mathrm{H}), 4.36$ $(\mathrm{dd}, J=9.0,6.0 \mathrm{~Hz}, 1 \mathrm{H}), 3.38-3.36(\mathrm{~m}, 1 \mathrm{H}), 3.30-3.24(\mathrm{~m}, 1 \mathrm{H}) ;{ }^{13} \mathrm{C}$ NMR (75 MHz, DMSO- $\left.d_{6}\right) \delta 170.6,148.2,142.1,134.9,132.3,129.9$, 117.4, 100.5, 53.2, 35.6; MS (ESI) calcd for $\mathrm{C}_{15} \mathrm{H}_{11} \mathrm{ClF}_{3} \mathrm{~N}_{3} \mathrm{O}_{2} 358.0571\left[\mathrm{M}+\mathrm{H}^{+}\right]$, found 358.0592.

\section{Construction of the Aba-specific $p$ EVOL-MmPylRS plasmid}

The pyrrolysyl-tRNA synthetase variant suitable for charging azobenzene amino acids was previously reported by Hoppmann et al. ${ }^{[1]}$ We used $p$ CMV6-MmPylRS-U6-tRNA plasmid ${ }^{[2]}$ as the template and performed three rounds of site-directed mutagenesis to generate mutations: A302T, L309S, N346V, C348G using the following primers pairs:

MmPylRS-A302T-PO-F: 5'- cccatgcttaccccaaccctttacaactactcccgcaag -3' MmPylRS-A302T-PO-R: 5'- aagggttggggtaagcatgggtctcaggcagaagttg -3' MmPylRS_309_F: 5'-gctccaaacctttacaactactccegcaagcttgacagggccetg -3' MmPylRS_309_R: 5'- cagggccetgtcaagcttgcgggagtagttgtaaaggtttggagc -3 ' MmPylRS_346_348_F: 5'- cctcgaagagtttaccatgctggtgttcggccagatgggatcgggatgcac -3' MmPylRS_346_348_R: 5'-gtgcatcccgatcccatctggccgaacaccagcatggtaaactcttcgagg -3'

The MmPylRS mutant gene was amplified by PCR using the following primers to introduce the SpeI and Sall restriction sites at the 5'- and 3'- ends, respectively:

MmPylRS-SpeI-F: 5'- taagcaactagtatggataaaaaaccactaaac -3'

MmPylRS-SalI-R: 5'- tgcttagtcgacttacaggttggtagaaatccc -3' 
The gene fragment was cloned into the $p$ GEM-T (Promega) vector using TA cloning following manufacturer's instructions to give $p$ GEM-MmPylRS and subsequently subcloned into the $p$ EVOL vector (GENEWIZ, South Plainfield, NJ) to obtain the Aba-specific $p$ EVOL-MmPylRS plasmid.

\section{Expression and purification of the azobenzene-alanine (Aba)-containing sfGFP proteins}

BL21(DE3) cells were co-transformed with Aba-specific pEVOL-MmPylRS and pET-sfGFPS2TAG plasmids. The cells were recovered in $950 \mu \mathrm{L}$ Terrific Broth following transformation and incubated at $37{ }^{\circ} \mathrm{C}$ for 1 hour before plating on LB agar plate containing chloramphenicol (Cam, $34 \mu \mathrm{g} / \mathrm{mL}$ ) and ampicillin (Amp, $100 \mu \mathrm{g} / \mathrm{mL}$ ). A 2-mL overnight culture from a single colony was used to inoculate $10 \mathrm{~mL} \mathrm{LB}$ medium supplemented with Cam and Amp. Cells were grown at 37 ${ }^{\circ} \mathrm{C}$ in a shaker-incubator $(280 \mathrm{rpm})$, and protein expression was induced by adding $1 \mathrm{mM}$ IPTG, $0.2 \%$ arabinose and $1 \mathrm{mM}$ of the desired azobenzene amino acid when $\mathrm{OD}_{600}$ reached 0.5 . The control experiment contained only arabinose and IPTG. After 7-hour induction, cells were harvested, resuspended in a lysis buffer $\left(50 \mathrm{mM} \mathrm{NaH}_{2} \mathrm{PO}_{4}, 300 \mathrm{mM} \mathrm{NaCl}, 10 \mathrm{mM}\right.$ imidazole, $\mathrm{pH}$ 8.0): BugBuster Protein Extraction Reagent (3:1), vortexed for $60 \mathrm{sec}$, and then rotated at room temperature for $15 \mathrm{~min}$. The lysate was centrifuged $\left(40 \mathrm{~min}, 17,136 \mathrm{~g}, 4^{\circ} \mathrm{C}\right)$. The supernatant was incubated with $0.1 \mathrm{~mL}$ Ni-NTA beads (Thermo HisPur ${ }^{\mathrm{TM}}$ ) at $4{ }^{\circ} \mathrm{C}$ overnight. The bound protein was eluted off the beads using an elution buffer $(50 \mathrm{mM} \mathrm{Na} 2 \mathrm{HPO} 4,300 \mathrm{mM} \mathrm{NaCl}, 250 \mathrm{mM}$ imidazole, $\mathrm{pH}$ 8.0). The supernatant was concentrated using an Amicon Ultra-15 Centrifugal Filter (10k MWCO, Millipore). The protein purity was analyzed by LC/ESI-MS. The calculated mass corresponded to the mass of sfGFP-S2Aba with the first methionine removed, and the observed mass was derived from the deconvolution of the protein charge ladder using ProMass as shown previously. ${ }^{[3]}$

\section{References}

[1] Hoppmann, C.; Lacey, V. K.; Louie, G. V.; Wei, J.; Noel, J. P.; Wang, L. Angew. Chem. Int. Ed. 2014, 53, 3932-3936.

[2] Li, N.; Ramil, C. P.; Lim, R. K.; Lin, Q. ACS Chem. Biol. 2015, 10, 379-384.

[3] Yu, Z.; Lin, Q. J. Am. Chem. Soc. 2014, 136, 4153-4156. 


\section{${ }^{1} \mathrm{H}$ and ${ }^{13} \mathrm{C}$ NMR Spectra}

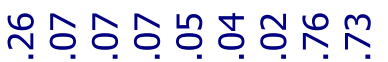

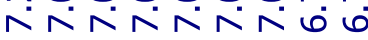
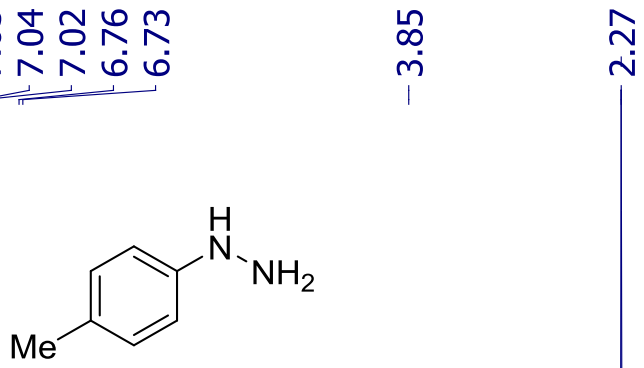

$2 a$

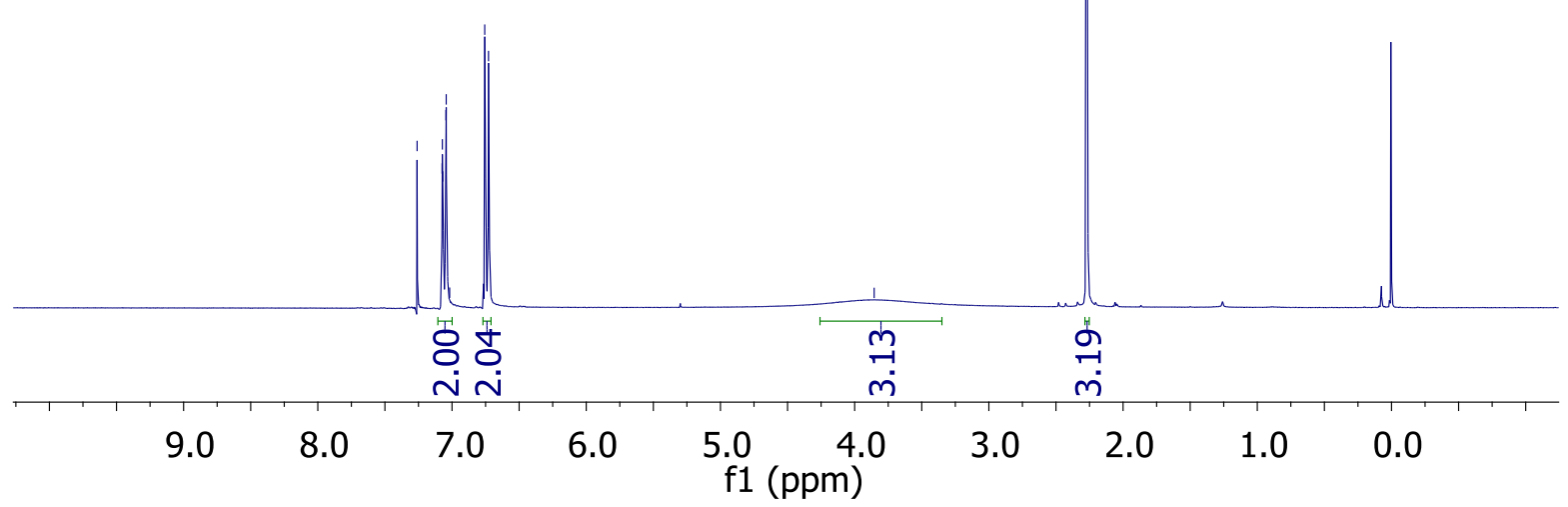

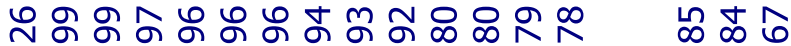
ㅂ ம<smiles>COc1ccccc1NN</smiles>

2b

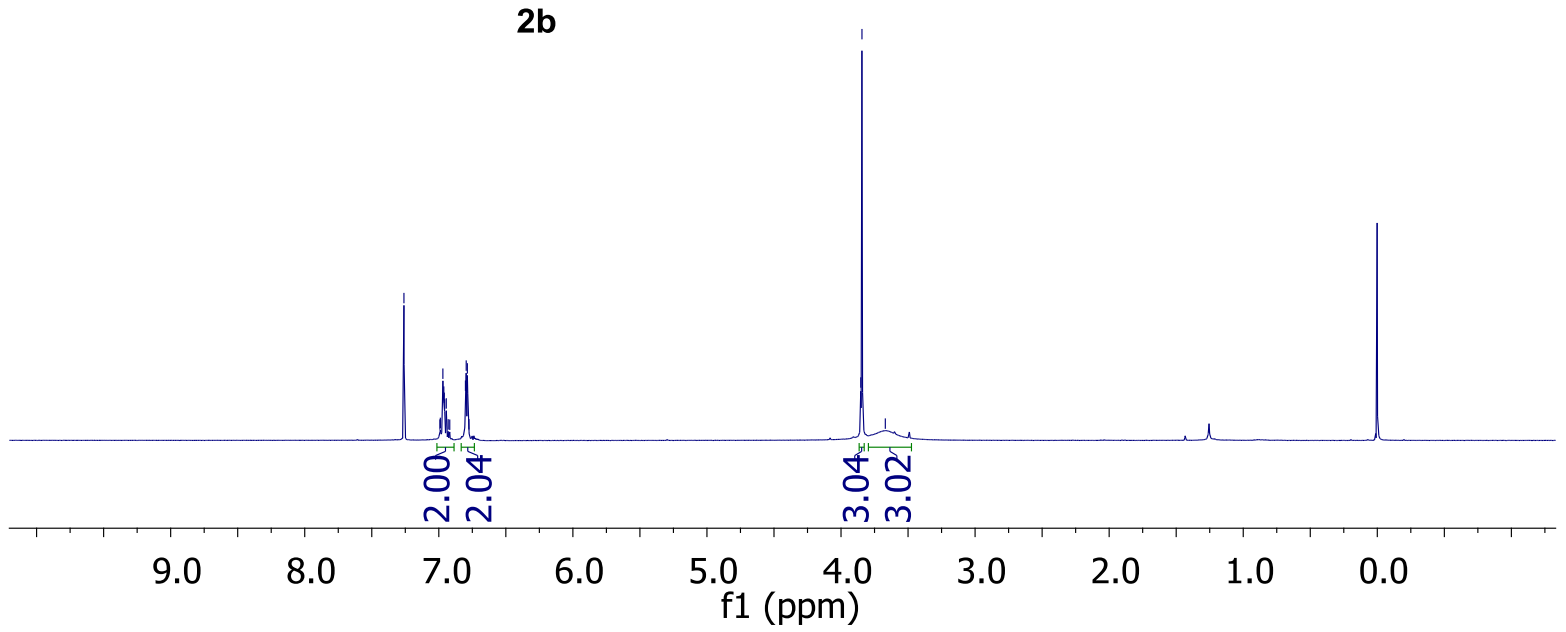




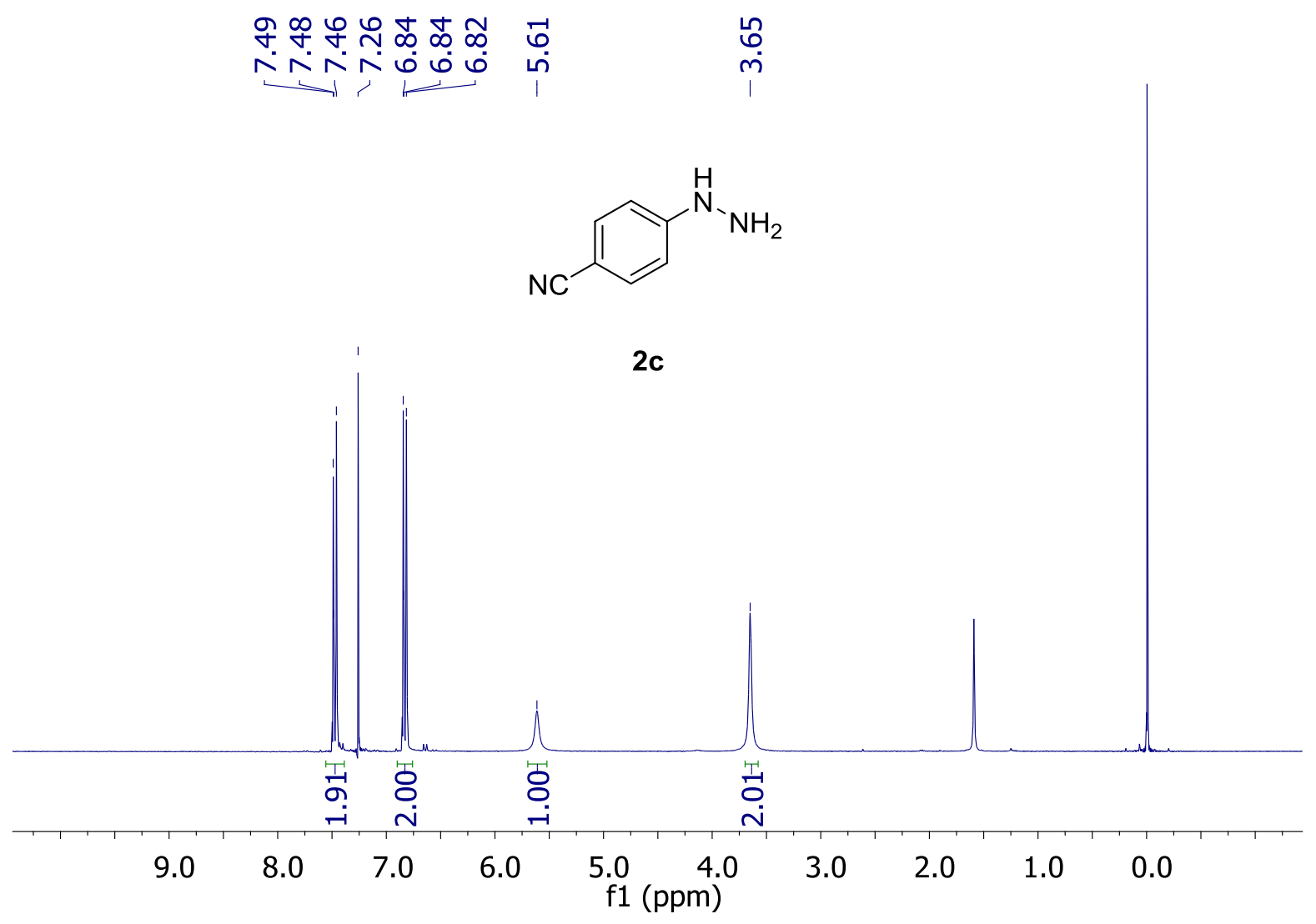

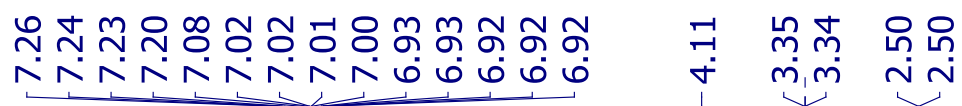<smiles>N#Cc1cccc(NN)c1</smiles>

2d

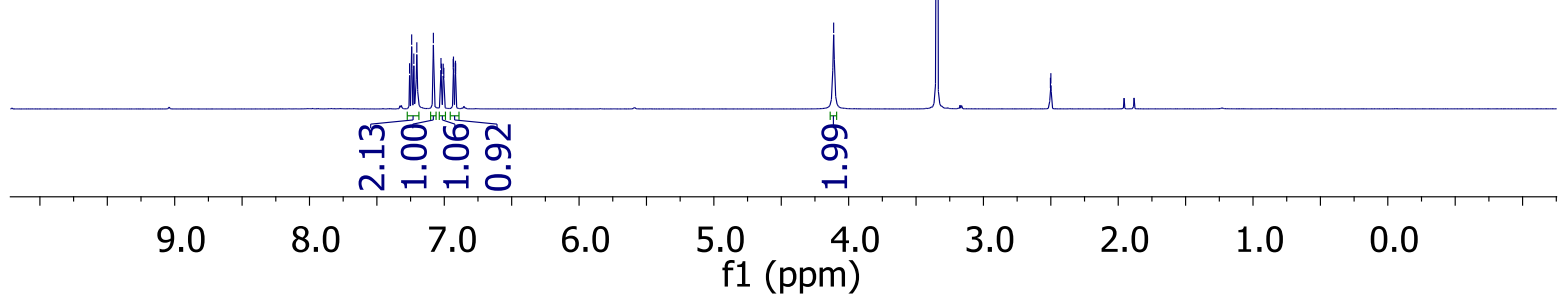


<smiles>C=Cc1cccc(NN)c1</smiles>

$2 e$

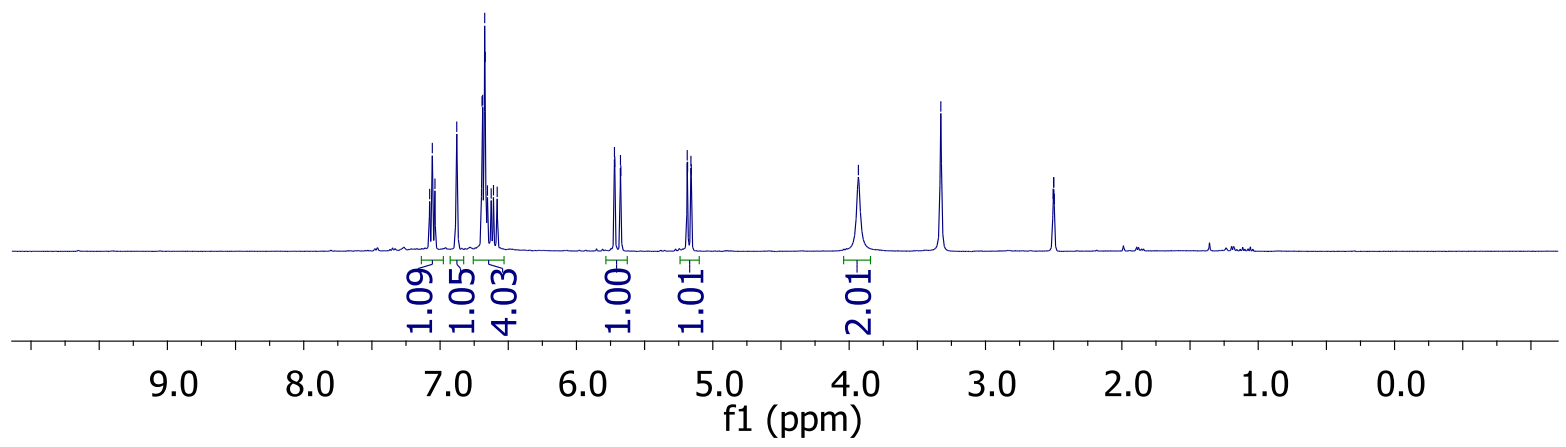

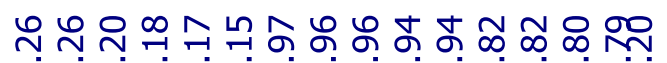

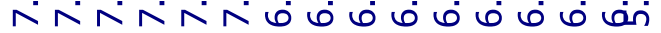
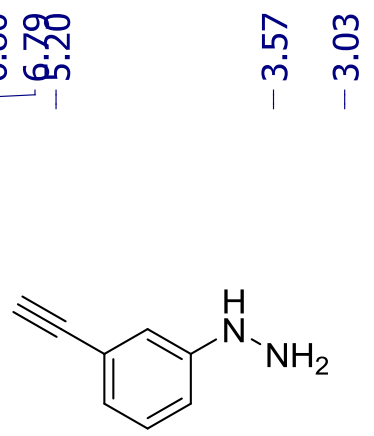

$2 f$

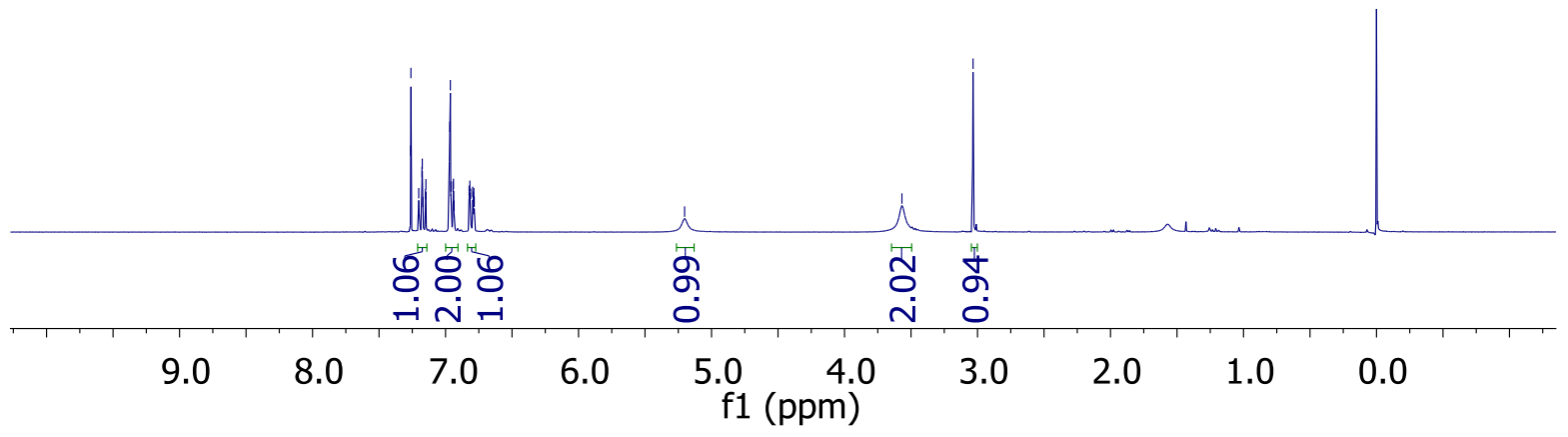




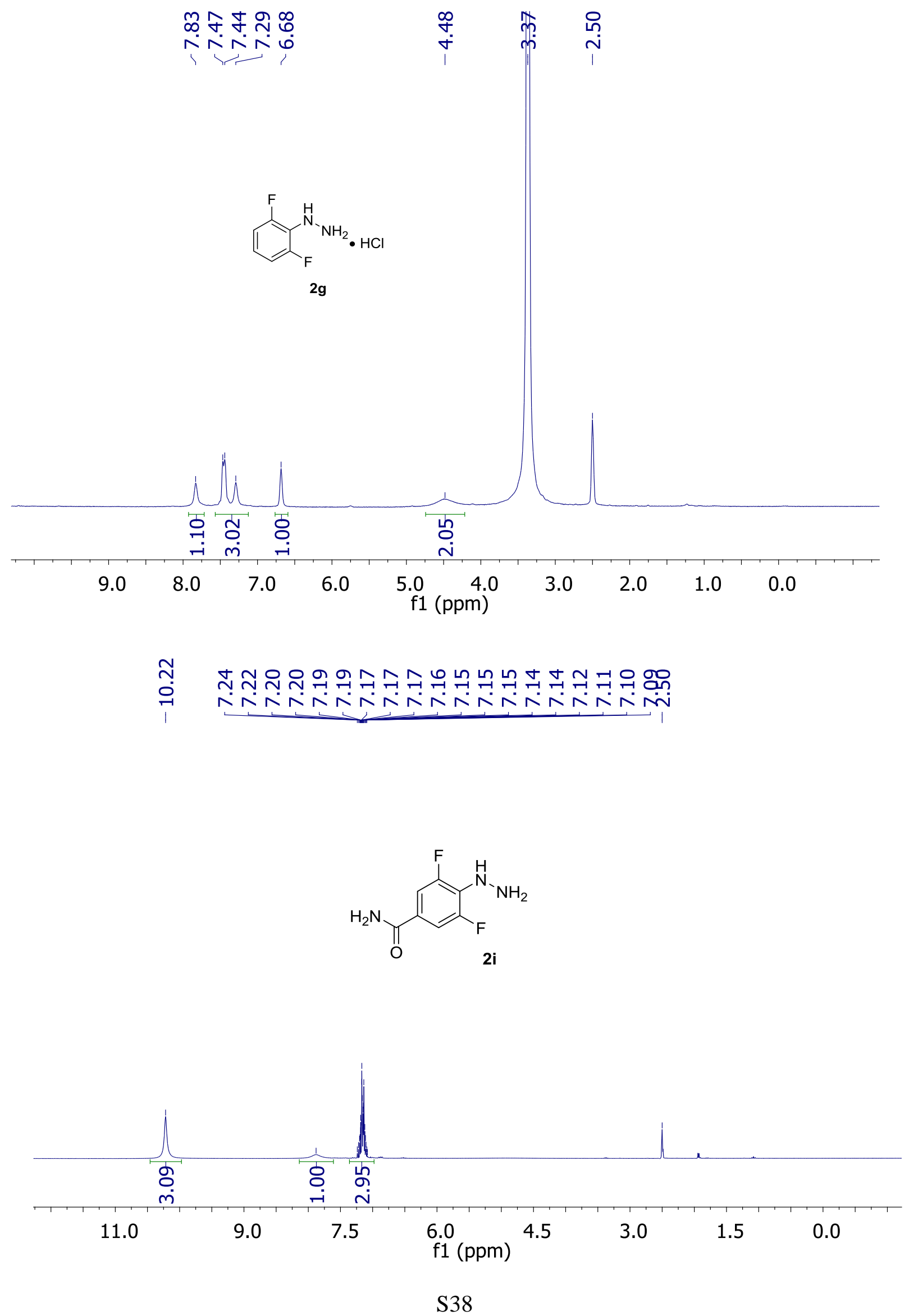




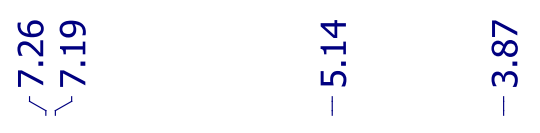
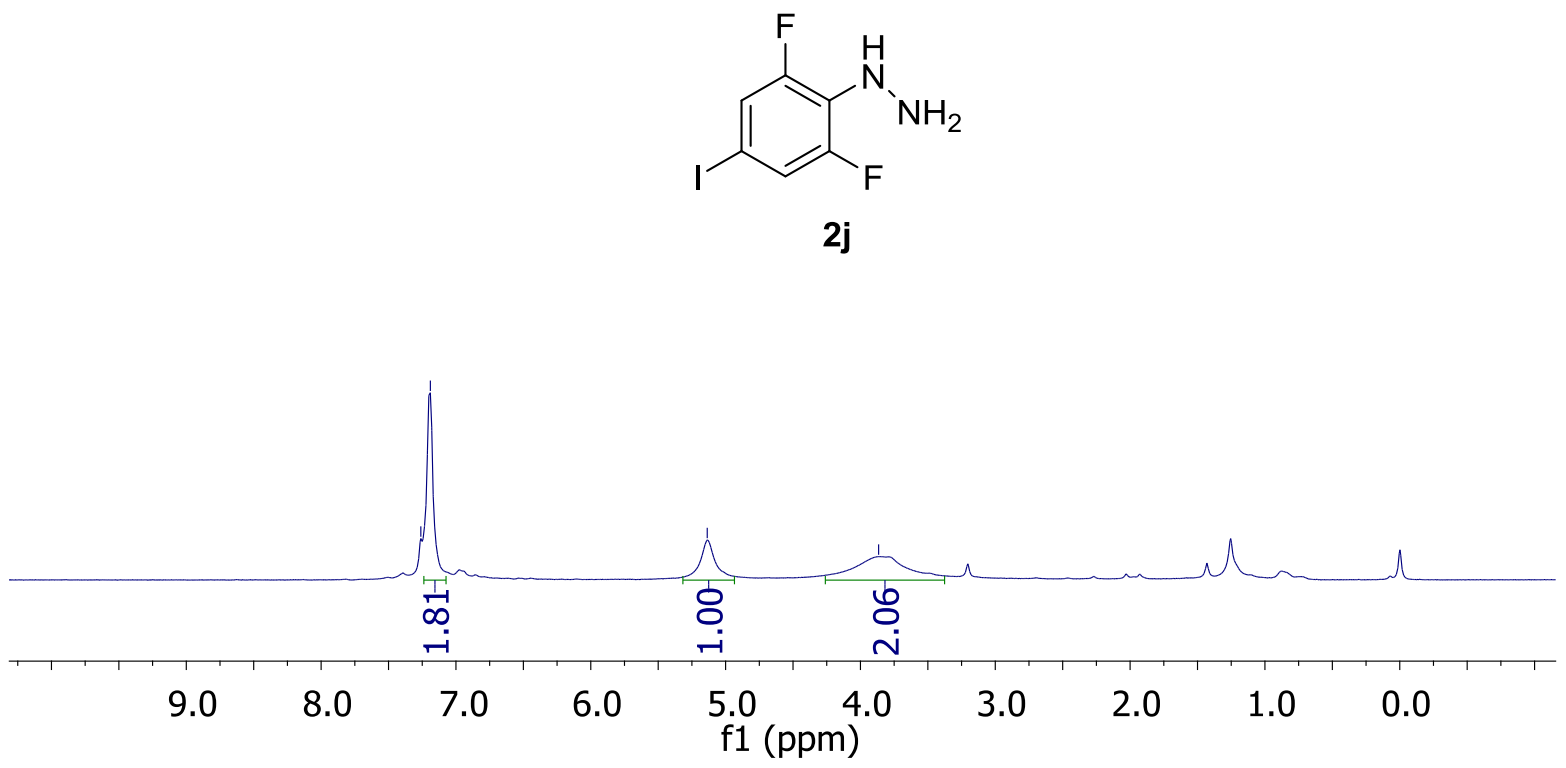

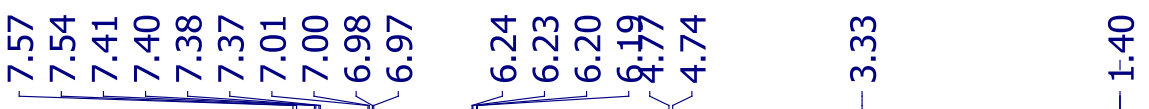
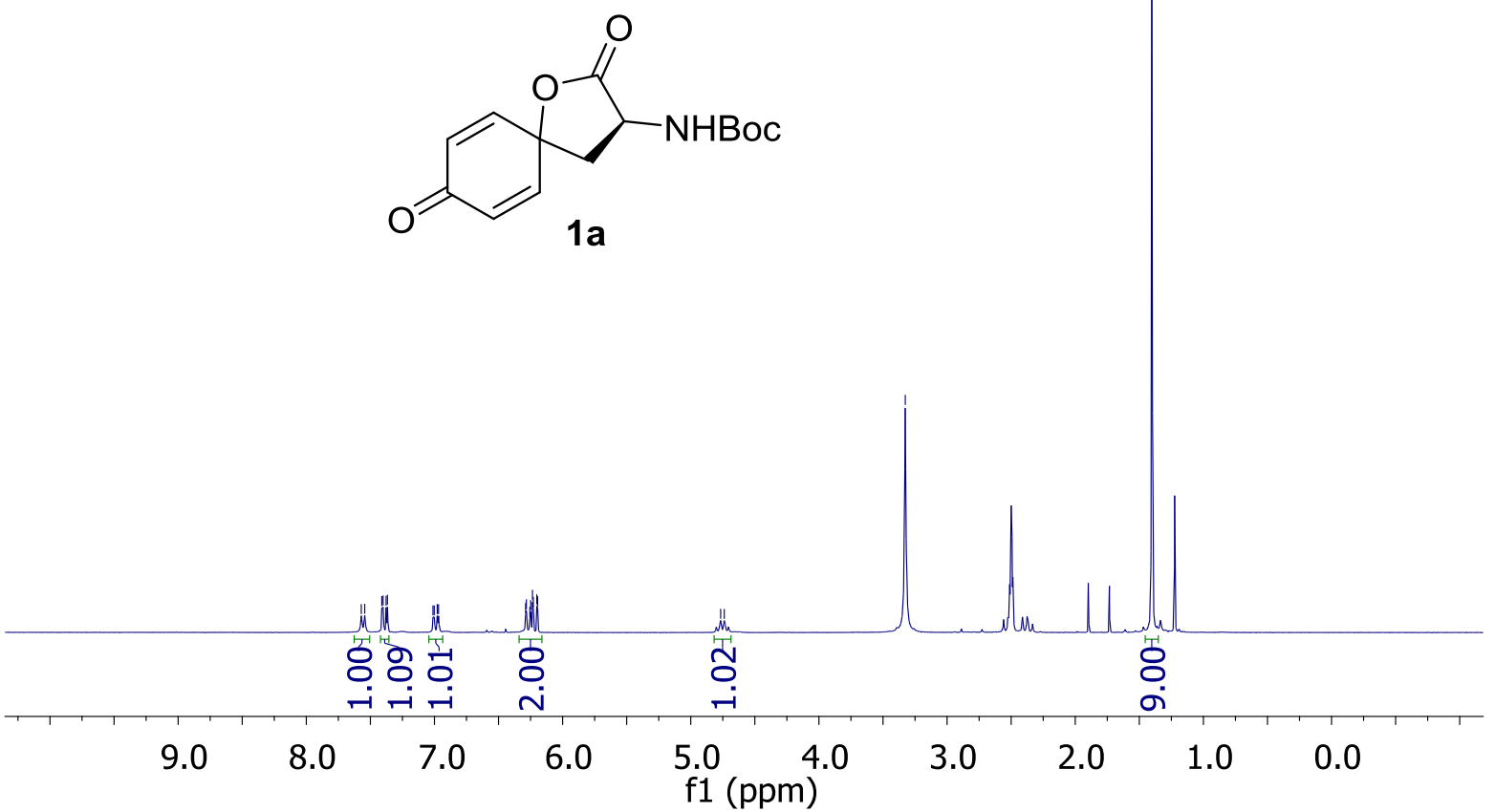


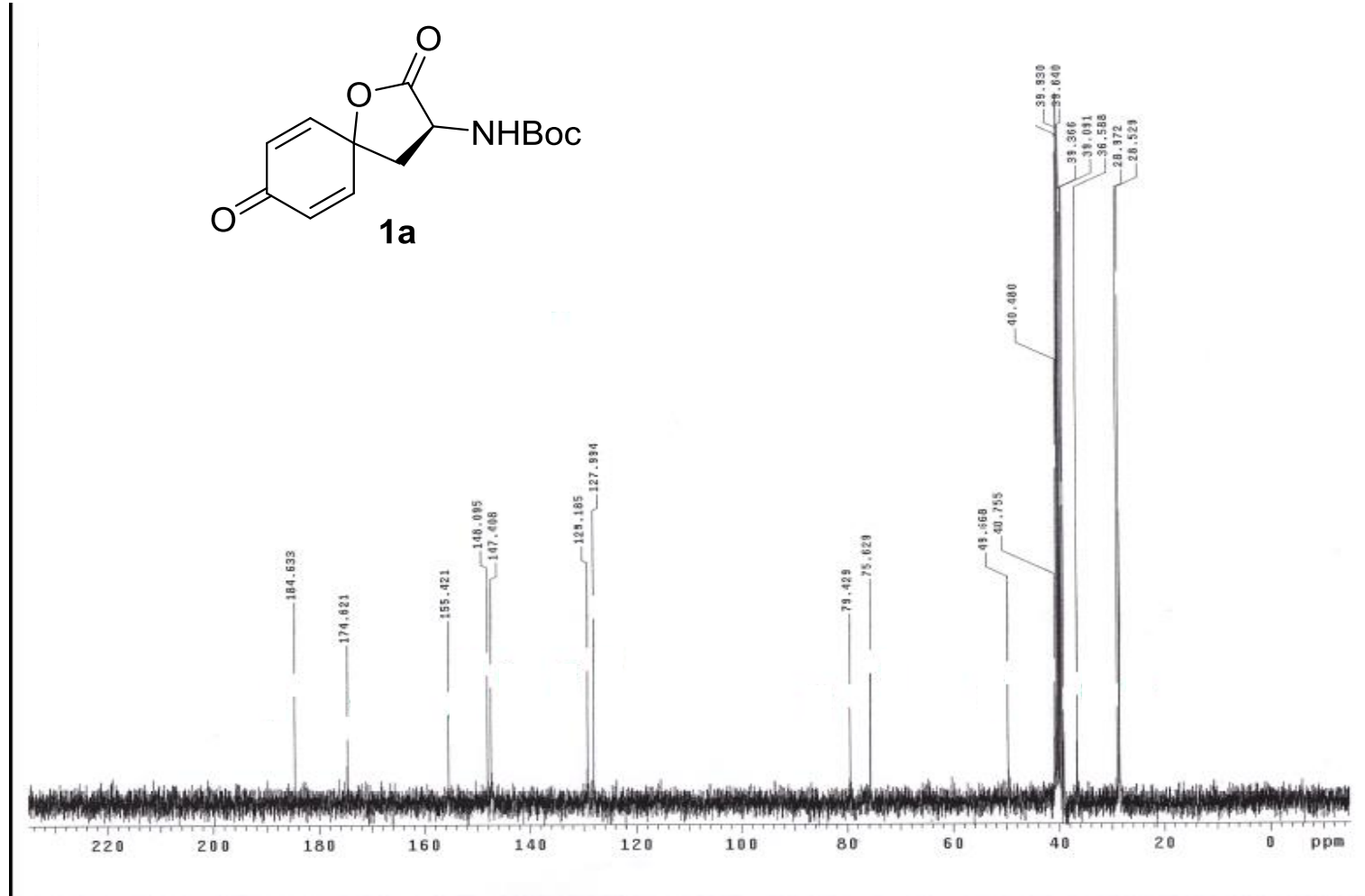

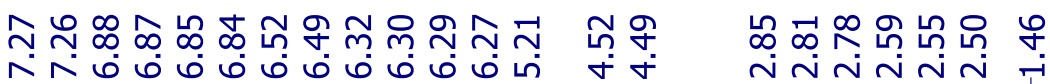

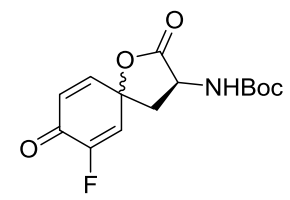

Diastereomer 1 - 1b

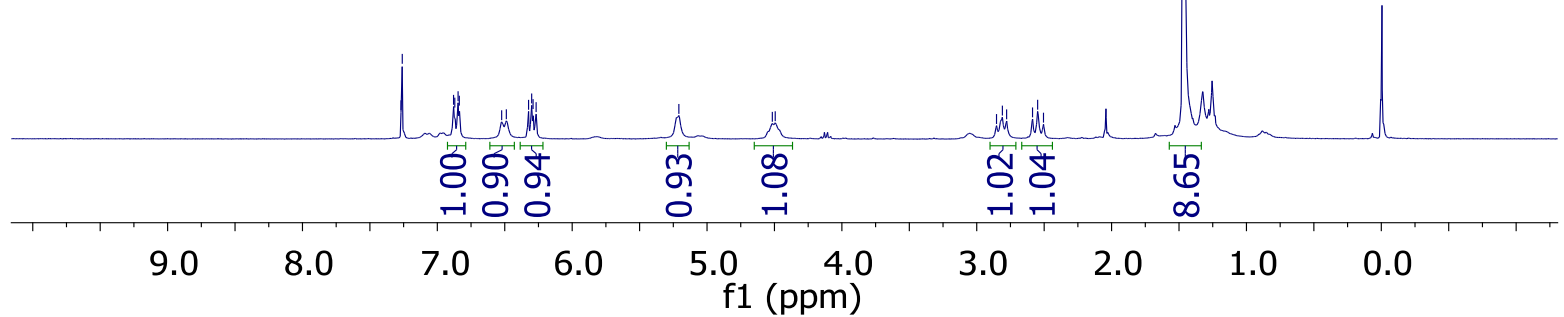


ํํำ ศุ N<smiles>O=C(O)CCCCNC(=O)C1C[C@]2(C=CC(=O)C(F)=C2)OC1=O</smiles>

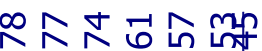

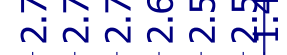

Diastereomer 2 - 1b
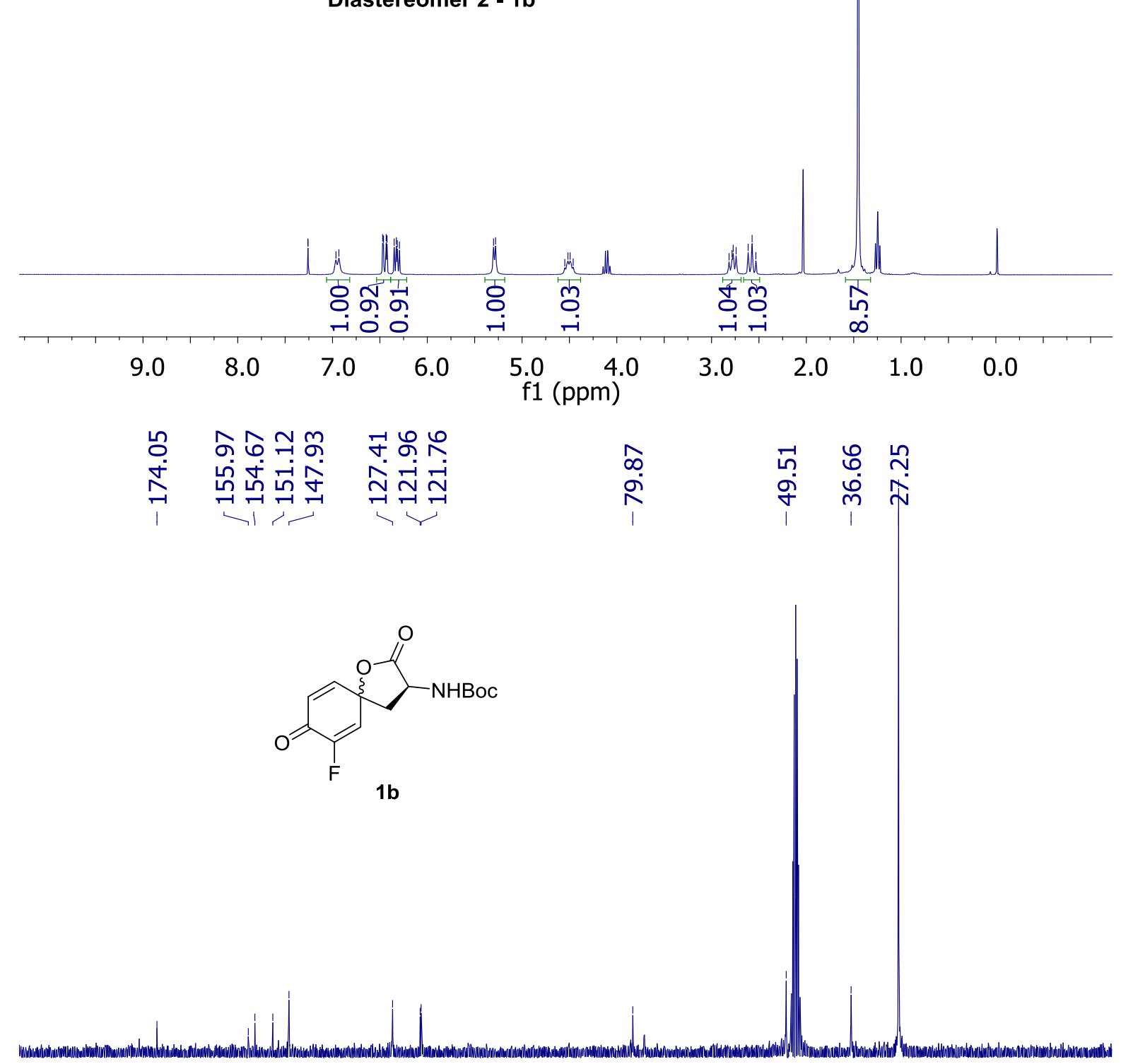

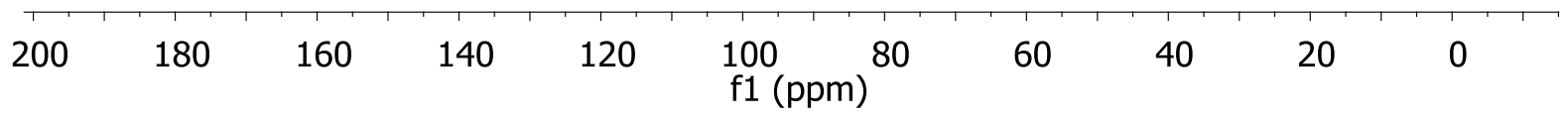


ํํํำำำ

ヘヘペ்

Diastereomer 1 - 1c

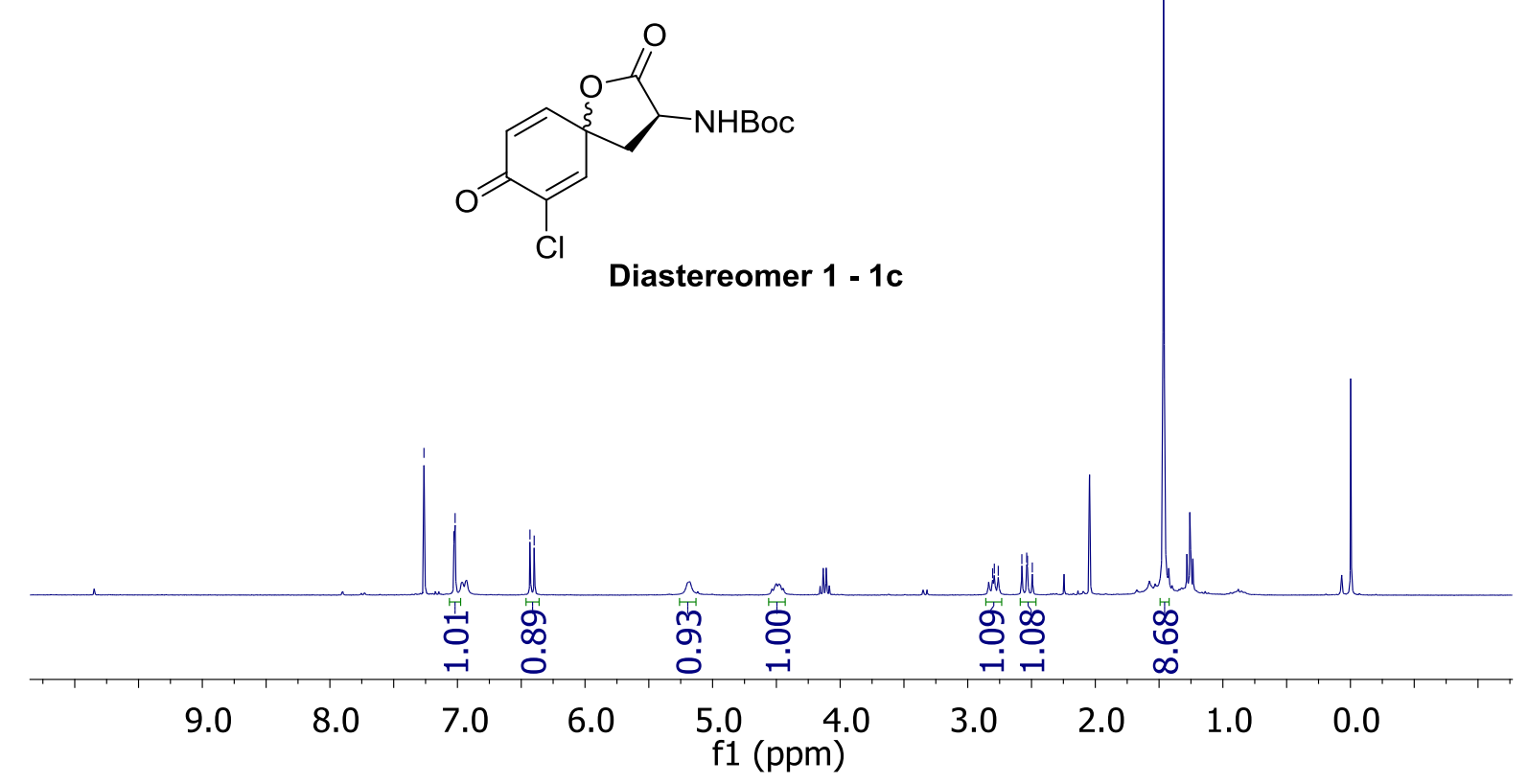

ㅇำ

กั่งกำ

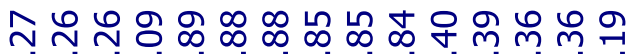
NヘNヘ

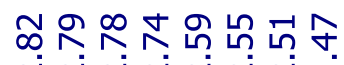
กั่งกั่งกั
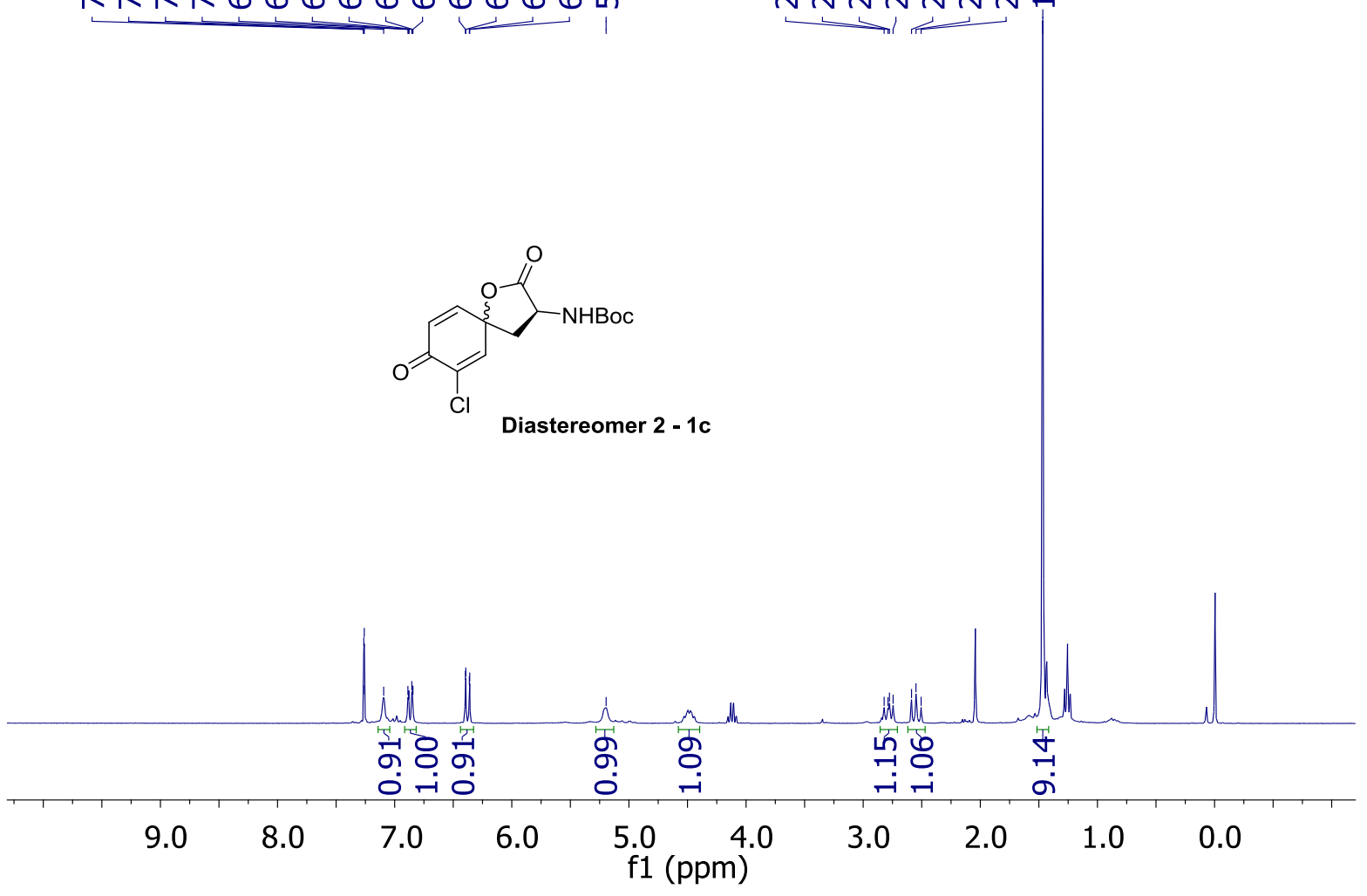


\begin{tabular}{|c|c|c|c|c|}
\hline 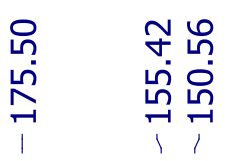 & 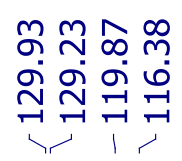 & \begin{tabular}{l}
\multirow{+}{*}{} \\
$\dot{\infty}$ \\
1
\end{tabular} & 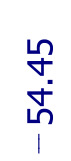 & 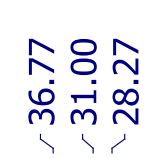 \\
\hline
\end{tabular}
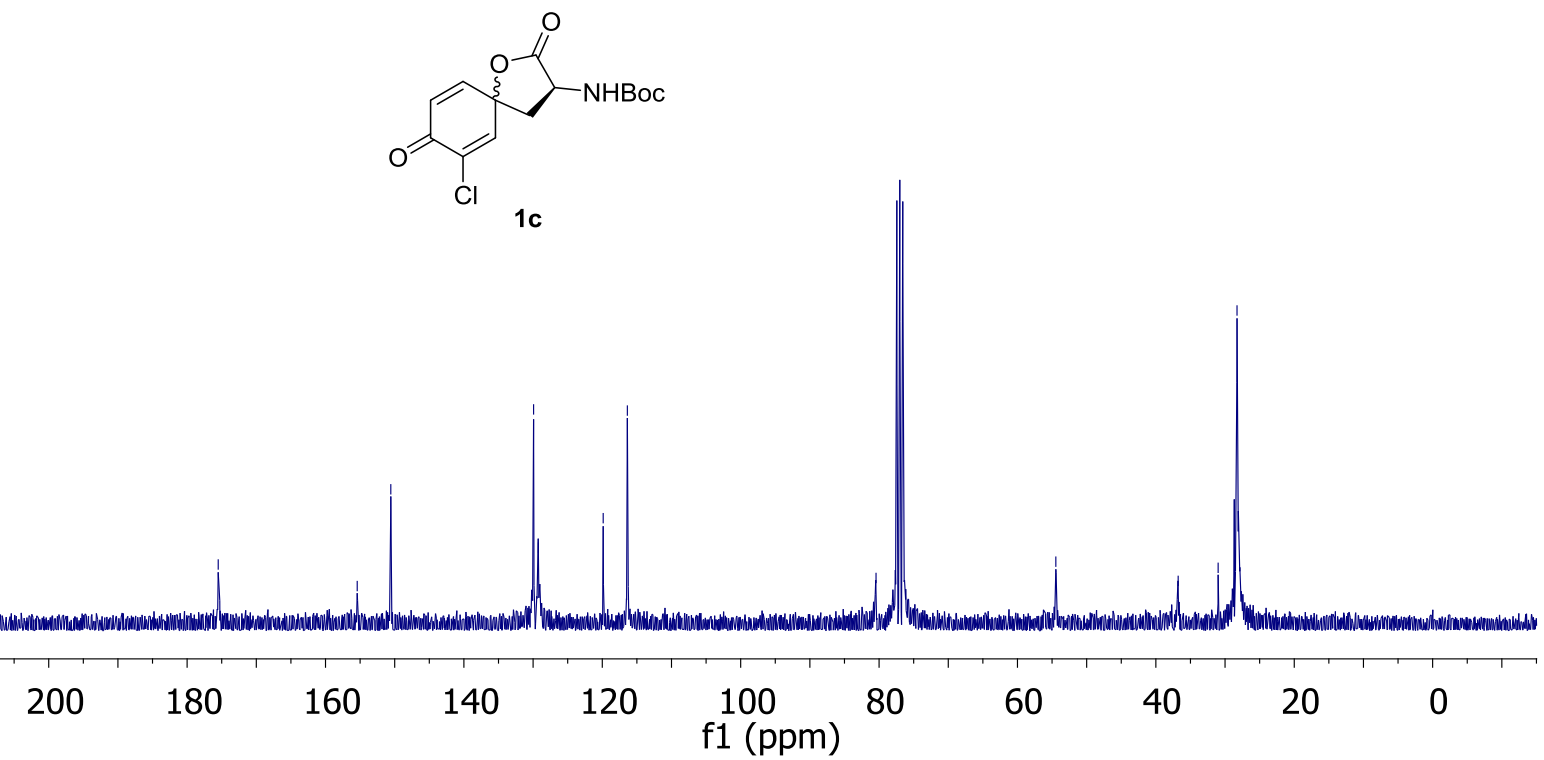

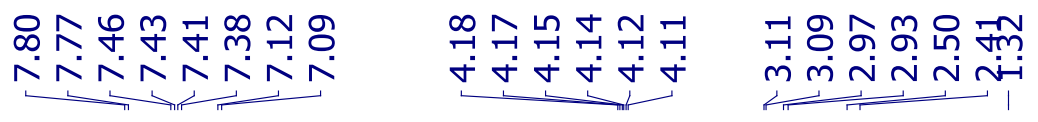
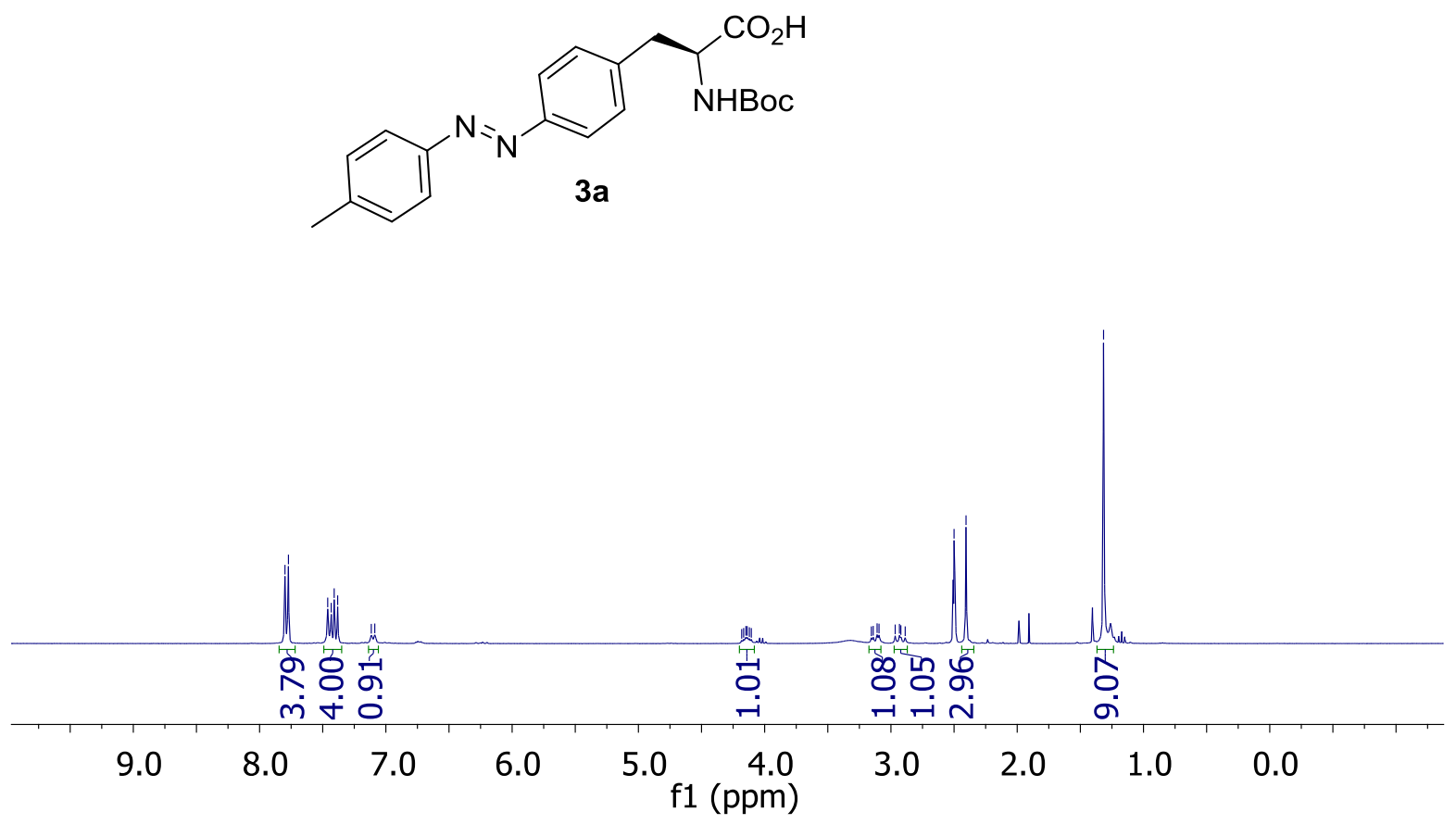


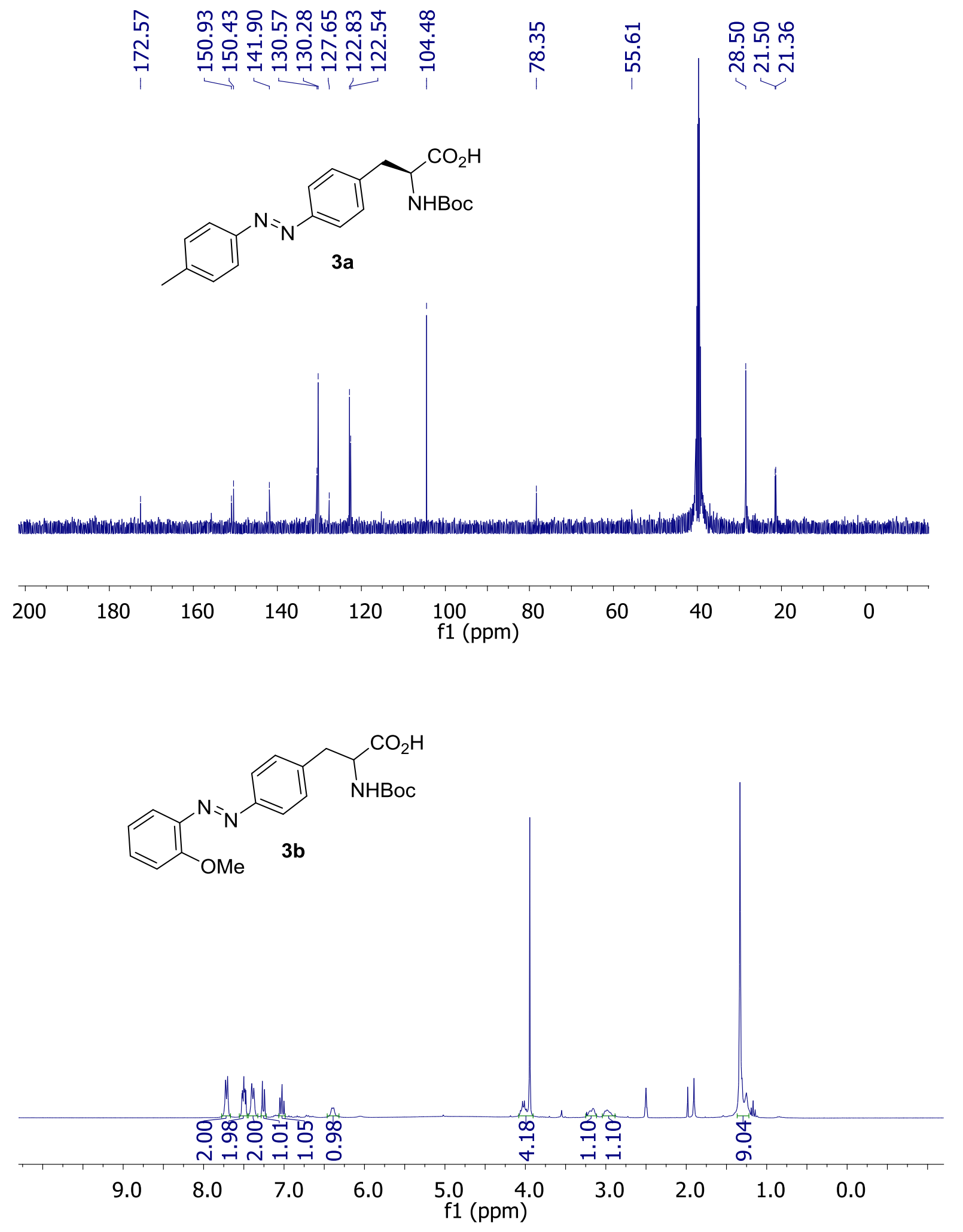




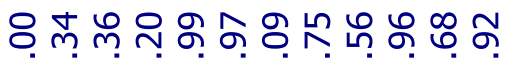

슴

作1,

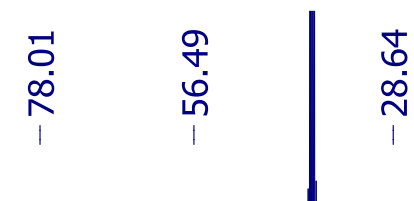<smiles>COc1ccccc1/N=N/c1ccc(CC(NC(=O)OCc2ccccc2)C(=O)O)cc1</smiles>

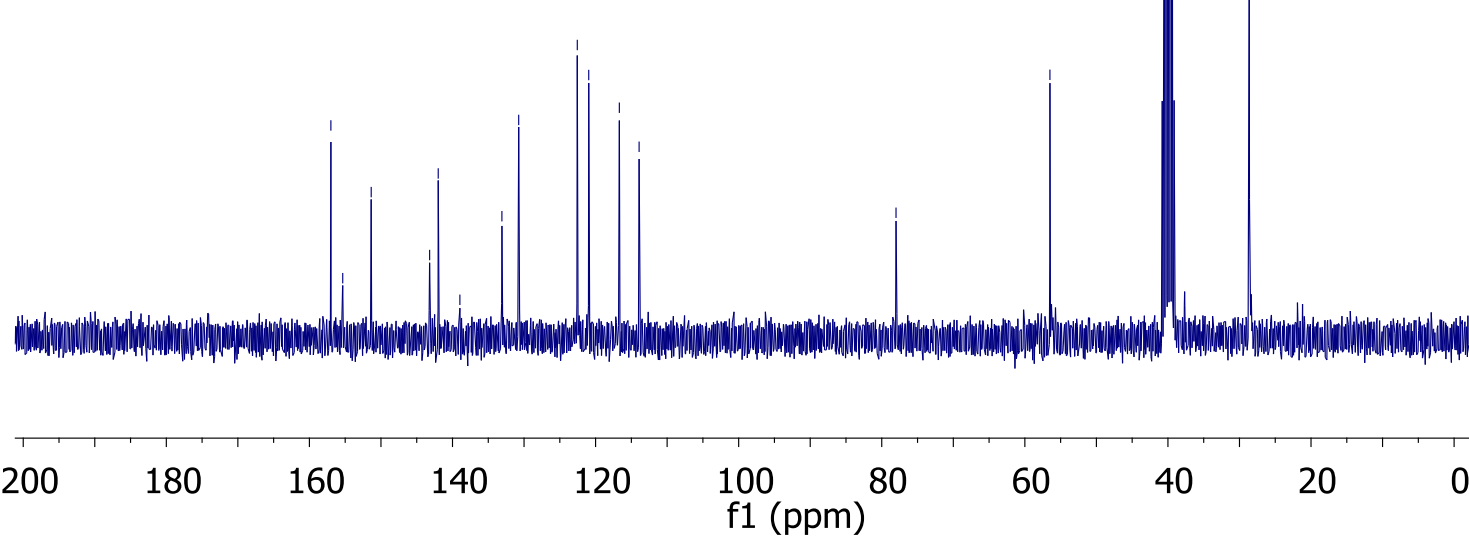

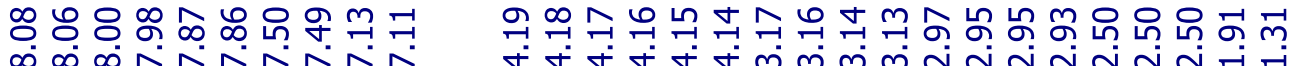

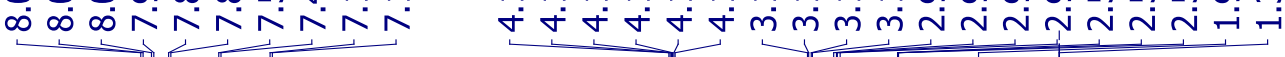<smiles>N#Cc1ccc(N=Nc2ccc(C[C@H](N)C(=O)O)cc2)cc1</smiles>

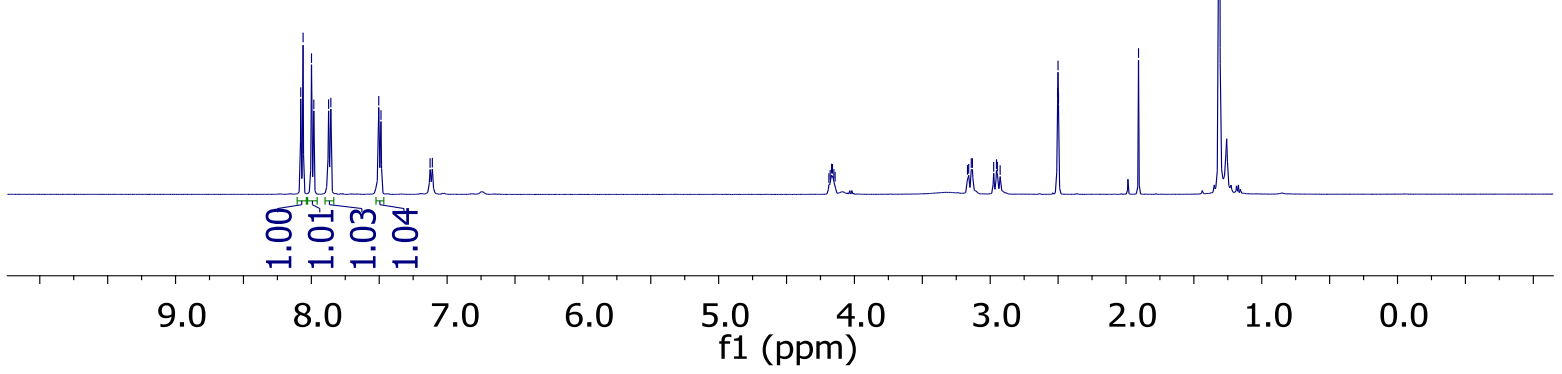



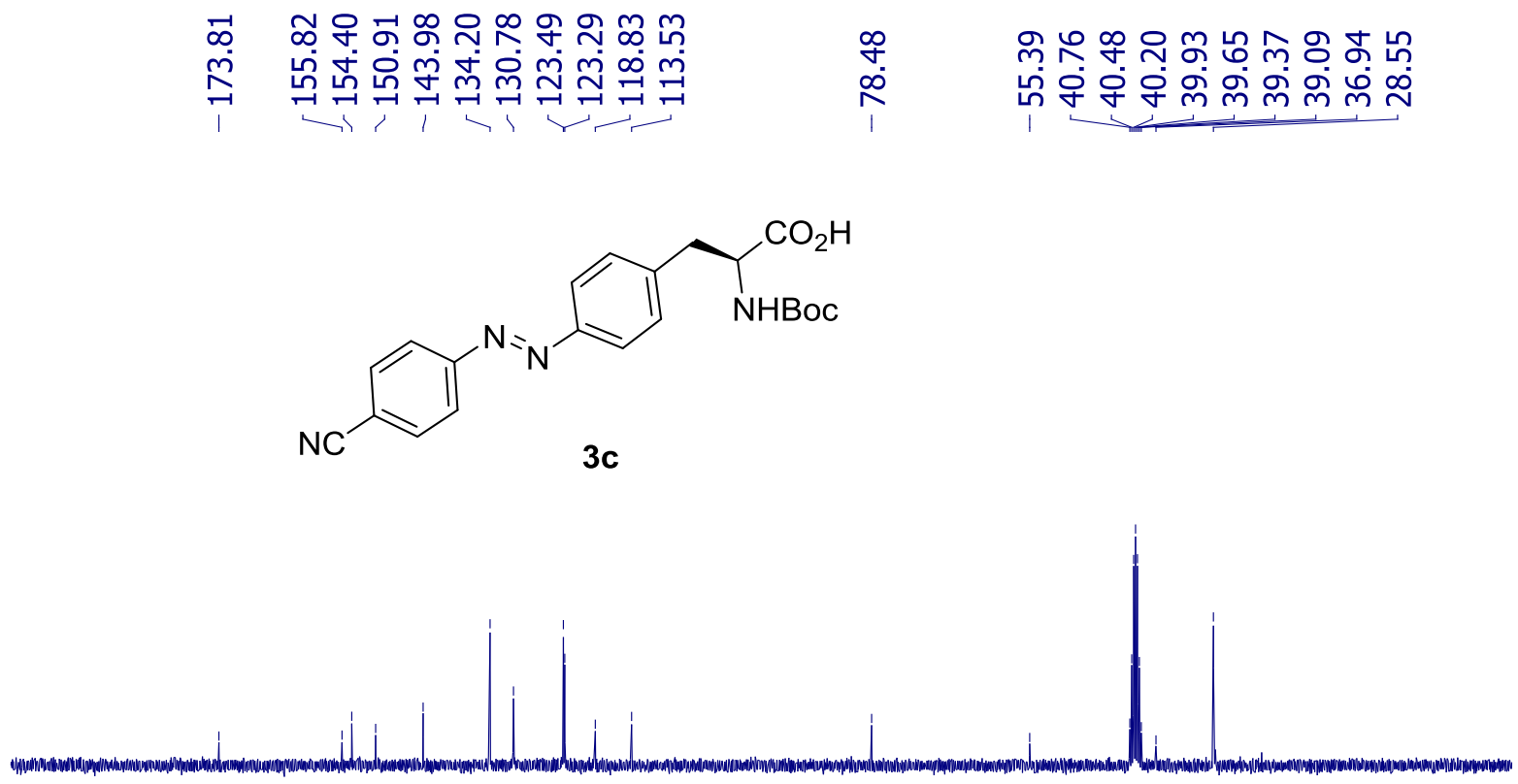

\begin{tabular}{|c|c|c|c|c|c|c|c|c|c|c|}
\hline 200 & 180 & 160 & 140 & 120 & $\begin{array}{l}100 \\
\text { f1 (ppm) }\end{array}$ & 80 & 60 & 40 & 20 & 0 \\
\hline
\end{tabular}

ํㅡㅁㄷㅁㅇㅇㅇ

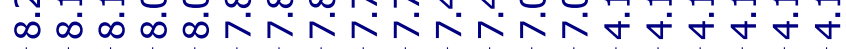<smiles>N#Cc1cccc(/N=N/c2ccc(C[C@H](NC(=O)O)C(=O)O)cc2)c1</smiles>

mำ mं $\mathrm{N} \sim \mathrm{N} \sim$

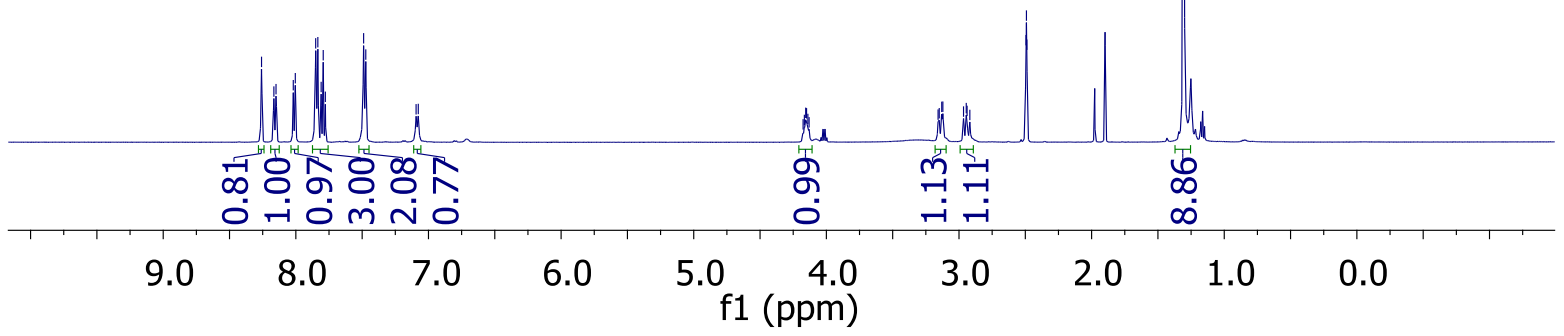


চ

mं

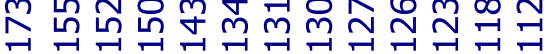

+) ำ

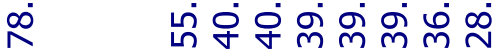

I<smiles>N#Cc1cccc(/N=N/c2ccc(C[C@H](NC(=O)O)C(=O)O)cc2)c1</smiles>

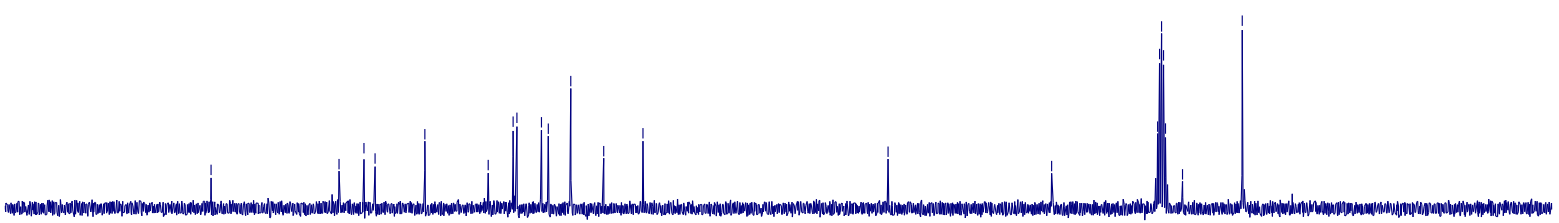

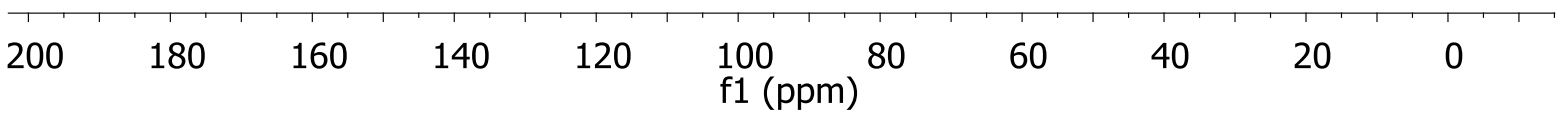

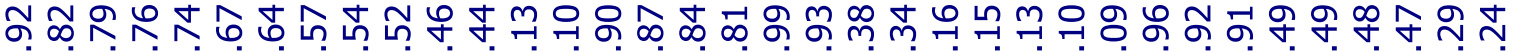

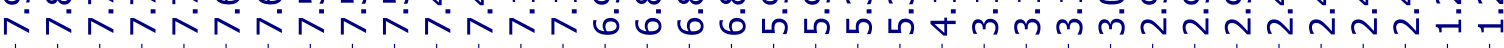<smiles>C=Cc1cccc(/N=N/c2ccc(C[C@H](NC(=O)OCc3ccccc3)C(=O)O)cc2)c1</smiles>

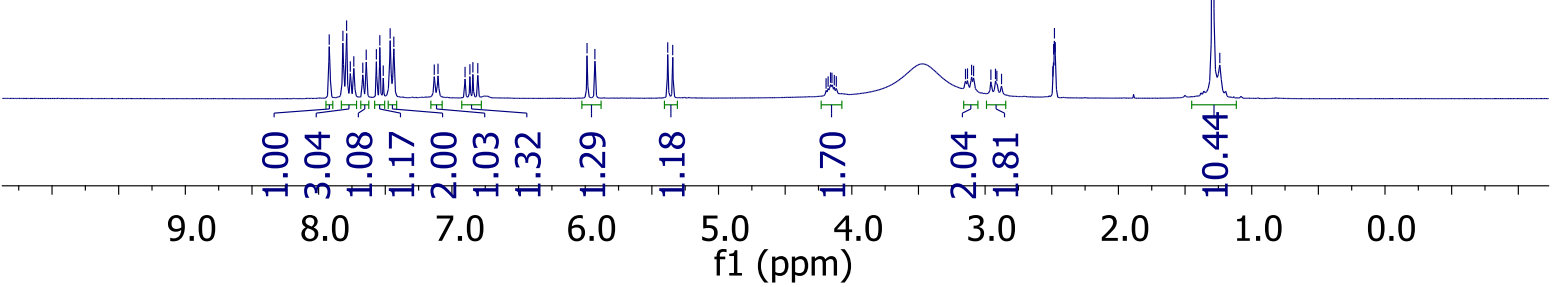


ハீ min

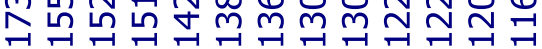
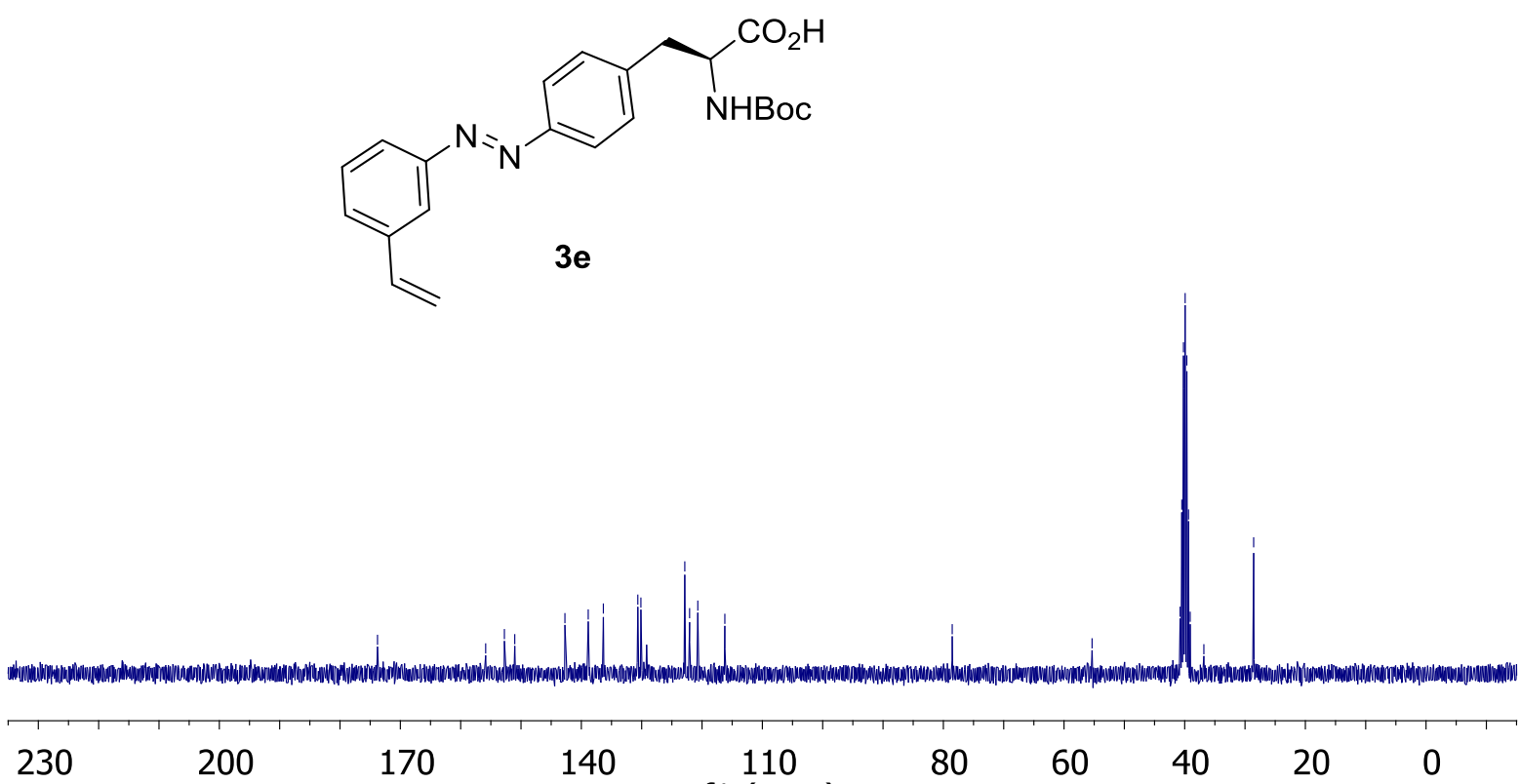

170

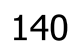

110

f1 (ppm)
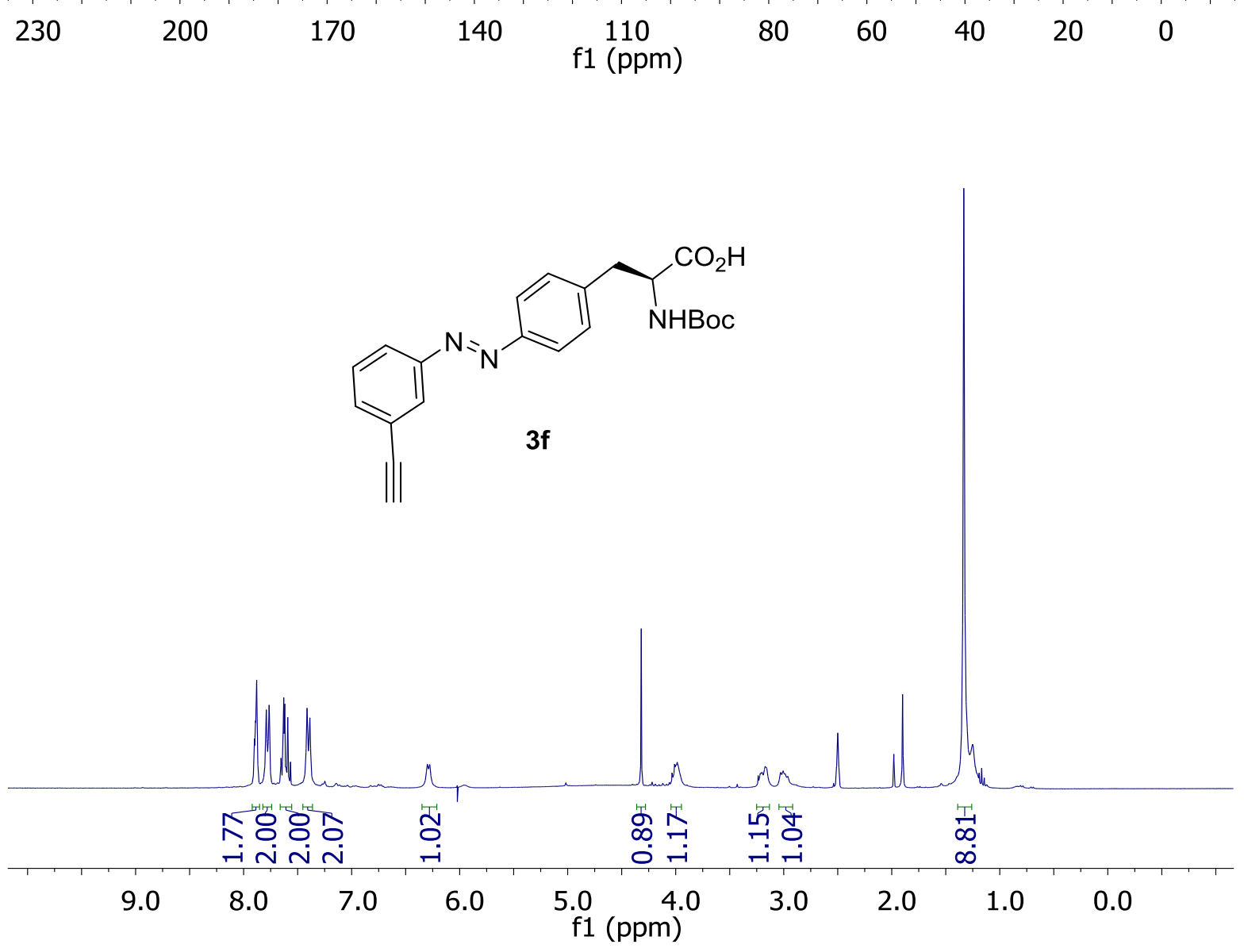


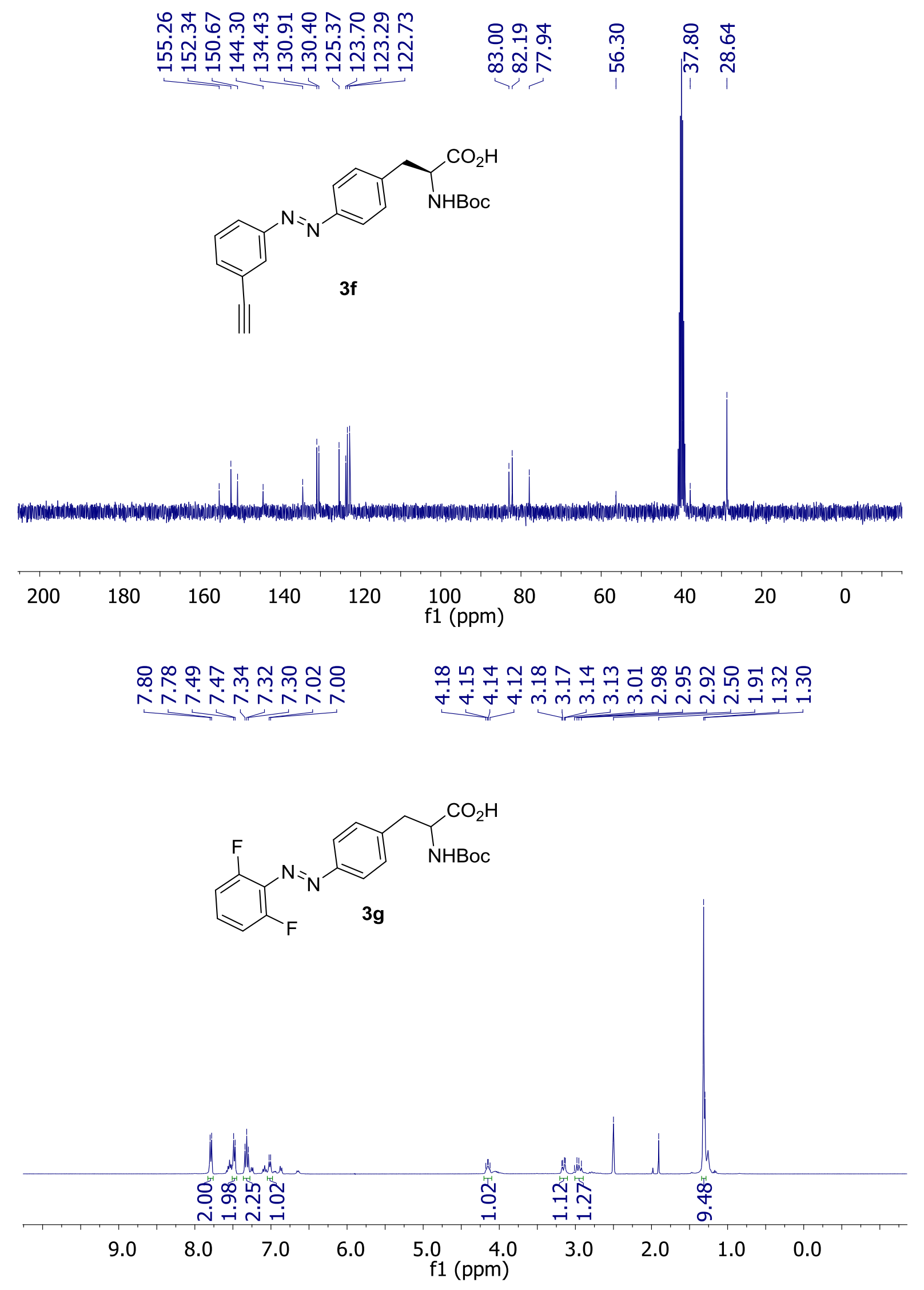



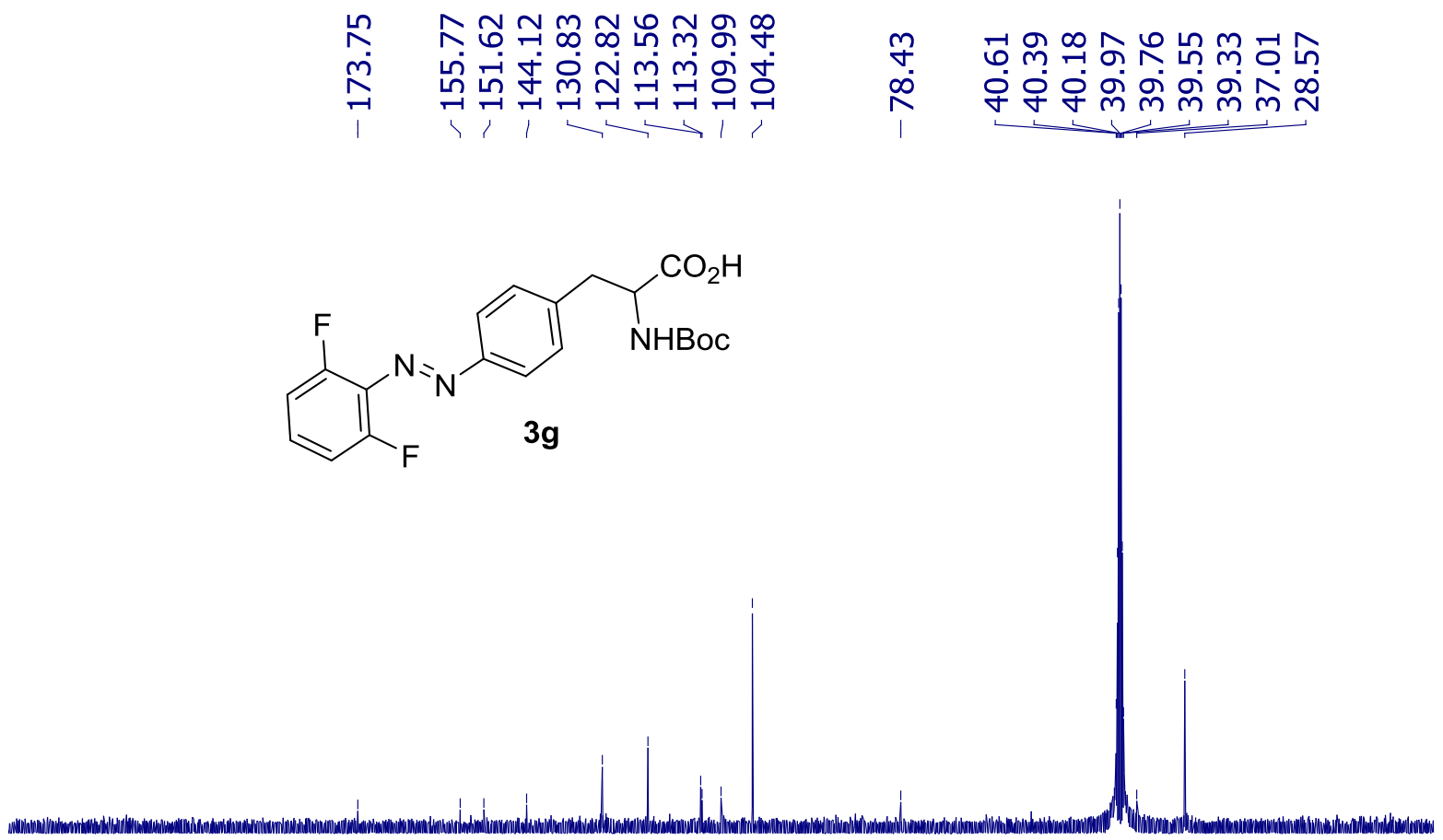

\begin{tabular}{|c|c|c|c|c|c|c|c|c|c|}
\hline 230 & 200 & 170 & 140 & $\begin{array}{l}110 \\
\mathrm{f} 1(\mathrm{ppm})\end{array}$ & 80 & 60 & 40 & 20 & 0 \\
\hline
\end{tabular}

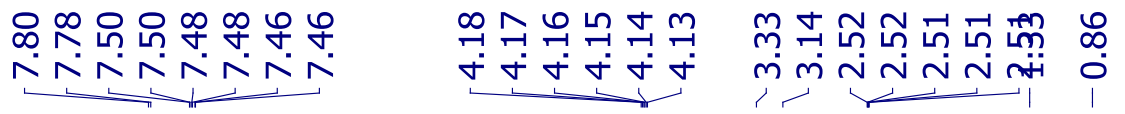

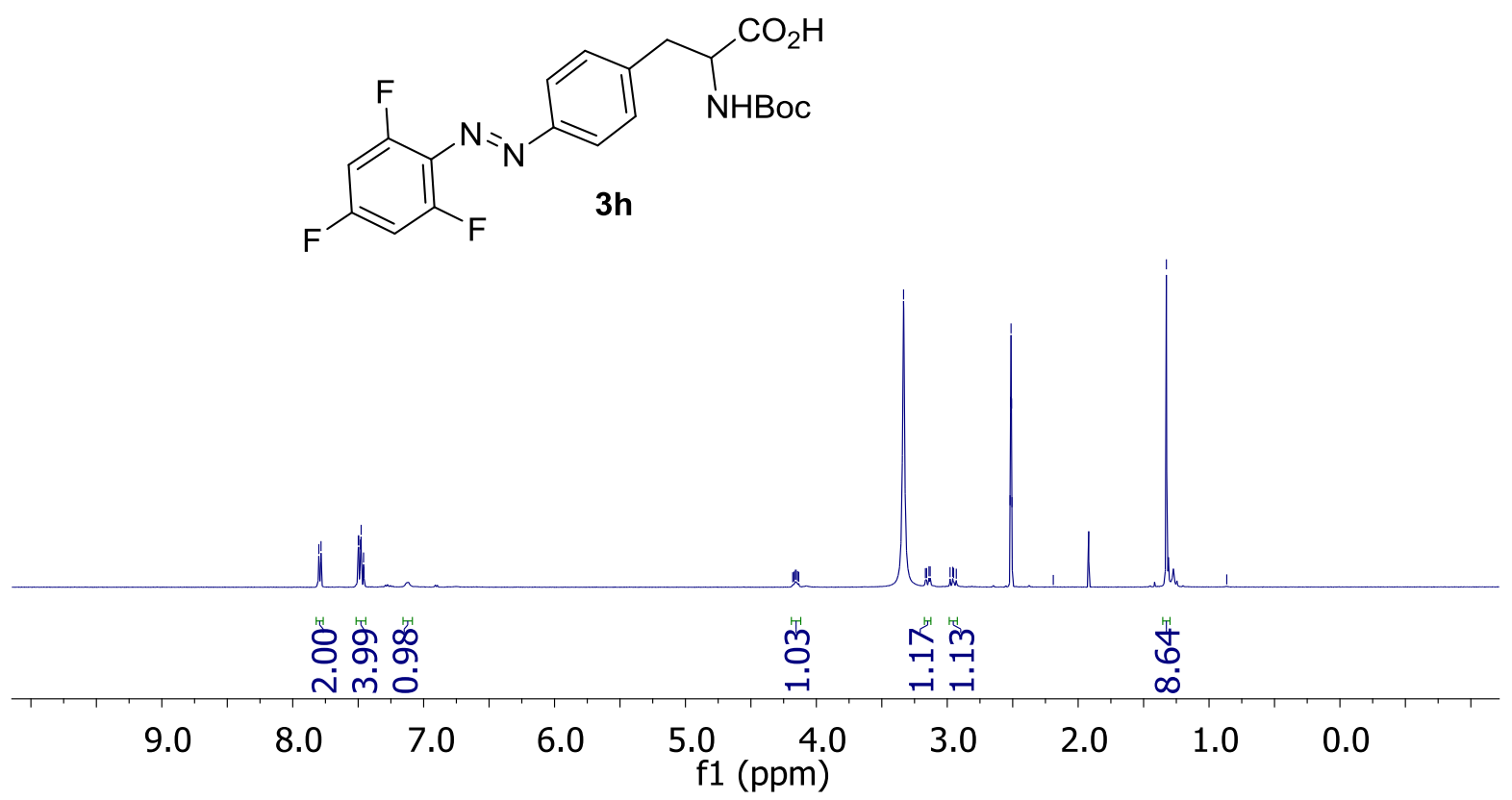


교 $\quad$ m

m촉

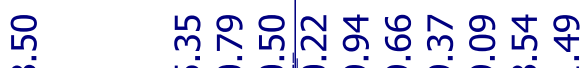

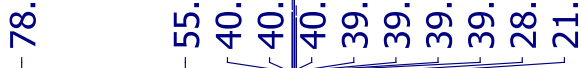<smiles>CC(C)(C)OC(=O)NC(Cc1ccc(N=Nc2c(F)cc(F)cc2F)cc1)C(=O)O</smiles>

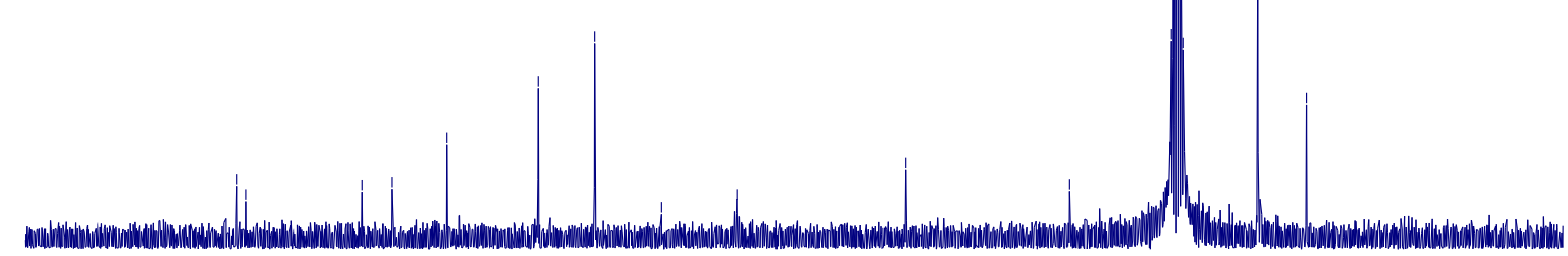

\begin{tabular}{|c|c|c|c|c|c|c|c|c|c|}
\hline 200 & 180 & 160 & 140 & 120 & $\begin{array}{l}100 \\
\mathrm{f} 1(\mathrm{ppm})\end{array}$ & 80 & 60 & 40 & 20 \\
\hline
\end{tabular}

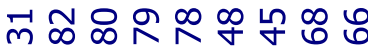

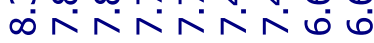
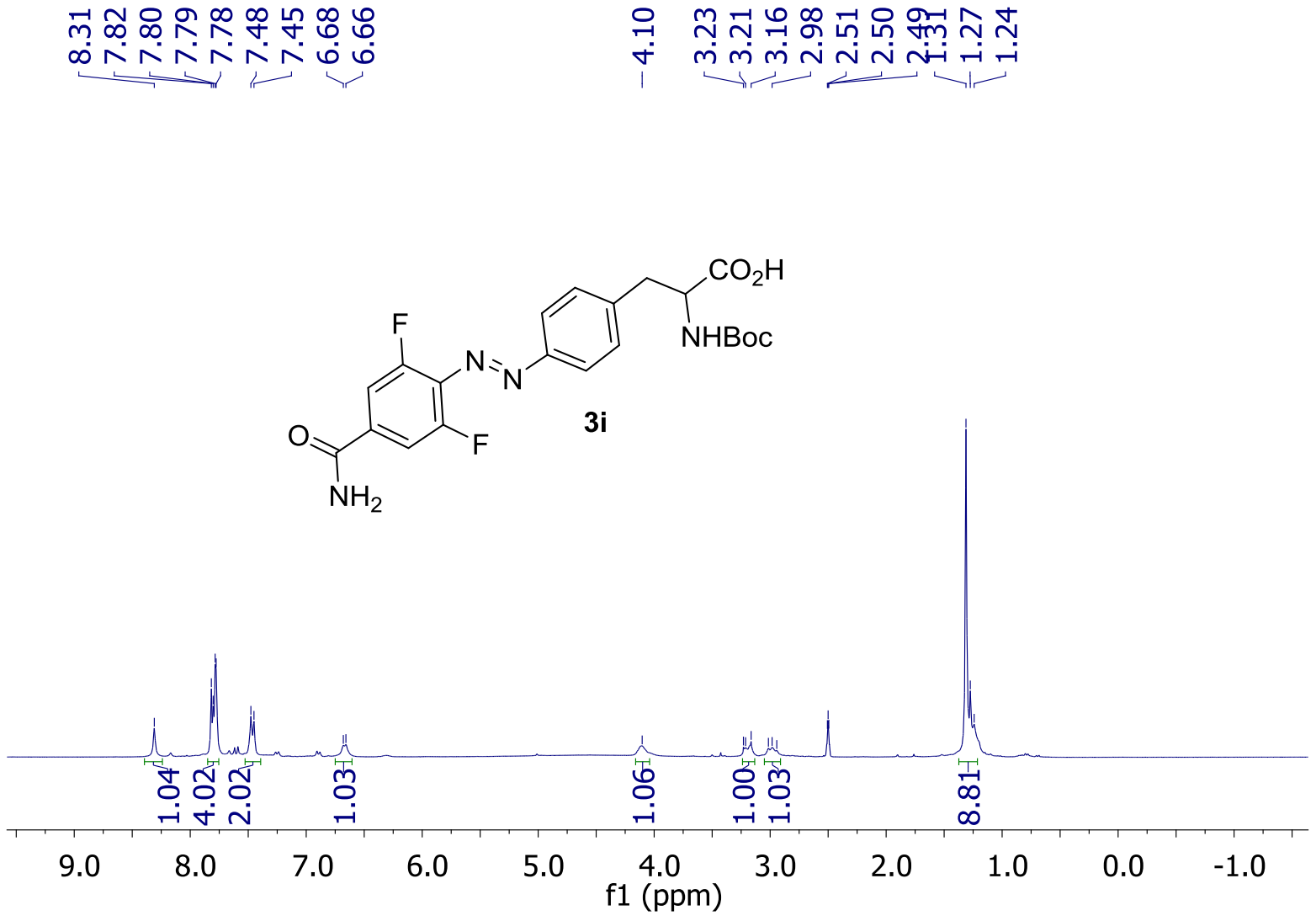


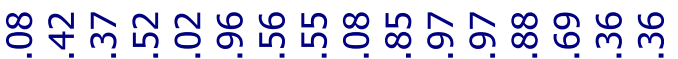
ก่

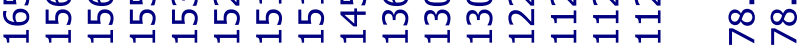<smiles>NC(=O)c1cc(F)c(N=Nc2ccc(CC(NC(=O)O)C(=O)O)cc2)c(F)c1</smiles>

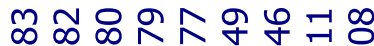

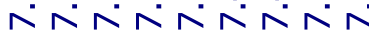<smiles>CC(C)(C)NC(=O)C(Cc1ccc(N=Nc2c(F)cc(I)cc2F)cc1)C(=O)O</smiles><smiles>CCC</smiles>

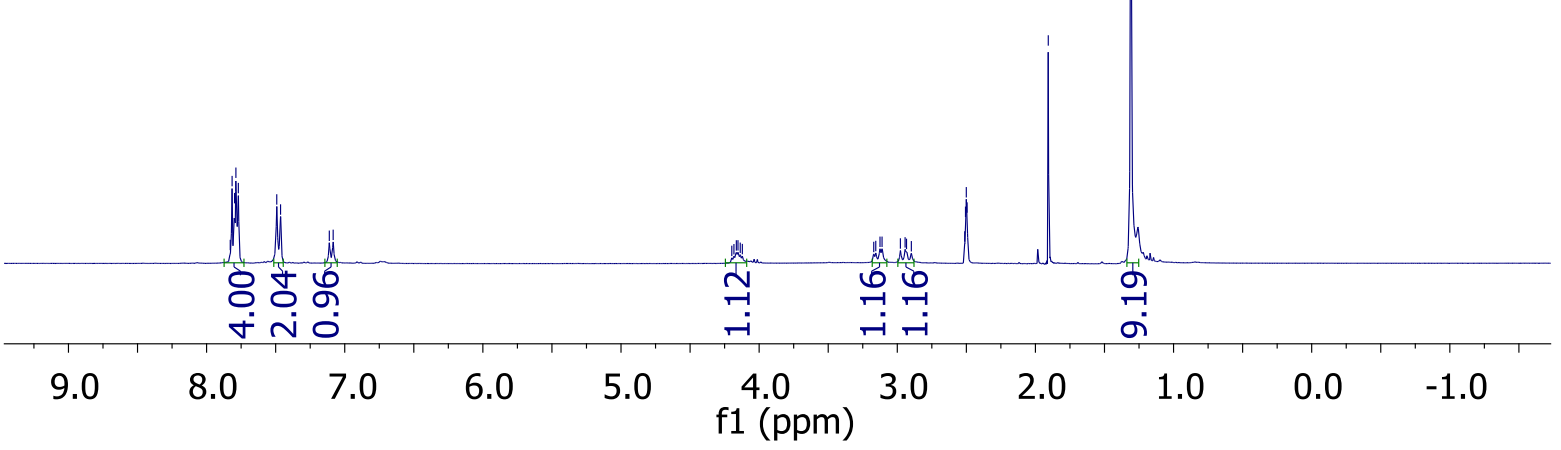




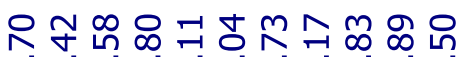
ल் N $N$ 뉻ำ<smiles>CC(C)(C)NC(Cc1ccc(N=Nc2c(F)cc(I)cc2F)cc1)C(=O)O</smiles>

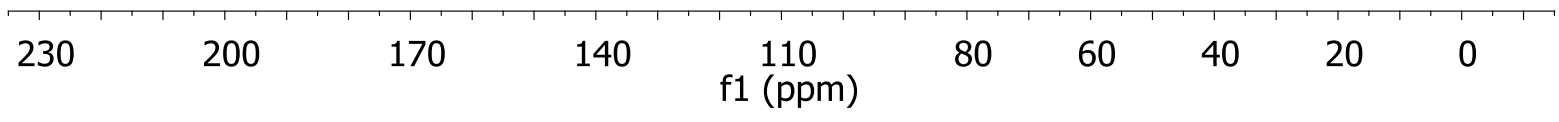

$\infty$

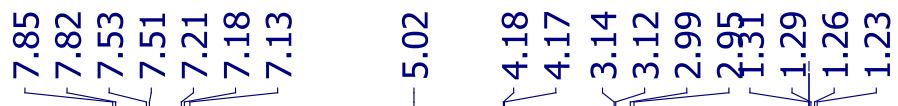
กี่<smiles>O=C(O)C(Cc1ccc(N=Nc2c(F)c(F)c(F)c(F)c2F)cc1)C(=O)O</smiles>

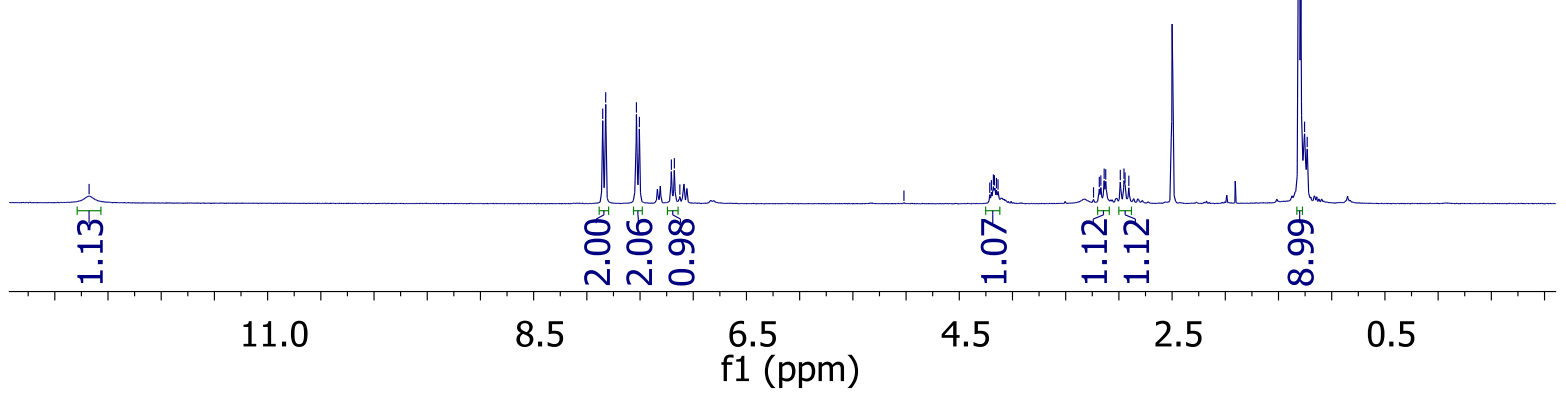




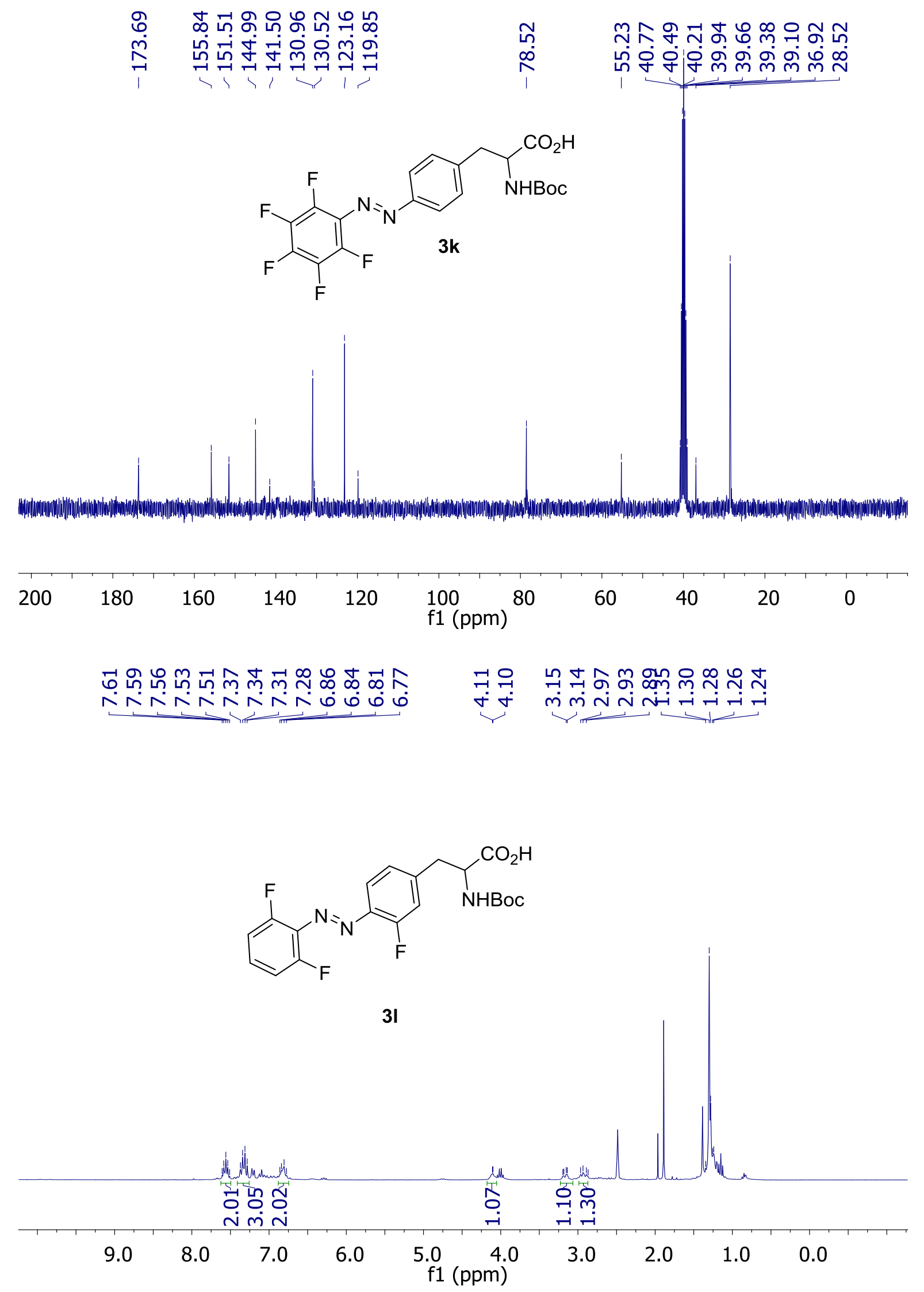



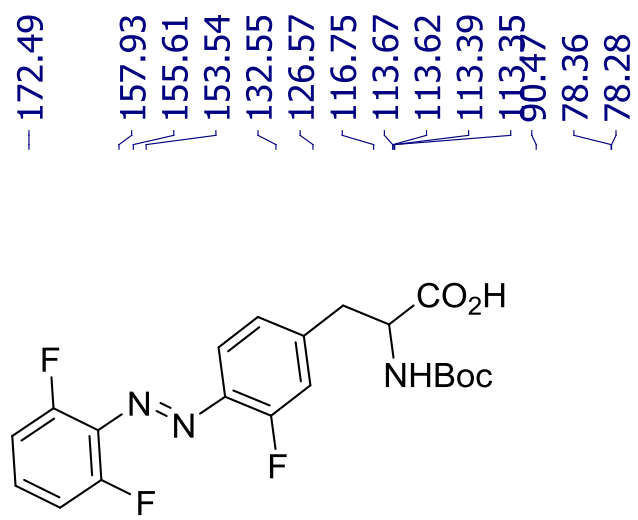

$3 \mathbf{I}$

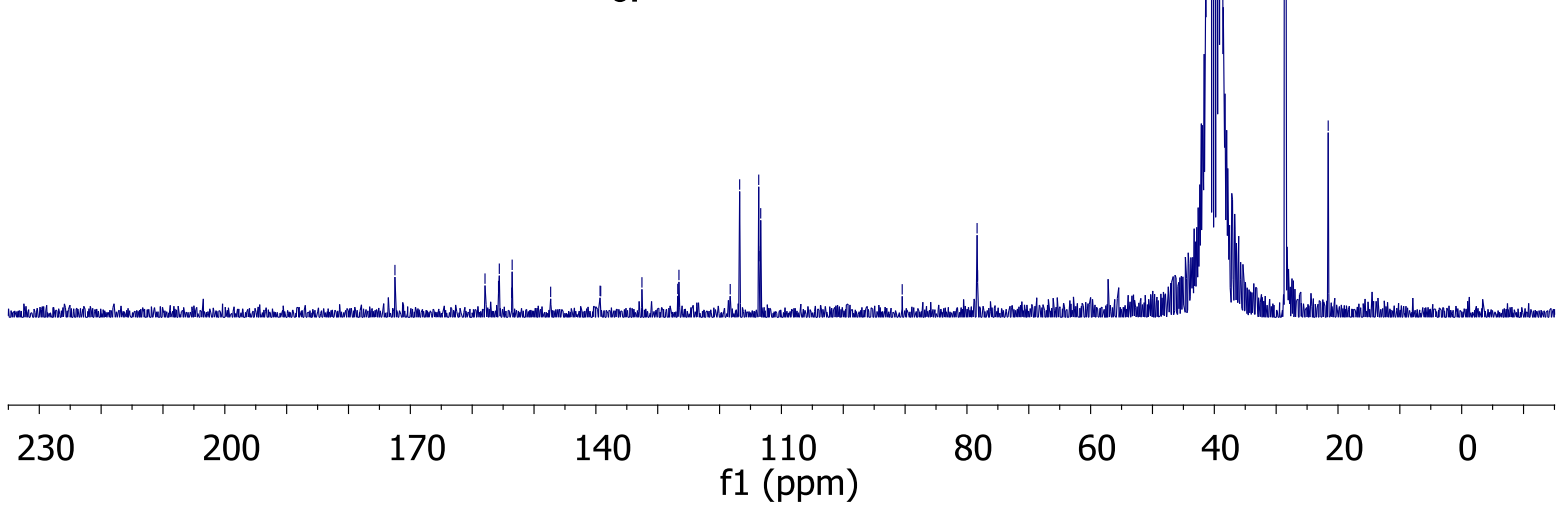

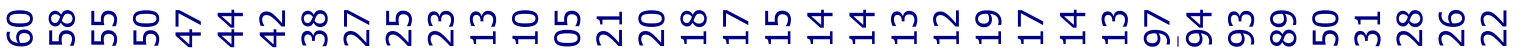

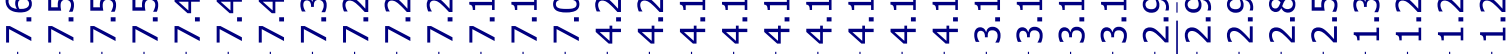<smiles>CC(C)(C)NC(Cc1ccc(N=Nc2c(F)cc(F)cc2F)c(F)c1)C(=O)O</smiles>

$3 m$

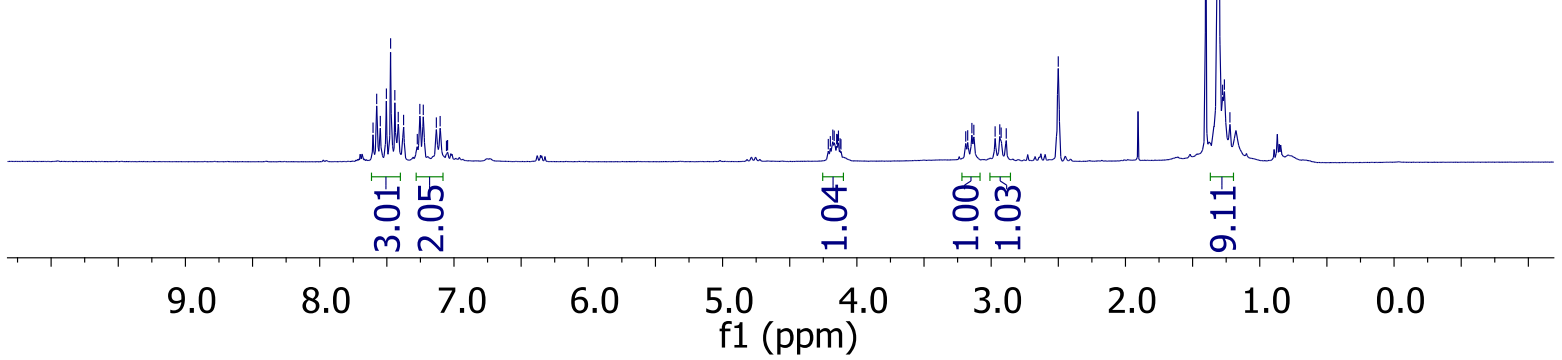



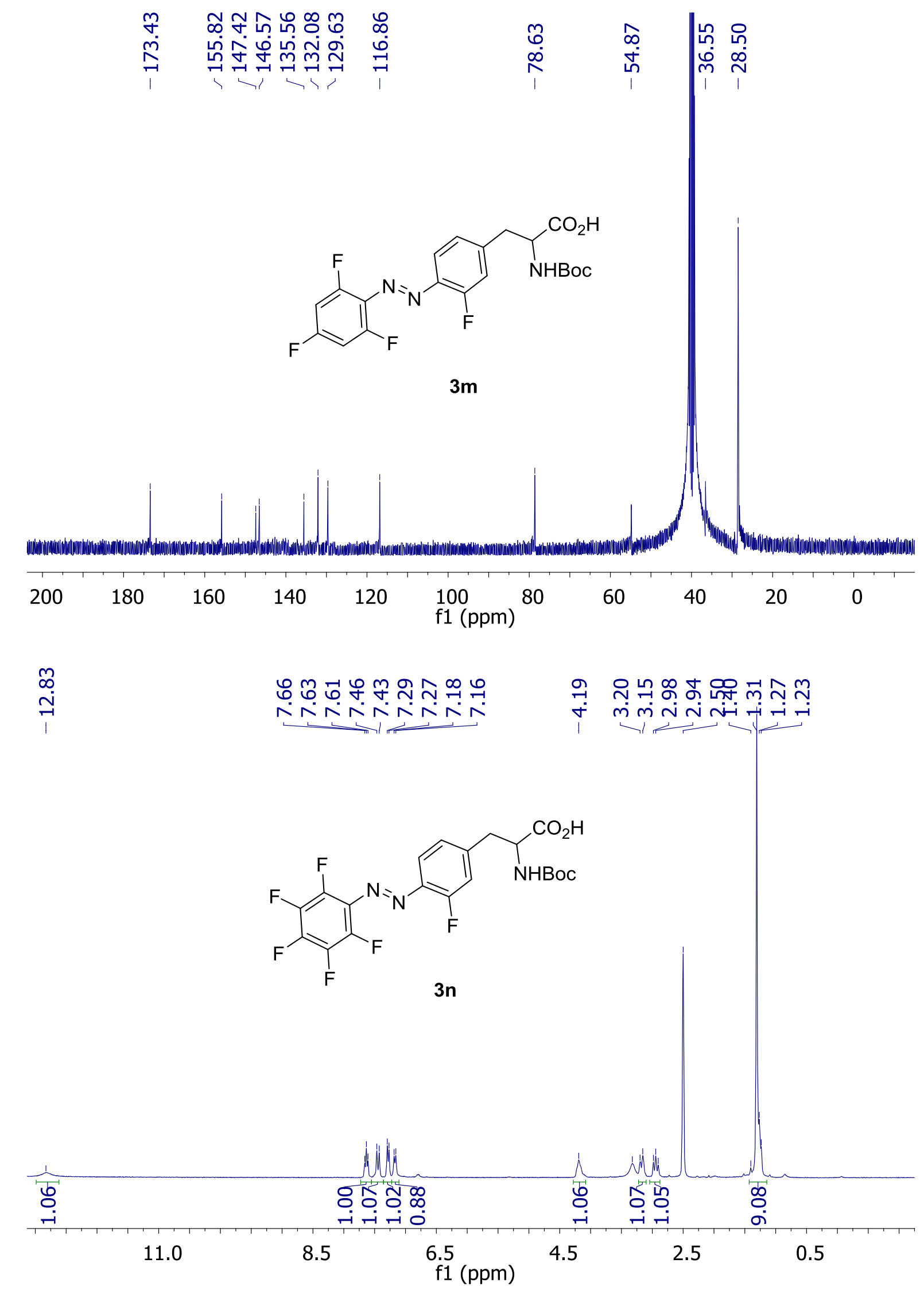


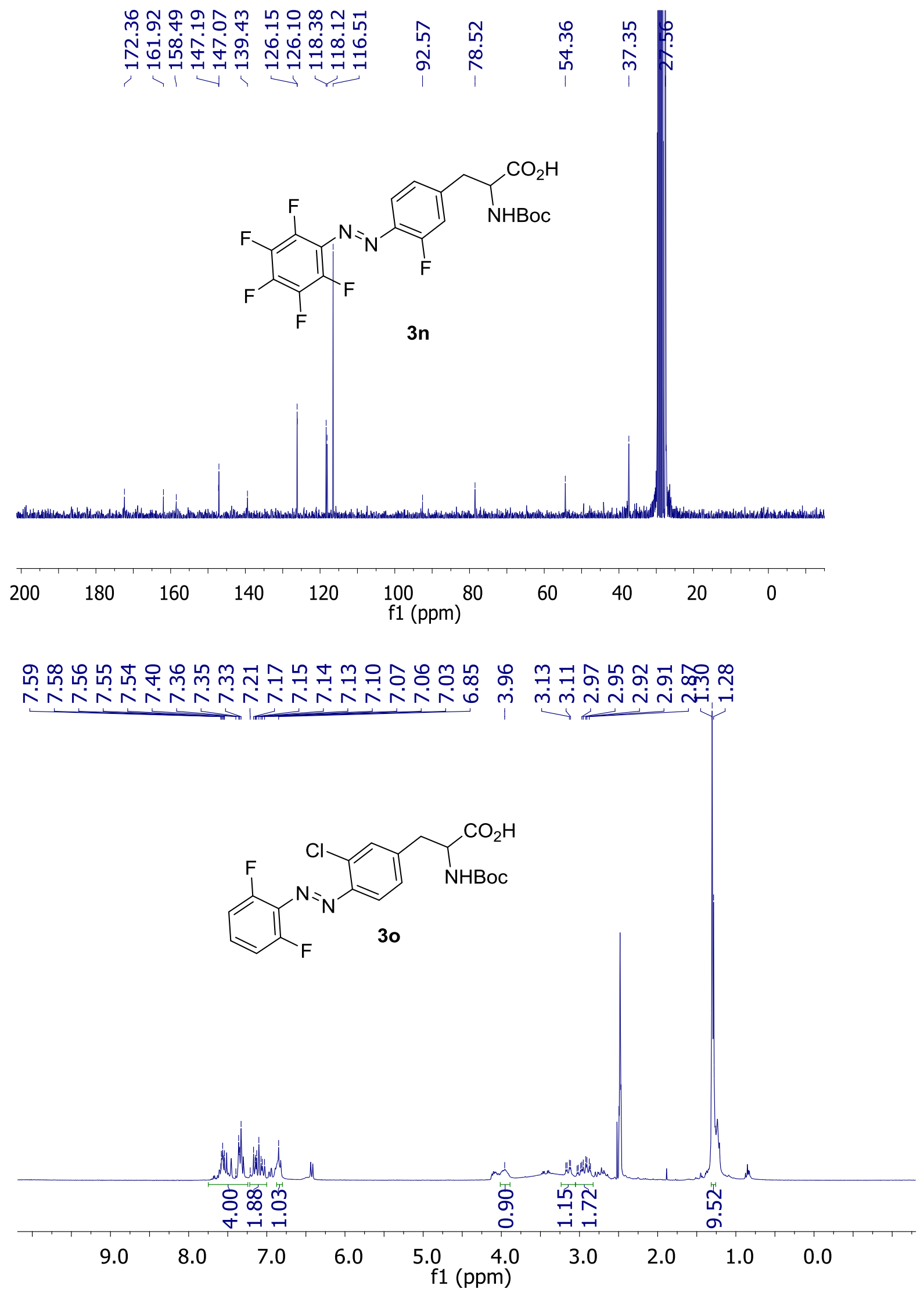




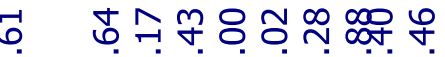

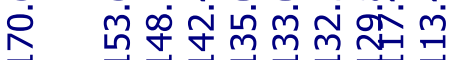

I<smiles>CCCCC(NC(Cc1ccc(N=Nc2c(F)cccc2F)c(Cl)c1)C(=O)O)C(=O)O</smiles>

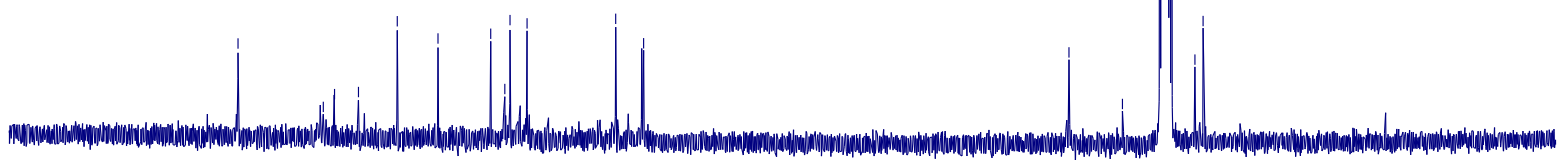

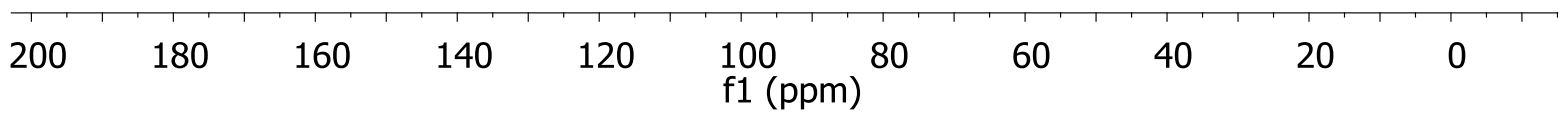

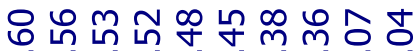

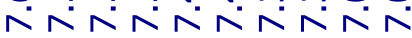

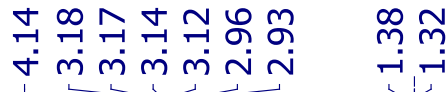<smiles>O=C(O)NC(Cc1ccc(N=Nc2c(F)cc(F)cc2F)c(Cl)c1)C(=O)O</smiles>

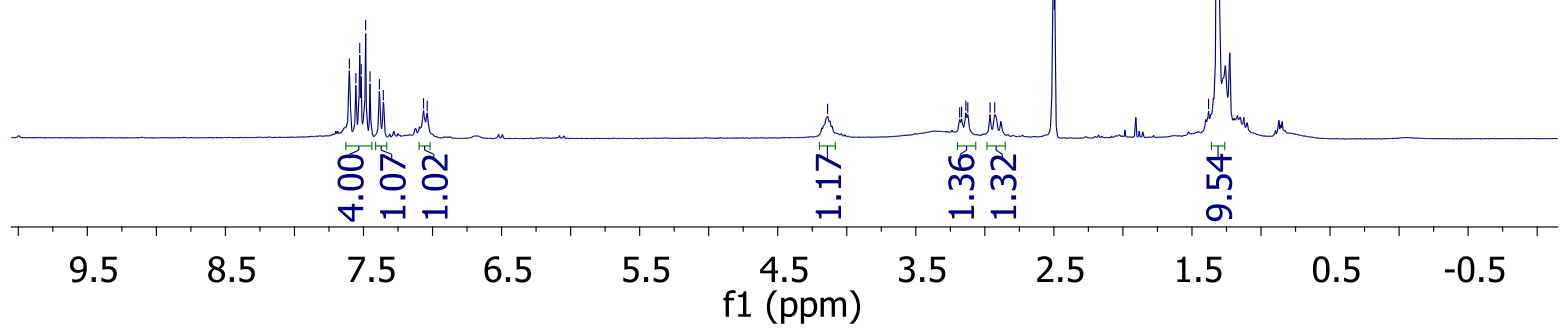




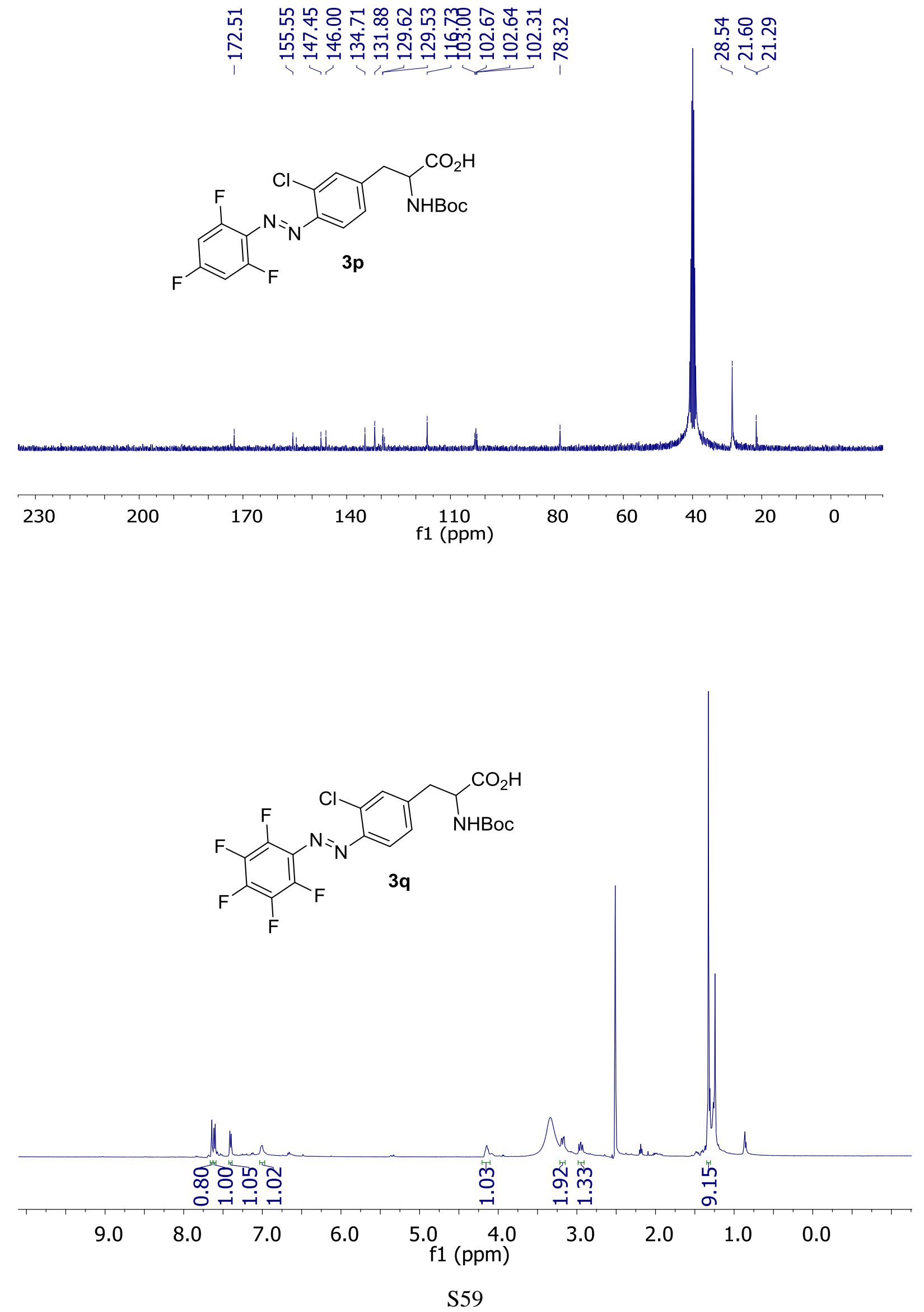




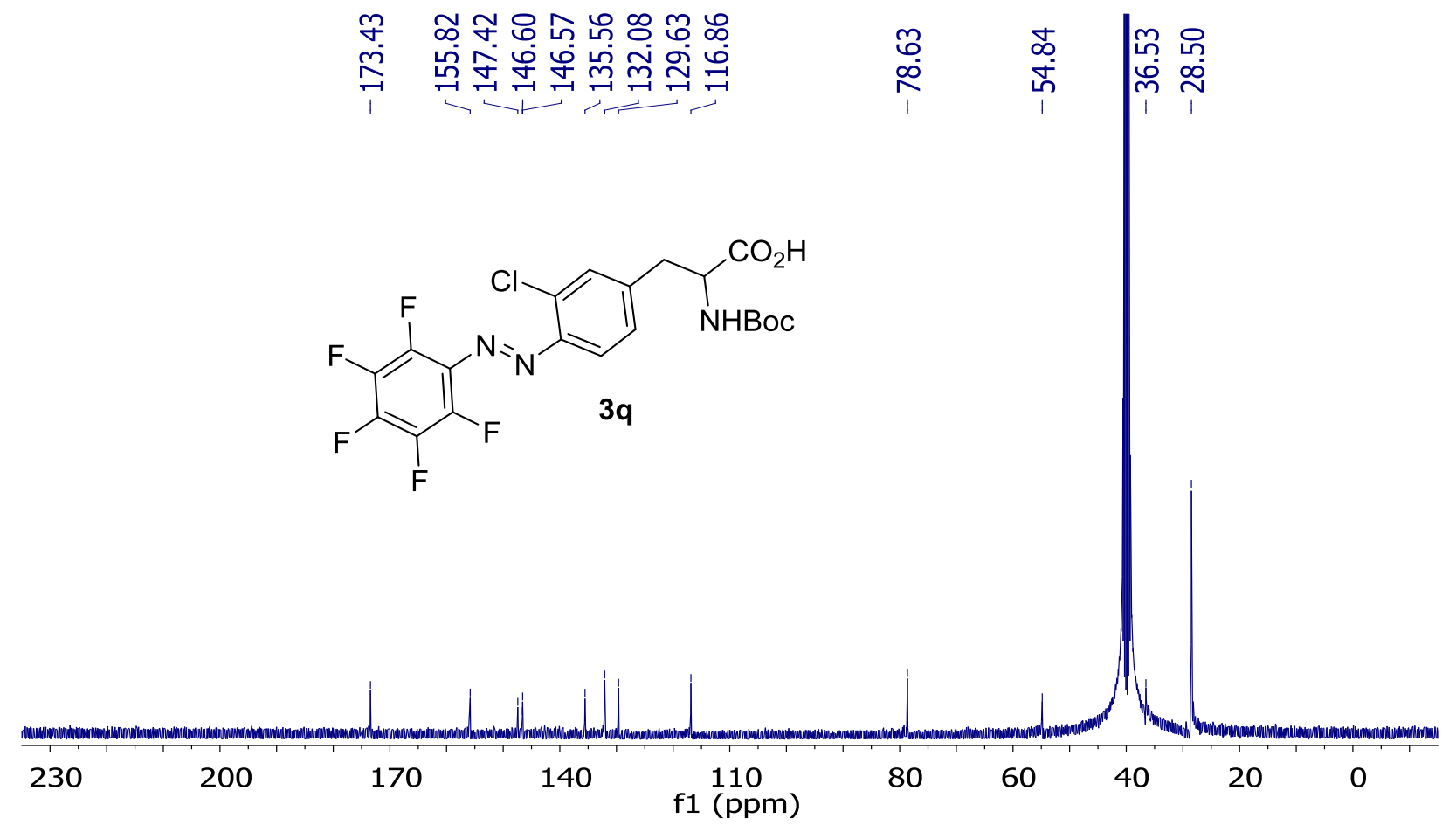

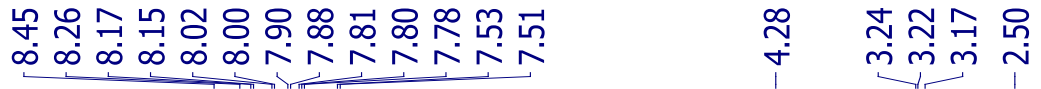
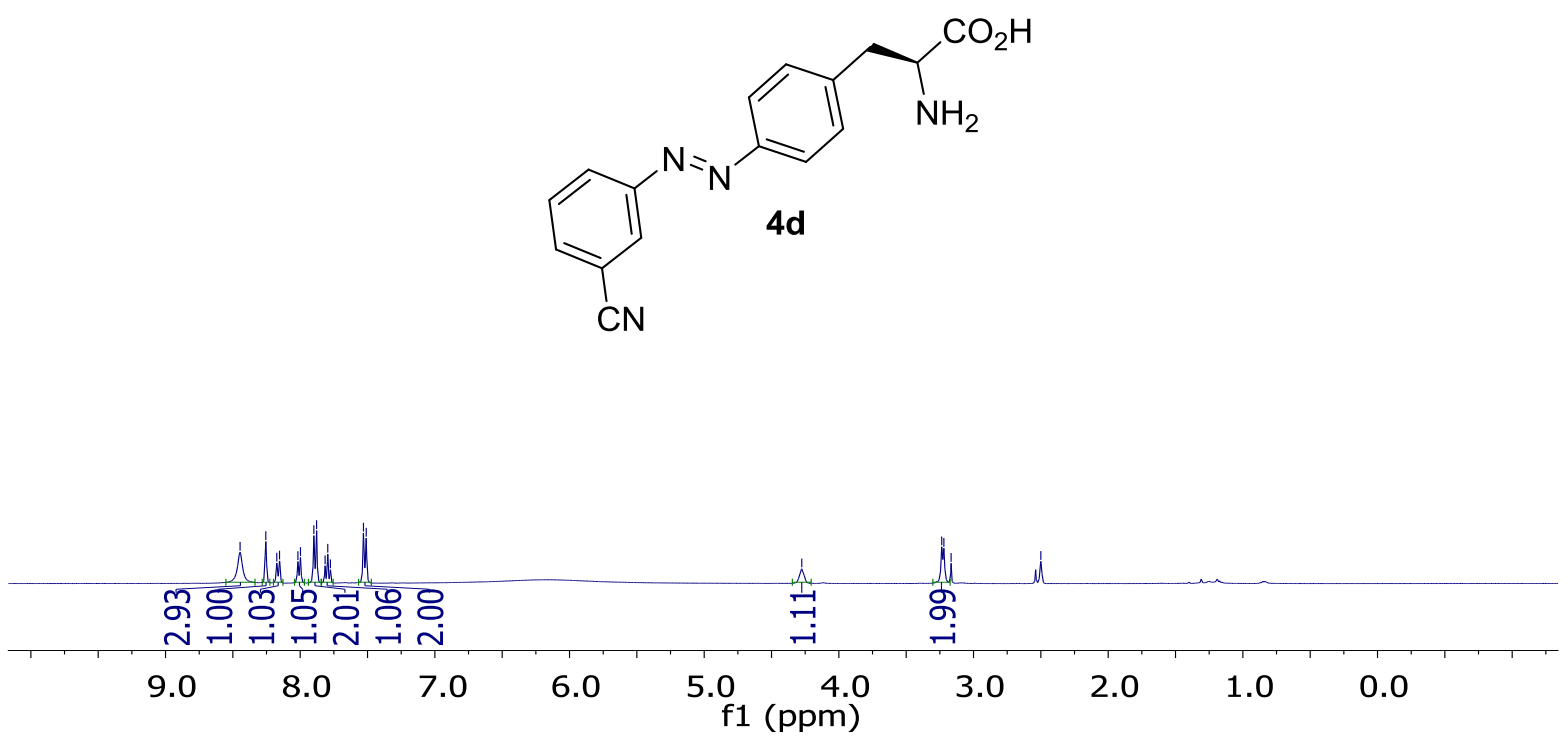

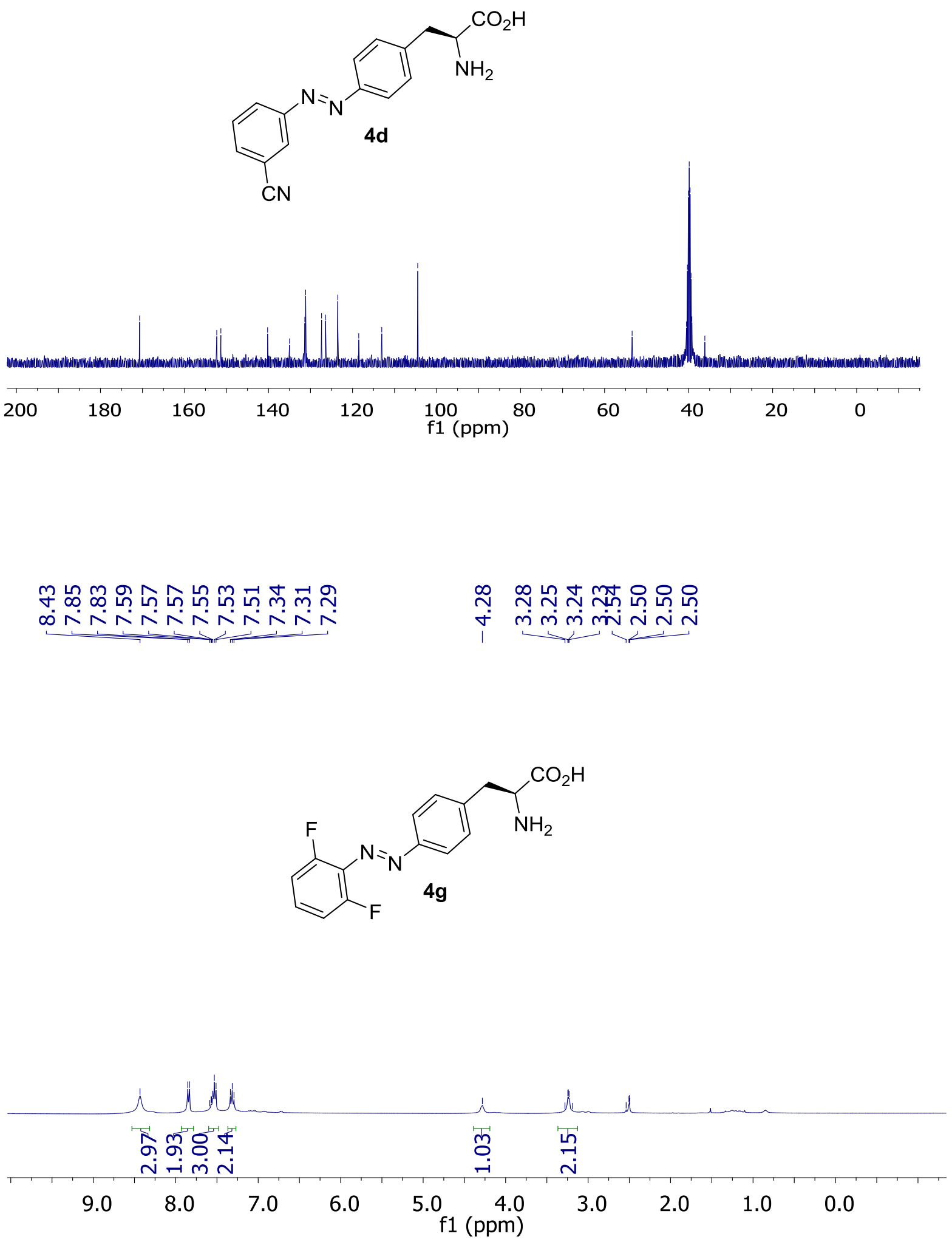


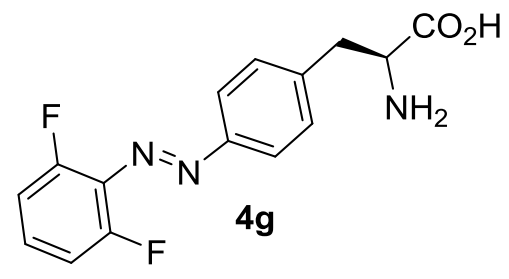

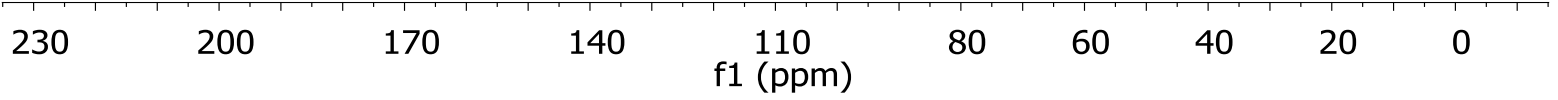

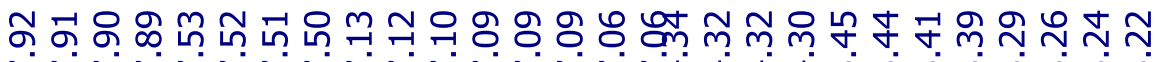

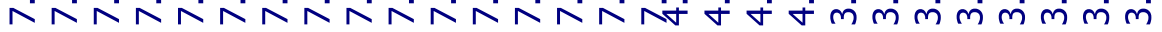<smiles>N[C@@H](Cc1ccc(/N=N/c2c(F)cc(F)cc2F)cc1)C(=O)O</smiles>

4h

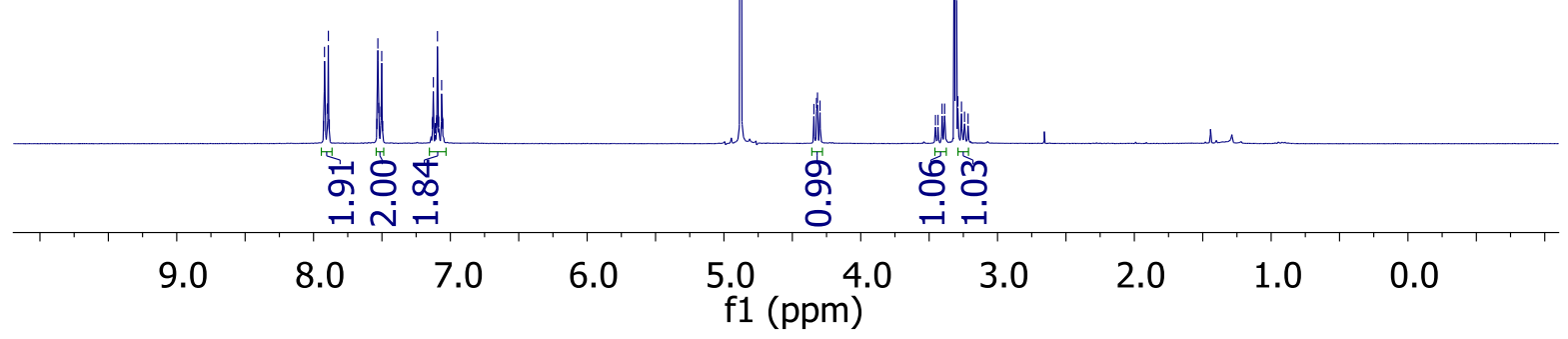




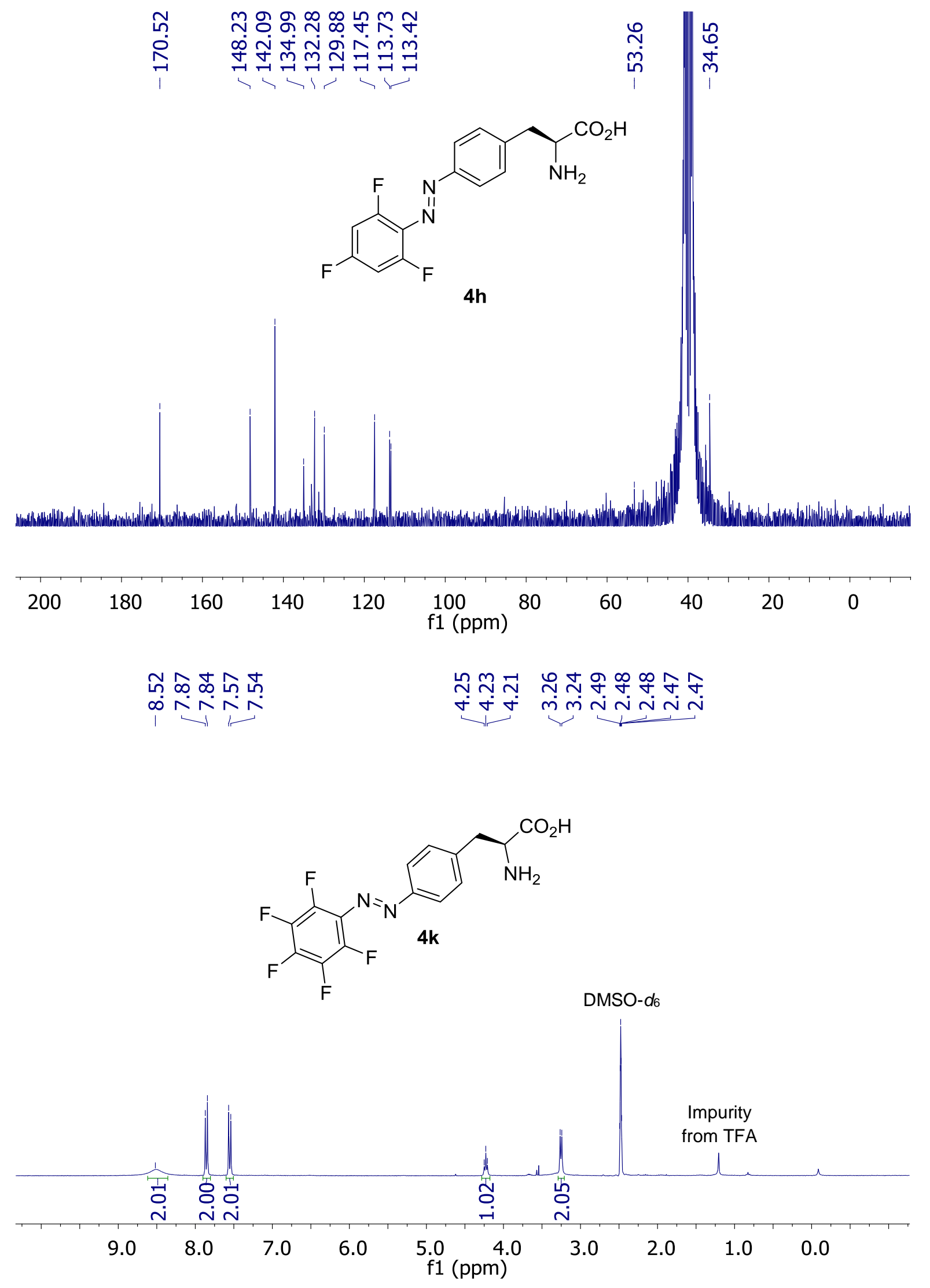



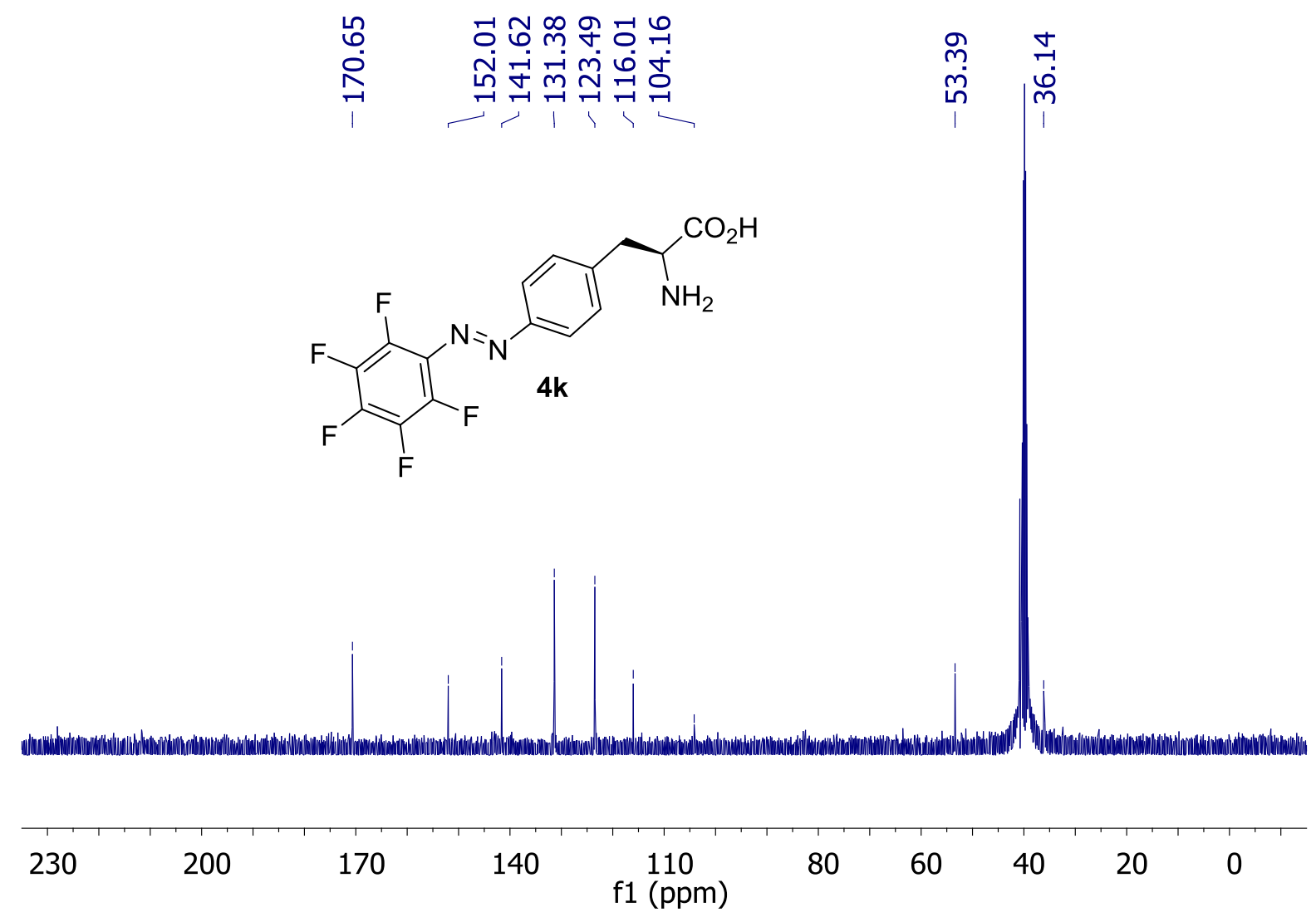

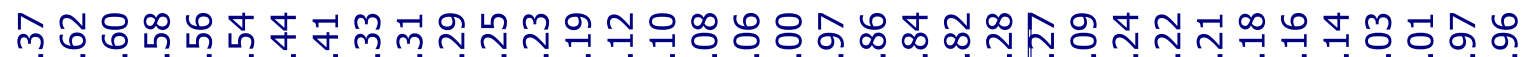

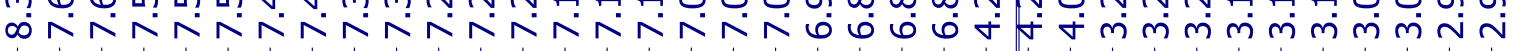

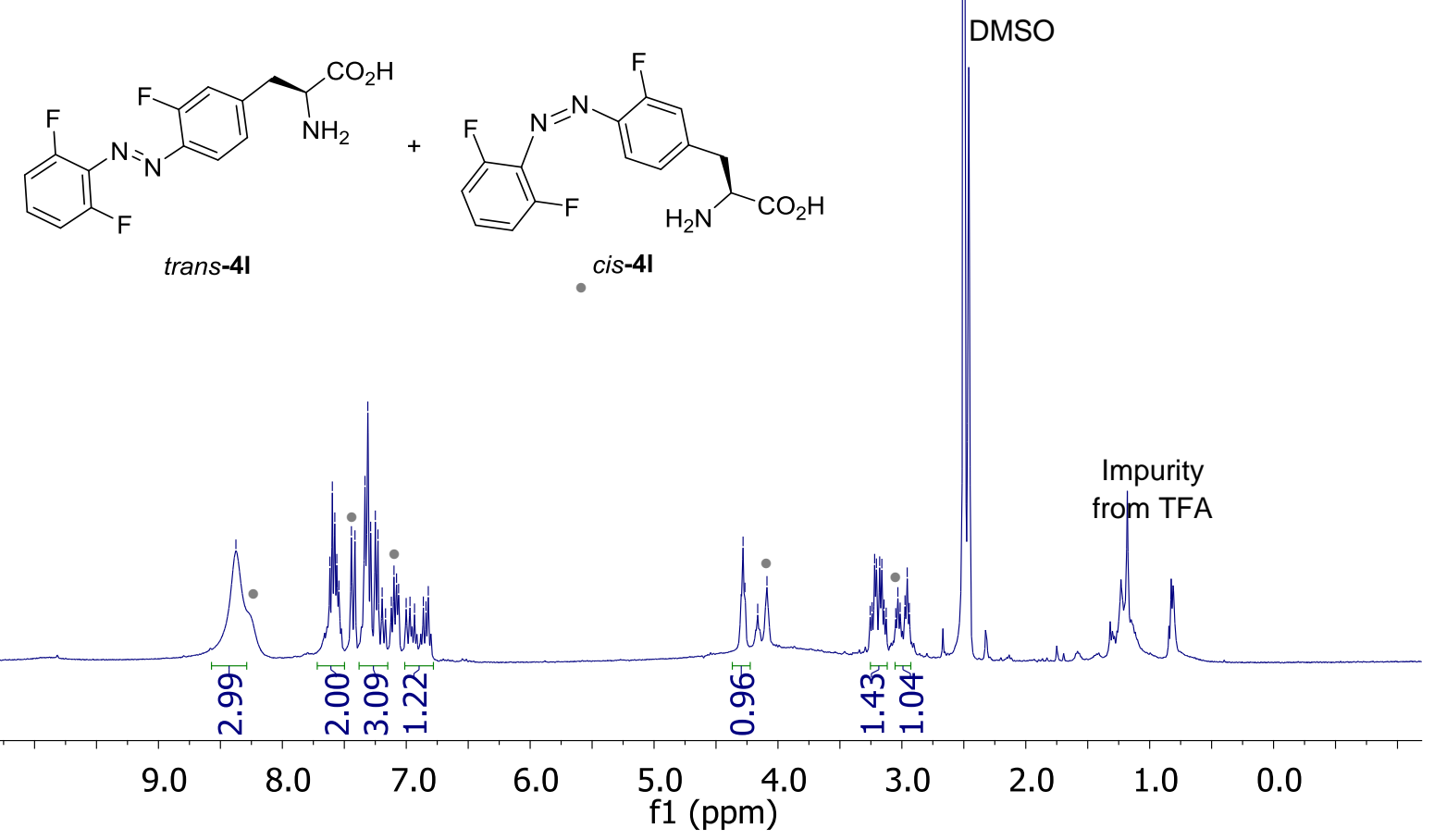




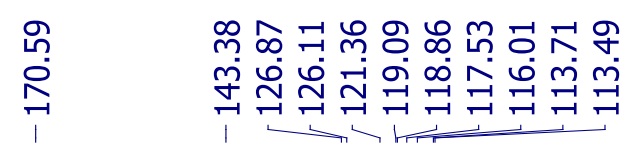

กู่<smiles>N[C@@H](Cc1ccc(/N=N/c2c(F)cccc2F)c(F)c1)C(=O)O</smiles>

4I

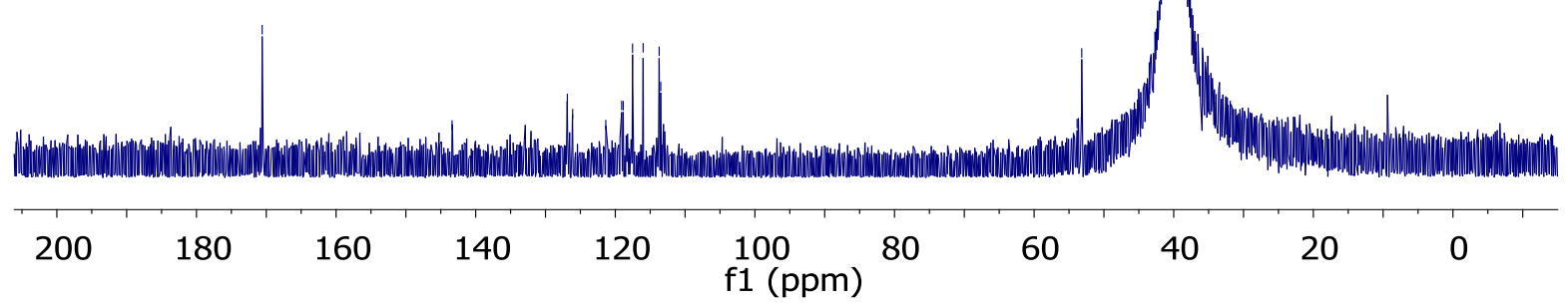

ஸ̊

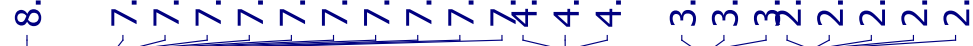<smiles>N[C@@H](Cc1ccc(N=Nc2c(F)cc(F)cc2F)c(F)c1)C(=O)O</smiles>

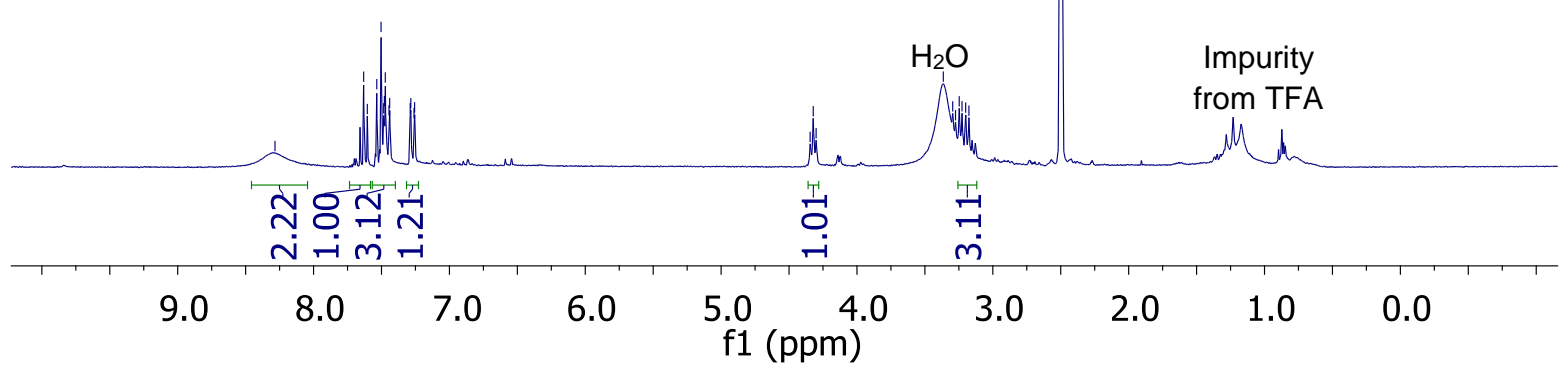




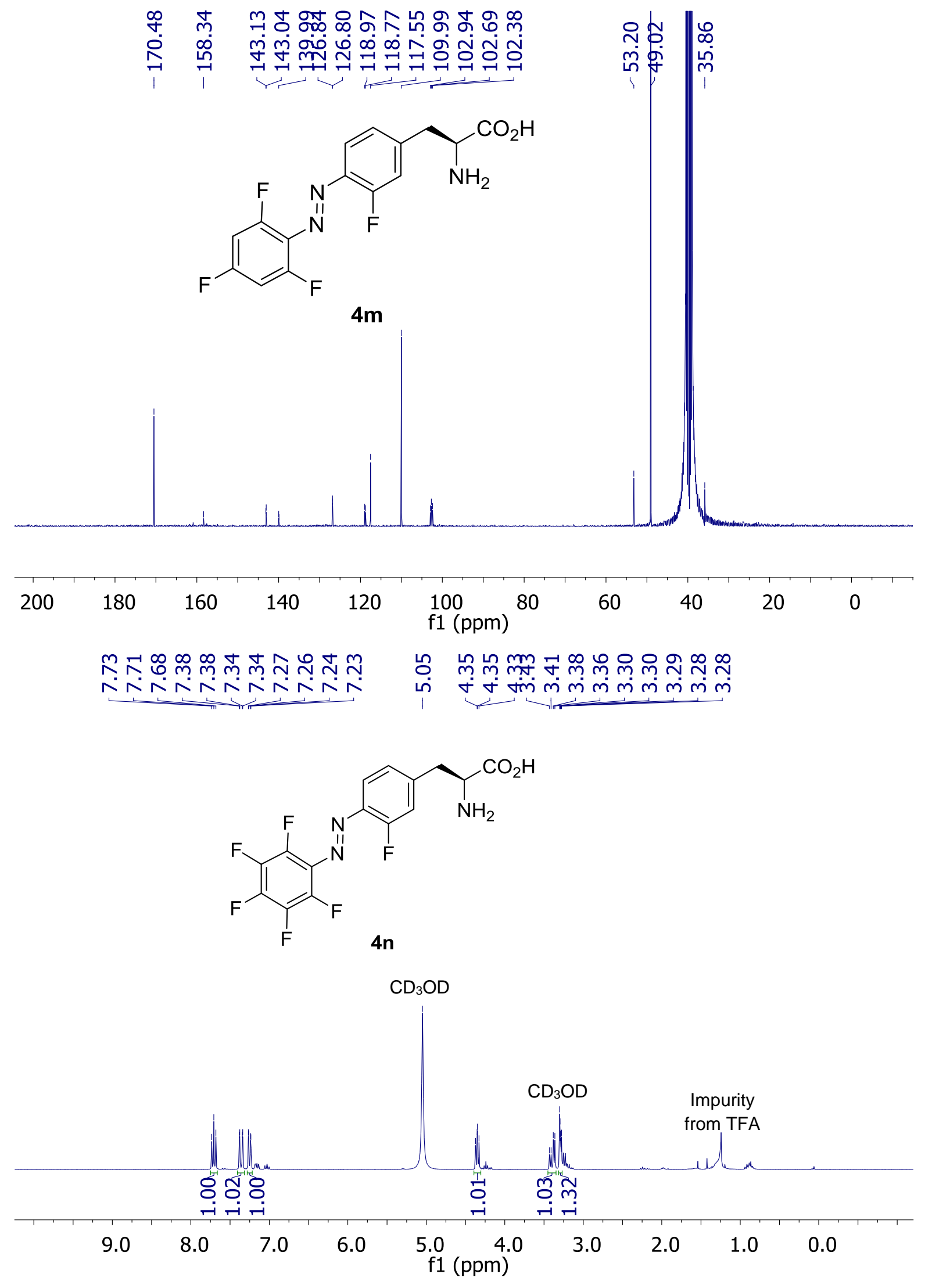



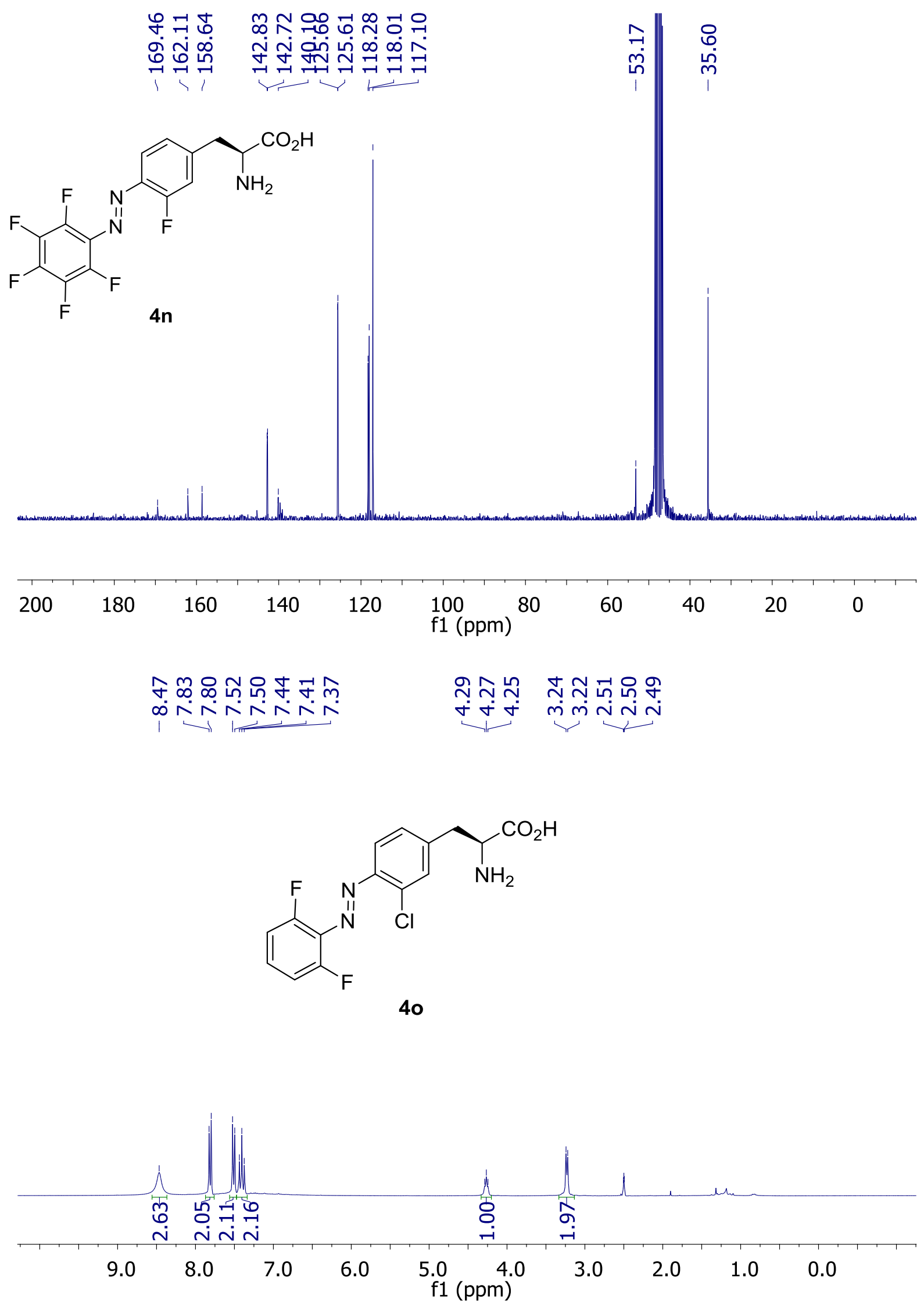

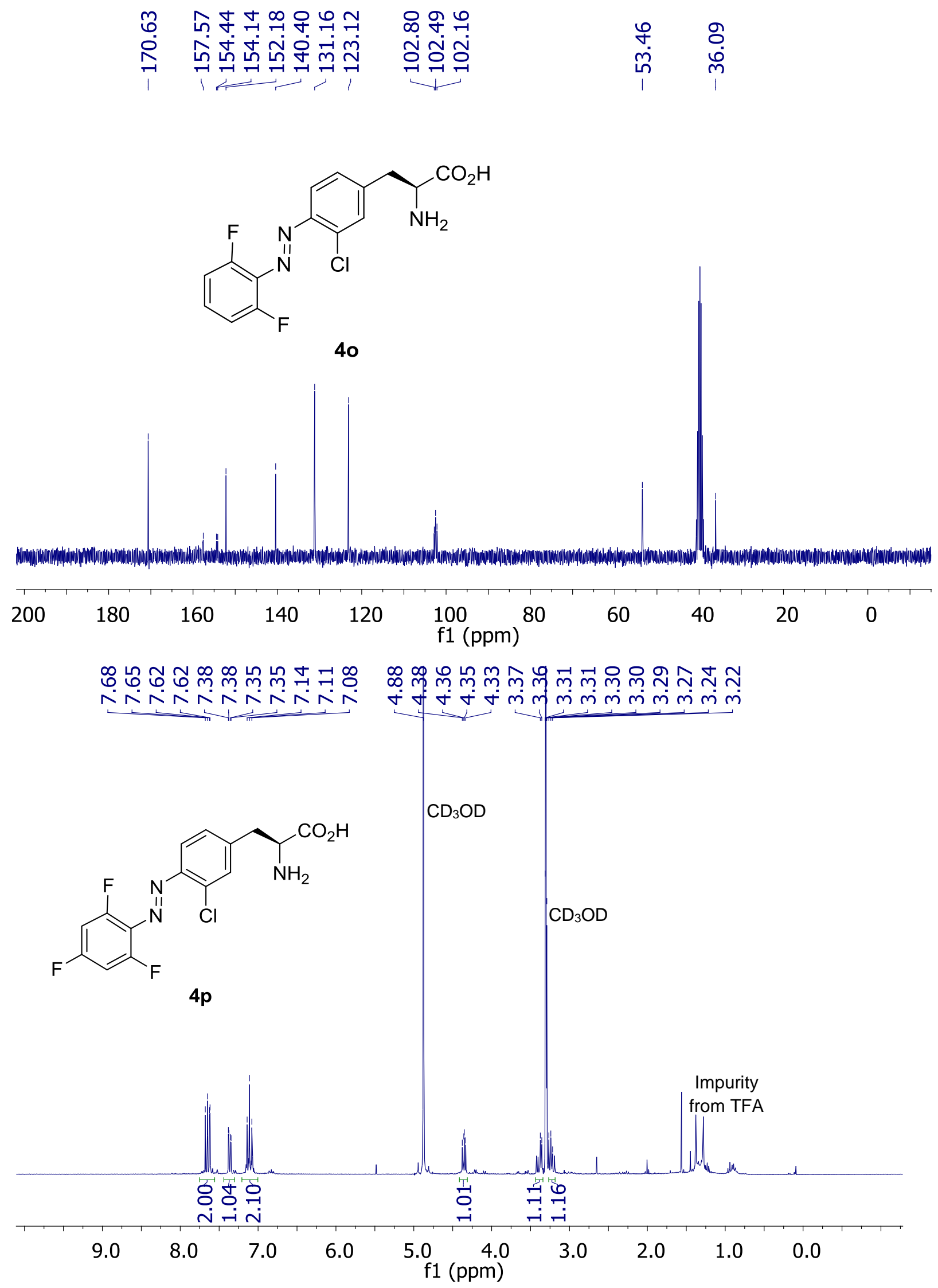


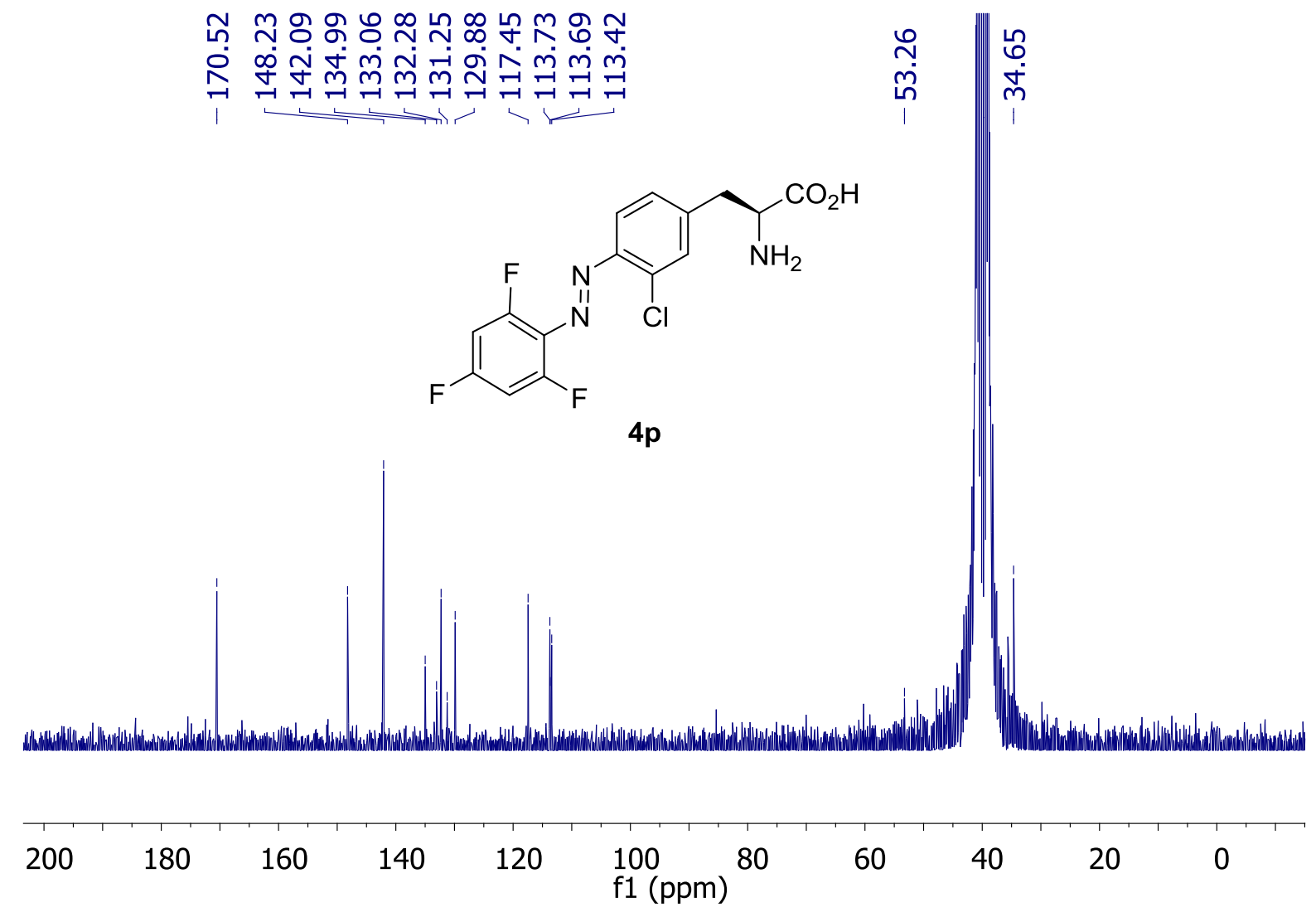

